\title{
Frost Closure of Roof Vents in Plumbing Systems
}

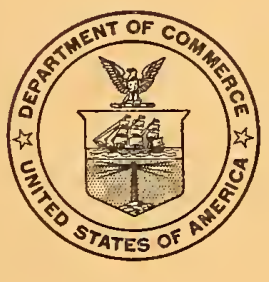

United States Department of Commerce

National Bureau of Standards

Building Materials and Structures Report 142 


\section{BUILDING MATERIALS AND STRUCTURES REPORTS}

On request, the Superintendent of Documents, U. S. Government Printing Office, Washington 25 , D. C., will place your name on a special mailing list to receive notices of new reports in this series as soon as they are issued. There will be no charge for receiving such notices.

If 100 copies or more of any report are ordered at one time, a discount of 25 percent is allowed. Send all orders and remittances to the Superintendent of Documents, U. S. Government Printing Office, Washington 25, D. C.

The following publications in this series are available by purchase from the Superintendent of Documents at the prices indicated:

BMS1 Research on Building Materials and Structures for Use in Low-Cost Housing

BMS2

BMS3

BMS4

BMS5

BMS6

BMS7

BMS8

BMS9

BMS10

BMS11

BMS12

BMS13

BMS14

BMS15

BMS16

Methods of Determining the Structural Properties of Low-Cost House Constructions.

Suitability of Fiber Insulating Lath as a Plaster Base

Accelerated Aging of Fiber Building Boards -

Structural Properties of Six Masonry Wall Constructions

Survey of Roofing Materials in the Southeastern States...

Water Permeability of Masonry Walls.

Methods of Investigation of Surface Treatment for Corrosion Protection of Steel -

Structural Properties of the Insulated Steel Construction Co.'s "Frameless-Steel" Con-

structions for Walls, Partitions, Floors, and Roofs sored by the H. H. Robertson Co

Structural Properties of the Curren Fabrihome Corporation's "Fabrihome" Constructions for Walls and Partitions.

Structural Properties of "Steelox" Constructions for Walls, Partitions, Floors, and Roofs, Sponsored by Steel Buildings, Inc

Properties of Some Fiber Building Boards of Current Manufacture

Indentation and Recovery of Low-Cost Floor Coverings
Structural Properties of "Wheeling Long-Span Steel Floor" Construction Sponsored

by the Wheeling Corrugating Co
Structural Properties of a "Tilecrete" Floor Construction Sponsored by Tilecrete

BMS17 Sound Insulation of Wall and Floor Constructions

Supplement to BMS17, Sound Insulation of Wall and Floor Constructions.

Supplement No. 2 to BMS17, Sound Insulation of Wall and Floor Constructions

BMS18 Structural Properties of "Pre-fab" Constructions for Walls, Partitions, and Floors

Sponsored by the Harnischfeger Corporation.
Preparation and Revision of Building Codes

BMS19

BMS20

Ba

BMS21

BMS22

Structural Properties of "Twachtman" Constructions for Walls and Floors Sponsored by Connecticut Pre-Cast Buildings Corporation -

Structural Properties of a Concrete-Block Cavity-Wall Construction Sponsored by the National Concrete Masonry Association-- "Dut

Structural Properties of "Dun-Ti-Stone" Wall Construction Sponsored by the W. E. Dunn Manufacturing Co

BMS23

BMS24

BMS25

Structural Properties of a Brick Cavity-Wall Construction Sponsored by the Brick
Manufacturers Association of New York, Inc Manufacturers Association of New York, Inc--
ctural Properties of a Reinforced-Brick Wall Construction and a Brick-Tile CavityWall Construction Sponsored by the Structural Clay Products Institute .....-..

Structural Properties of Conventional Wood-Frame Constructions for Walls, Partitions, Floors, and Roofs

BMS26 Structural Properties of "Nelson Pre-cast Concrete Foundation" Wall Construction Sponsored by the Nelson Cement Stone Co., Inc...

BMS27 Structural Properties of "Bender Steel Home" Wall Construction Sponsored by the Bender Body Co

BMS28 Backflow Prevention in Over-Rim Water Supplies

BMS29 Survey of Roofing Materials in the Northeastern States.-.....

BMS30 Structural Properties of a Wood-Frame Wall Construction Sponsored by the Douglas

Fir Plywood Association
BMS31 Structural Properties of "Insulite" Wall and "Insulite" Partition Constructions Sponsored by The Insulite $\mathrm{Co}_{-}$

-Out of print.

†Superseded by BMS116.

[List continued on cover page III] 


\title{
Frost Closure of Roof Vents in Plumbing Systems
}

\author{
Herbert N. Eaton and Robert S. Wyly
}

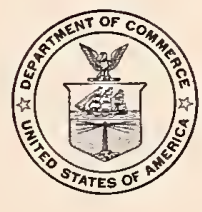

Building Materials and Structures Report 142

Issued October 25, 1954 



\section{Foreword}

For several years the National Bureau of Standards conducted for the Housing and Home Finance Agency of the Federal Government a series of investigations of the physical aspects of the flow phenomena in the sanitary drainage systems of buildings. Problems of venting were involved in these inrestigations, and this led naturally later to a consideration of how the partial or complete closure of roof vents by frost in cold weather might affect the renting of a building drainage system. Very little information as to the conditions under which frost closure might occur is a vailable, and, as a result, the requirements in plumbing codes have generally been based on local practices without any regard to the consideration of the factors that affect its occurrence.

Because of the importance of the problem, the Housing and Home Finance Agency requested the National Bureau of Standards to undertake an experimental investigation of this phenomenon as part of a broad investigation of building drainage systems, the physics of the closure of vents by frost being emphasized, rather than the effects of such closure on the drainage srstem. Experimental studies were conducted in which the roof vent of a simulated building drainage srstem was enclosed in a low-temperature chamber, and rents as large as 3 inches in diameter were completely closed by frost.

Later, when the report was being written, a theoretical analysis was made of the heat-transfer processes that are involved in the freezing of a roof rent, and this analysis made it possible to predict to what extent an exposed roof rent of any given diameter will freeze up under any given conditions.

The experimental part of the investigation was undertaken for the Housing and Home Finance Agency as part of the research program of that Agency under its statutory authority. The analysis of the problem and the writing of this report were sponsored by the National Bureau of Standards.

A. V. Astix, Director. 


\section{Contents}

Foreword

1. Introduction

2. Purpose and scope of the investigation -

3. Previous investigation of the problem

4. Analysis of conditions in service and test installations

4.1. Analysis of service installation $\ldots \ldots \ldots$

4.2. Test apparatus ..............

4.3. Analysis of test installation

a. Conditions outside of system

b. Conditions inside of system

c. Conditions in manometer line.

5. Friction losses involved in the upward flow of air in th

5.1. Head loss at transition from street sewer to building sewer

5.2. Head loss in building sewer and drain

5.3. Bend loss at entrance to stack

5.4. Head loss at contraction, upper end of bend

5.5. Head loss due to friction in stack

5.6. Head loss at transition to roof vent

5.7. Head loss due to friction in roof vent

5.8. Head loss at outlet of roof vent

6. Physics of frost closure of roof vents

6.1. General considerations

6.2. Heat transfer in a roof vent $\ldots \ldots \ldots \ldots \ldots$

a. Transfer of heat from air stream in vent to inner wall of vent_.....

b. Transfer of heat through ice layer and pipe wall

c. Transfer of heat from outer wall of vent to outer air............

d. Computation of the temperature of the ice-air surface in the vent

7. Test procedure

8. Test results

8.1. Tests on system with house trap.

8.2. Tests on system with air flow up stack

9. Discussion of frost closure-field reports

10. Methods of retarding or preventing closure of roof vents by frost_............

11. Conclusions

12. References 


\title{
Frost Closure of Roof Vents in Plumbing Systems
}

\author{
Herbert N. Eaton and Robert S. Wyly
}

\begin{abstract}
Results are reported of a laboratory investigation of the freezing up of roof vents in extremely cold weather and an analysis is given of the heat-transfer process that leads to the partial or complete closure of these vents by frost under sufficiently severe conditions. Information as to the occurrence of frost closure in Canada and methods used there to avoid or minimize the freezing up of roof vents is also included.
\end{abstract}

\section{Introduction}

It has been recognized for years that in severely cold weather the roof-rent pipes of building drainage systems may be rendered ineffective as a result of the accumulation of frost inside the vent pipe. When waste water flows down a stack, it carries air with it because of the friction exerted by the falling water on the core of air in the middle of the pipe cross section, and this air is carried away through the building drain or through vents connecting to the lower portion of the stack or to the building drain. The air thus removed must be replaced, and this occurs normally by means of inflow through the roof rent. Hence if this inflow is prevented or restricted because the roof vent is wholly or partly blocked by frost, the pneumatic pressure in the system may fall, when fixtures are discharging into the stack, until air is sucked into the svstem through the trap seals of the fixtures attached to the system. This may lead to sufficient losses of water in the trap seals of fixtures to allow slight excesses of pneumatic pressure that occur when fixtures are discharging to force sewer air through the reduced trap seals into the rooms of the building.

Occurrences of partial or complete closure during rery cold weather have been reported from northern states in this country and from Canada [1]. ${ }^{1}$ Various-expedients, such as requiring the use of minimum sizes of roof rents larger than those that would be required for adequate venting in normal weather; the requirement that the vents be enlarged at or a little below the roof line; and the reduction of the exposed length of vent to the minimum that is feasible have been proposed and are being used successfully in Canada.

The formation of ice or frost in a roof vent results from the condensation and freezing of the moisture carried by the relatively warm air that rises in the stack during periods of cold weather at times when there is little or no flow of waste water down the

1 Figures in brackets indicate the literature references at the end of this paper. stack. When this warm moist air comes in contact with the cold inner surface of the vent pipe above the roof of the building, some of its moisture condenses on the wall of the rent pipe, where it may freeze if the outdoor air temperature is low enough. The formation of frost or ice inside of the vent pipe becomes possible whenever the temperature of the inner wall drops at least to the freezing point and remains there for some time. provided there is a stream of warm moist air lising through the vent constantly or intermittently. In very cold weather it may happen that the rent pipe will be at a temperature below $32^{\circ} \mathrm{F}$ for some distance from its upper end; for example, when it extends down through an unheated attic or similar space beneath the roof.

Moisture is carried to the cold portion of the vent pipe by several means, any or all of which may be going on simultaneously:

1. The principal cause is the existence of an upward current of air in the stack or vent die to temperature differences between the outside atmosphere and the air in the stack and sewer. In systems comnected directly to a street sewer or a septic tank without the insertion of a house trap. the weight of the heavier cold ail outdoors acts through the manholes or other openings, calusing an upward motion of moisture-laden, wamerand hence lighter-air inside the honse drainasu system. This convection can take place also in systems having a house trap with a fresh-sil rent on the building side of the trap, but to al lesere extent, since the air entering through this rent is at the temperature of the outeloor sir sull cammot rise in the stack until it is wamed somewhat.

2. Diffusion of water rapor in the stack maly be a minor factor. Whenerer fixtures alle discharged, water vapor is introduced into the stack in high concentration, especially if rery lot water is discharged. 'This water vapore temels 10 diffuse through the stack and renting srstem amel misy in this way come in eoutact with the cold surfare of the rent pipe. 
3. Air currents are set up by the intermittent discharge of the fixtures owing to the displacement of the air in the drainage system and to friction between the air and the water. This may temporarily reverse the direction of the normal conrective cument and tend to chill the stack and roof vent by drawing cold outdoor air into the system through the roof vent.

4. Pressure changes in the rent pipe induced by wind blowing past the rent or by gusts striking down on the opening in the vent owing to the presence of nearby buildings may increase or decrease the rate of flow of air in the vent. It has also been suggested that the frosting of the rent will be affected by the tendency of cold outdoor air to force its way into the vent near the wall of the pipe, where the velocity of the rising air is least.

As will be shown later in this paper, frost closure of a roof rent may assume either of two general forms, or a combination of the two. The first form, the one that is analyzed in this paper, is that of a layer of ice or frost which builds up ammularly on the interior wall of the vent, until, if conditions are serere enough and last long enough, the rent pipe may be completely blocked by frost. The other way in which the vent may be blocked by frost is through the building up from the rim of the rent pipe of a frost cap which may assume various forms. As this cap builds up, a hole remains in the center of the cap, permitting air from the stack to flow up through it. However, under sufficiently serere conditions, this hole gets smaller and smaller, until the frost cap may completely close the rent. A photograph of such a frost cap is shown in figure 1 .

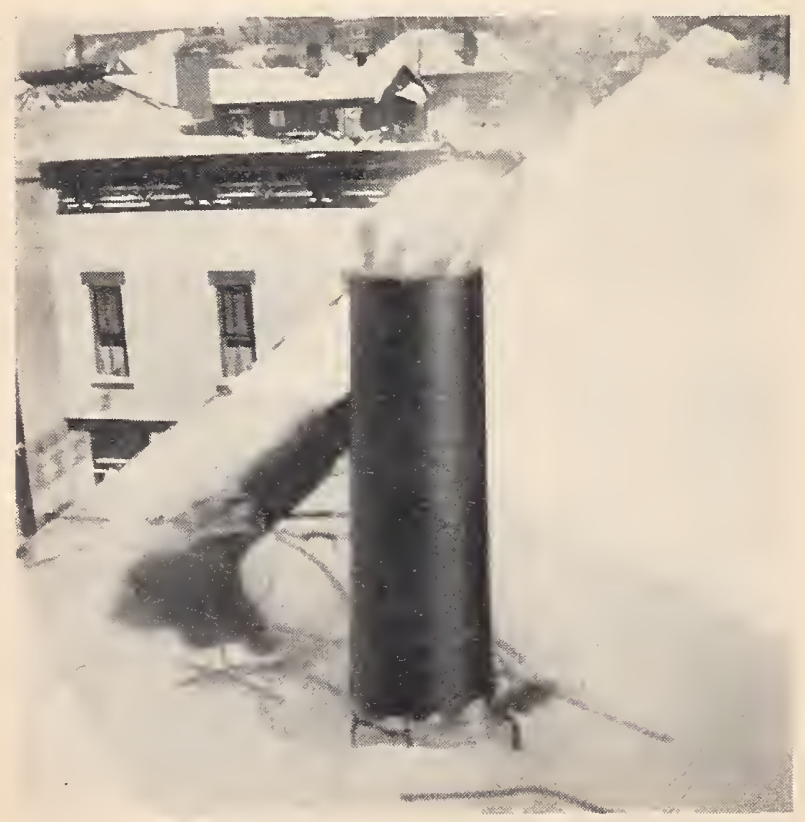

Figcre 1. Frost cap.

\section{Purpose and Scope of the Investigation}

This investigation was undertaken at the suggestion of the Housing and Home Finance Agency as a result of questions that arose in meetings of the Uniform Plumbing Code Committee when that Committee was preparing its report. Doubt was expressed that complete frost closure could occur. Owing to the scarcity of information as to actual cases of the occurrence of this phenomenon, it was proposed that, if possible, experiments be made to determine whether roof vents could be completely closed by frost under any reasonably conceivable conditions, and the Hydraulics Section of the National Bureau of Standards was asked to look into the matter.

Obviously it was impossible to conduct such a study on actual installations in the District of Columbia because of the mild winter temperatures that prevail here. However, the possibility of simulating actual service conditions by extending the roof vent of a laboratory plumbing stack up into a cold chamber in which low temperatures could be maintained was considered. Such an installation was constructed as shown in figure 4 . It was necessary to use a blower to provide artificially the updraft of ain in the stack that ordinarily would result from "chimney action". in an untrapped stack in winter. In the tests the updraft rate was adjusted to correspond to the rate computed for the assumed service conditions. This problem is analyzed in a later section of this paper.

Because of the limited purpose of the investigation when it was started, the desirability of simulating closely an actual installation, and the limited time and funds that were then available the experimental investigation was of a practical nature rather than of a broad, scientific nature. However, it did demonstrate certain basic principles and pointed the way in which a more scientific study of the problem can be made at some later date.

Over a period of time subsequent to the experimental investigation, an analysis of the frost closure of vents was made on the basis of heat. transfer relationships at the vent section. The analysis yielded results in general agreemeni with observations of frost closure in the field, and is presented in some detail to indicate the nature of the phenomenon.

\section{Previous Investigation of the Problem}

The late Roy B. Hunter of the Nationa Bureau of Standards considered the question 0 the effect of frost closure on trap seals in $\mathrm{BH} 13$ "Recommended Minimum Requirements fo Plumbing" [2]. Tests simulating conditions o partial closure of roof vents by frost were made by 
reducing the openings in the tops of stacks and roof rents by replacing the topmost portion of the rents with pipes of smaller diameters. Thus, Hunter was interested in the effect of partial closure of the roof rent on the drainage system, not in how the phenomenon of frost closure occurs. Other unpublished material relating to later tests made at the National Bureau of Standards also deals with this effect. Hunter states: "Frost closure was simulated by setting sections of pipes of rarious diameter's and lengths into the stack top. To measurable effect was produced by setting a $1^{1}$-in. pipe $20 \mathrm{in}$. long into the tops of the 3-in. stacks of the different systems. A 1 -in. pipe 12 in. long set in the 3 -in. stack only slightly increased the racuum produced by a heary discharge from the fixtures. No doubt the effect would be felt more with an increase in the volume of discharge. With a complete closure of the stack top, the water was sucked from one or more traps by the discharge of a single water closet on the system."

Tests made at a later date have confirmed these conclusions and have indicated that, if the top opening in a 3 -in. stack is reduced to $1 \mathrm{in}$. in diameter, undesirable reductions in trap seal may occur in the fixture traps in a one- or two-storyand-basement installation.

Hunter states further: "Chief reliance for" rentilation of the drainage srstem and for the relief of pressure changes set up by fixture discharge is placed upon a free course of air from street sewer to roof terminal. Effects of frost closure as determined by experiments apparently are so slight as to be negligible if a clear opening is left at the top of the stack equal in area to a circle of $1 \frac{1}{2}$ in. in diameter." It is assumed that the diameter of opening referred to applies in the case of a 3 -in. stack.

A rent diameter of $4 \mathrm{in}$. at the roof line has been found adequate under most conditions, but, in some parts of the United States and in Canada, the serere climatic conditions encountered have led to the use of increasers 2 in. larger in diameter than the pipe below the roof. It has also been found that rent pipes that extend but a few inches abore the roof are less subject to frost closure than longer lengths. This, however, may increase the effect of wind pressure on trap seals. Extension of such pipes above the elevation of possible snowdrifts has been found unnecessary, as the escaping warm air "honeycombs" the snow sufficiently to prevent serious obstruction.

Gray [3] states that a system connecting directly to the street sewer and having no trap in the house drain "favors high humidity and closure of rents by frost in winter". He also indicates that a system having back circuits or loop rents provides considerably greater heating surface for the air passing through it, which tends to make the temperature of the air higher as it passes through the roof vent than would be the case for a stack-rented system. His conclusion appears to indicate that a stack-rentorl swotern ronnecterl rireretly to the strect sewere is more likely to be affereted by frost relosure than ano ofther systems, other factors being equal.

Gray points out that heat fiom the roof mat cause the temperature of the air surpounding the roof vent to be somewhat higlues than the a verage outdloor air temperature on windless rlays. This herst may rome either from the attic spares (as, for example, from a heated attic) or from the absorption and reflection of the sunlight. Furthermor", he states that although at night the temparatire of the air around the roof vent will usually be lower than in the daytime, the infrerguent ise of the plumbing fixtures during the late exoning and early morning hours results in lower humirlity of the air passing through the system. Gray siregests that it is desirable to enlarge the stack, not at the roof line, but at some distance below the roof, in order to take advantage of the laroco heating surface of the increaser below the roof line. Evidently he assumes here that the tomperature of the air in the space immediately below the roof would be higher than the temperature of the air in the stack. If this were not true, it is obrions: that heat would be lost by the air stream instead of gained.

The authors have received much interesting and significant information on the subjert of frost closure from Canadian sources, and this is summarized later in the paper.

Valuable information on instances of frost closure has also been found in a report of the Canadian Institute of Sanitary Enginecrs [1]. This report contains a lengthy discussion of the problem of frost closure of roof rents in rariouparts of Canada and gives the results of obserrations at Winnipeg, Manitoba, during a cold spell in January and February of an earlice rear. Figure 2 gives the daily minimum temperature at Winnipeg during this period and also the changes in closure of three stacks by frost, a 6-in. stack and an 8-in. stack at the Grain Exchange and a 6-in. stack at the Civic Curling Rink. Infortunately, we do not know how the daily minimum temperatures had raried just prior to the period in question, nol do we know what fixtunes discharged into the stacks, nor what wind rolecities prevailed. It will be noted from tignre? that the stack at the Curling Rink was chlarared from 4 to $6 \mathrm{in}$. in diameter just before pasing through the roof, which in this case had a stcent slope. 'This roof rent extended only $1^{12}$ in. above the roof on the high side. 'The other twe stacks at the Grain Exchinge were not colsined before passing through the roof and extemeled l? in. above the level of the flat root. "Lhery were exposed on all sides.

The opening in the s-in. roof rent was about is in. in diameter on January 24, the begmming of the period of observation. and the daily minimum temperature at this time was $-250 \mathrm{~F}$. Alehough the temperature rose shortly after this tare. 

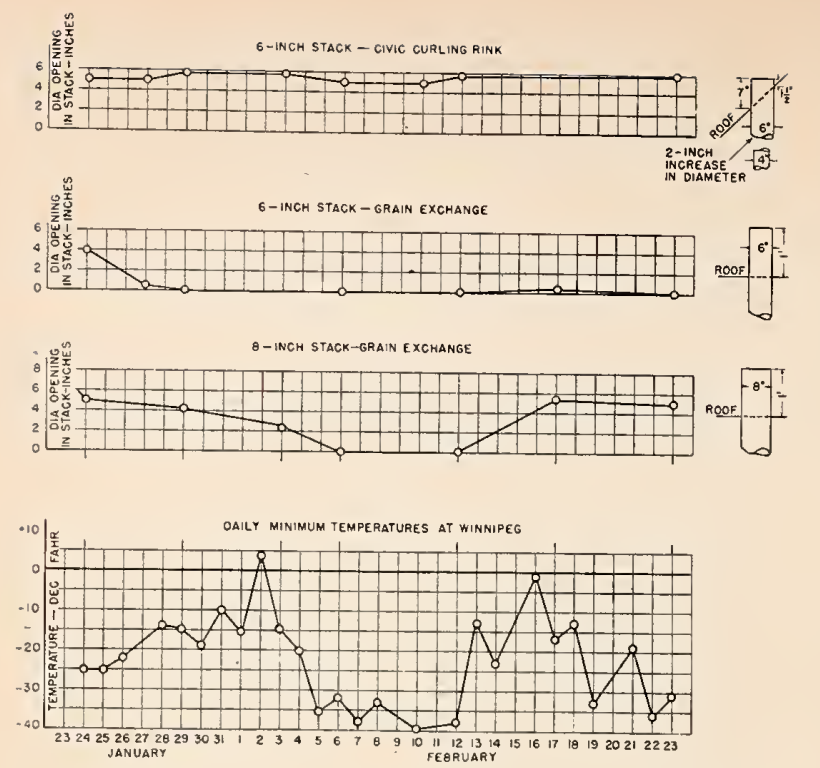

Figdre 2. Observations of frost closure at Winnipeg, Canada.

reaching a value of $+4^{\circ} \mathrm{F}$ on February 2, falling thereafter to $-32^{\circ} \mathrm{F}$ on February 6 , the vent continued to close up, until on February 6 it was completely closed. The daily minimum temperature remained below $-30^{\circ} \mathrm{F}$ until February 12 , when the stack was next observed and was found to be still completely closed.

Following this the temperature again rose, until on February 16 it was $-1^{\circ} \mathrm{F}$, when it again commenced to fall. The vent was observed on February 17 and was found to have opened partially, the diameter of the opening being about $5.4 \mathrm{in}$. Thereafter the temperature fell erratically, ending at $-31^{\circ} \mathrm{F}$ on February 23 , the last day of the period of observation. At this time the opening in the vent was about 5 inches.

The 6-in. roof vent at the Grain Exchange showed similar tendencies to those of the 8-in. vent, but it closed up sooner than the Jatter. It is, of course, possible that this vent might have opened up a little between the January 29 and the February 6 observations as a result of the warm spell during the latter part of this period.

The 6 -in. roof vent at the Curling Rink, which was enlarged from 4 to $6 \mathrm{in}$. in diameter below the roof and which extended only a very short distance above the roof, did not close completely at any time during the period of observation, and the diameter of the opening in the vent followed in a general way the fluctuations of temperature.

These observations of the frost closure of roof vents are the most detailed of any that have come to the attention of the authors and tend to support the conclusions given later in this paper as to the behavior of roof vents in very cold weather.

Another unusual and interesting case of frost closure will be described here, although it relates to the closure of a smoke stack from a stove rather than the closure of a roof vent. The instance was brought to the attention of the authors by Robert F. Legget, Director, Division of Building Research National Research Council of Canada. The following is quoted from a letter from Mr. Legget,

Even though the record may sound fantastic, it may be of interest to you if I record the worst case that has come to my attention. The winter of 1945-46 was an unusually severe one in the North of Canada. At a small place called Baker Lake, which you will find at the end of Chesterfield Inlet on the West side of Hudson Bay, there are a few small buildings. One of these is oceupied by a Roman Catholic mission. It is heated by an open stove with a metal smoke stack extending through the roof and protected outside the roof in the usual way by a caribou hide. This is especially effective against the high winds that always blow at this location.

One night during this bad winter the combination of temperature and wind was such that the water vapor in the smoke stack coming from the fire started to freeze on the sides of the chimney. Once having started, it built up rapidly and eventually sealed the chimney tight, even though the fire was burning below. Two priests were severely gassed, but fortunately got out of the building in time.

In response to a further inquiry, Mr. Legget stated that this phenomenon occurred at least twice in this building and that the fuel being burned was coal.

Another example of frost closure has been called to the attention of the authors through $\mathrm{L}$. Glen Shields, Chief Plumbing Inspector for the City of Detroit, Mich. This instance occurred at the Hotel St. James in Ironwood, Michigan. This hotel has 204 -in. and 2 -in. stacks of cast-iron soil pipe. The vents extend about $2 \mathrm{ft}$ above a flat roof and are of the same diameter as the stacks. The building drain did not contain a house trap. On January 18, 1950, when the outside air temperature was $-23^{\circ} \mathrm{F}$, several of the 4 -in. vents were observed to be completely closed by frost, and all of the 2-in. vents were completely closed. All of the other 4 -in. stacks were partially closed. The inspector who made the observations estimated that at that time probably from 30 to 40 percent of all the vent stacks in İronwood were partially or completely closed by frost (see fig. 1).

At the time of the observation the outside air temperature was $-23^{\circ} \mathrm{F}$, and the temperatures on the preceding days had been as follows:

\begin{tabular}{|c|c|c|}
\hline Preceding day & Maximum & Minimum \\
\hline $\begin{array}{l}1 \mathrm{st} \ldots \\
2 \mathrm{~d}_{-} \\
3 \mathrm{~d}_{-}\end{array}$ & $\begin{array}{r}\circ F \\
0 \\
5 \\
20\end{array}$ & $\begin{array}{r}\circ F \\
-20 \\
-15 \\
+5\end{array}$ \\
\hline
\end{tabular}

The fixtures discharging into a typical 4-in. stack in the hotel were listed as follows: 4 bathroom groups and hot and cold process water.

Although much consideration has been given to the problem of frost closure of roof vents in Canada, and although the phenomenon has been ob- 
served, but not much commented upon, in the Cnited States, apparently no laboratory tests liare been made to study the problem previously, nor does any analysis of the phrsical factor's inrolved appear to have been made. Perhaps this may be due in part to the fact that, where frost closure is frequent and severe, methods of minimizing it have been developed by empirical inethods, some of which have proved rerieffective. Another reason mar be the difficulty involved in simulating service conditions in a laboratory test. Some of these difficulties are not apparent at first sight, and the tests reported in this paper required a quite complicated setup before service conditions could be simulated successfully.

\section{Analysis of Conditions in Service and Test Installations}

The tendency for air to flow upward in plumbing stacks and rents in cold weather, at least when there is little or no water flowing down the stack, is due to the same principle as is involved in the action of a chimner. The phenomenon is due to the fact that the static pressure differential between the bottom and the top of the stack is greater outside of the building than it is inside of the stack, since the air temperature outside of the building is lower in winter than the temperature of the air inside the stack.

The static pressure difference outside of the building between the levels of the top and bottom of the stack is determined by the weight of an air column of unit cross section extending between these two levels outside of the building. The air inside of the stack, being at a higher temperature than the air outside of the building during cold weather, weighs less than the air outside of the building. Hence the column of air in the stack will exert a smaller pressure at the bottom of the stack than the column of air outside of the stack, or at least it would if it were stationary. The result is that this difference in pressure of the two columns, due to difference in density, is available to create an upward flow of air in the stack, and this flow is of such magnitude that the sum of the pressure losses within the stack tue to wall friction to increases and decreases of diameter of the line, to bends in the line and to the creation of velocity of flow, is equal to this pressure difference.

In what follows it will be assumed that no water is flowing in the stack. This condition will exist in many buildings during a large part of the time. Any small flow of water down the stack will decrease the convective flow of air up the stack, and for larger flows the direction of the air current will be reversed, at least a portion of this air ultimately being carried out through the building drain and sewer to the street sewer. However, except in quite large buildings, the probability of finding an appreciable flow of water in the drainage stack at an arbitrarily chosen instant of observation is rather small.
In this papes no arrount is taken of the slight variation in density of the air vertirally in a coslumu of uniform temprerature. 'Taking this variation into account would scarrely chanere the lesilts and would complicate the romputations. Since the tests rondurterl in this investigation showerl that the air raising though the stark was nearly saturaterl with water vapor, the densities assumed for the relativcly warm air inside the system were those given for saturaterl air. On the other hand, since air at temperatures far below the freszing point of water can contain only a negligible amount of water vapor, the rlensities assumerl for the cold outside air were those griven for rlry air.

For the sake of simplicity it has been assumerl that the building drain and the building sexer have the same diameter and the same coefficient of friction per unit length. ${ }^{2}$

\subsection{Analysis of Service Installation}

Figure 3 shows a stack with a short enlargerl section at the top (the roof vent) and with a building drain and building sewer connecting to the street sewer. The building drain and serrer are assumed to be of the same diameter, so that no distinction is made between them in this drawing. The following considerations govern the assumptions made as to the different ail densities in rolved.

It is assumed that the temperature of the atmosphere outside of the building is below freezing. so that the mass density $\rho_{4 \mathrm{~s}}{ }^{3}$ of the air outside of the building is relatively high. Actually, as has already been mentioned, the density raries a little from the level of the top of the stack to the ground level, but for simplicity an a rerage value of $\rho_{4 \mathrm{~s}}$ is assumed to exist over this distance.

\footnotetext{
2 According to the Report of tbe Coordinating Committer for a liationas Plumbing Code, the building drain extends from the base of tbe stack to : point $3 \mathrm{ft}$ outside of the inner face of the building wall. The building se

extends from this point to the street scwer.
3 Tbe subscripts "s" and " $t$ " will be used to distinguish betwen the 3 The subscripts "s" and " $t$ " will be used to
sernice and the test systems discussed in this paper.
}

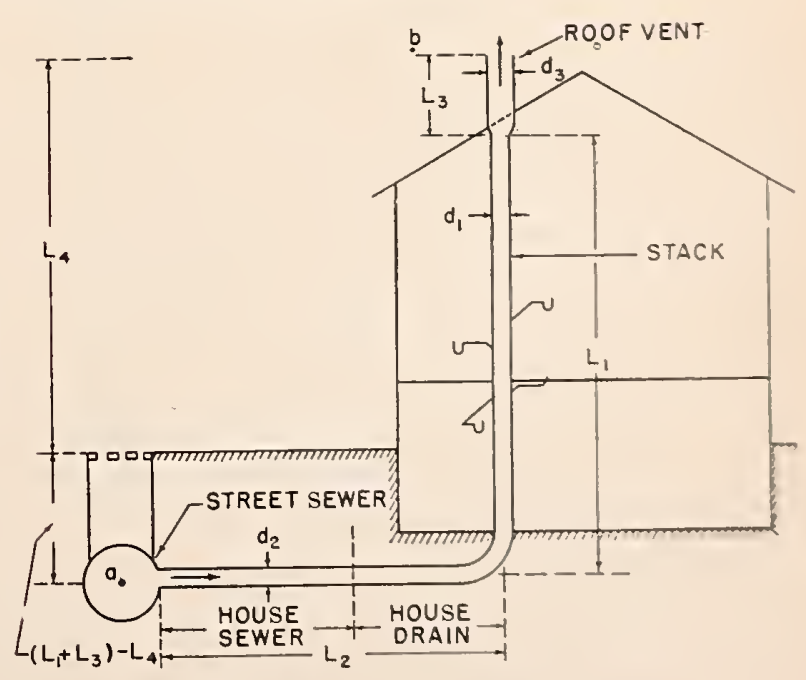

Figure 3. fmalysis of scrice instullatron 
The temperature of the air in the street sewer, the building sewer, and the building drain is assumed to be somewhat higher than that of the outdoor air. Actually it may increase a little as the air flows from the street sewer, through the building sewer and drain to the stack, but again for simplicity we assume that the mass density $\rho_{2 \mathrm{~s}}$ of the air in this part of the system is constant from the top of the manhole in the street sewer through the building sewer and drain to the base of the stack.

Similarly, as the air rises through the stack and roof vent, its temperature increases still further until it reaches the exposed part of the roof vent, where it will be cooled somewhat. However, for simplicity, it will be assumed that the mass density $\rho_{1 \mathrm{~s}}$ of the air in the stack and roof vent is constant.

With these assumptions in mind, one can easily see that the pressure increase outdoors from the level of the point "b" at the top of the roof vent to the point " $a$ " in the street sewer is given by

$$
\left.p_{\mathrm{as}}-p_{\mathrm{bs}}=\rho_{\mathrm{ss}} g L_{4 \mathrm{~s}}+\rho_{2 \mathrm{~s}} g\left(L_{1 \mathrm{~s}}+L_{3 \mathrm{~s}}-L_{4 \mathrm{~s}}\right)=\right\lrcorner p_{\mathrm{s}} .
$$

But as

$$
\lrcorner p=\rho_{\mathrm{w}} g \Delta h,
$$

where $\rho_{w}$ is the mass density of water, and $\Delta h$ is the height of water column in a manometer corresponding to the pressure $\Delta p$, eq (1a) mar be expressed as

$$
h_{\mathrm{as}}-h_{\mathrm{bs}}=\frac{\rho_{1 \mathrm{~s}}}{\rho_{\mathrm{w}}} L_{\mathrm{ss}}+\frac{\rho_{2 \mathrm{~s}}}{\rho_{\mathrm{w}}}\left(L_{1 \mathrm{~s}}+I_{\mathrm{s} 3 \mathrm{~s}}-L_{\mathrm{4s}}\right)=\Delta h_{\mathrm{s}} .
$$

If $r$ is used for the ratio of the air density to the water density, eq (1b) becomes

$$
h_{\mathrm{as}}-h_{\mathrm{bs}}=r_{4 \mathrm{~s}} L_{4 \mathrm{~s}}+r_{2 \mathrm{~s}}\left(L_{1 \mathrm{~s}}+L_{3 \mathrm{~s}}-L_{4 \mathrm{~s}}\right)=\Delta h_{\mathrm{s}} .
$$

Now, as the air in the stack is at a higher temperature than the outside atmosphere, the pressure difference between points "a" and " $b$ " under purely static conditions in the stack would be less than that which actually exists between these two levels in the outside atmosphere. As a result of this, air flows from the street sewer into the building sewer (if there is no house trap in the building drain), through the building sewer and drain, and up the stack at such a rate that the pressure loss $h_{\mathrm{fs}}$ due to wall friction, expansion and contraction, and the creation of velocity head, added to the static pressure difference between the points "a" and "b," measured inside the system, is equal to the pressure difference measured outside of the system.

Consideration of conditions inside the system indicates that

$$
h_{\mathrm{as}}-h_{\mathrm{bs}}=h_{\mathrm{fs}}+r_{1 \mathrm{~s}}\left(L_{1 \mathrm{~s}}+L_{3 \mathrm{~s}}\right) .
$$

After substituting in eq (3) the value of $h_{\mathrm{as}}-h_{\mathrm{bs}}$ from eq (1c) and reducing, the following expression for $h_{\mathrm{fs}}$ is obtained:

$$
h_{\mathrm{fs}}=\left(L_{1 \mathrm{~s}}+L_{3 \mathrm{~s}}-L_{4 \mathrm{~s}}\right)\left(r_{2 \mathrm{~s}}-r_{1 \mathrm{~s}}\right)+L_{4 \mathrm{~s}}\left(r_{4 \mathrm{~s}}-r_{1 \mathrm{~s}}\right) .
$$

Thus we have derived formally the fact that could have been predicted a priori, that the head available to produce flow of air up the stack is determined by the difference in density of the two static air columns between points "a" and "b," one inside the stack and the other outside the building, and by the height of the system.

\subsection{Test Apparatus}

Figure 4 shows the arrangement of the test apparatus that was used for the experimental work. A 3 -in. stack-vented, single-story-withbasement system was erected, complete with water closet, bathtub, lavatory, and kitchen sink. A pump supplied water for discharge through the bathtub at a constant rate and at any desired



Figure 4. Test apparatus.

A. Orifice plate; B, damper; C, large fan; D, device for measuring carbon dioxide content of air; E, inclined manometers; $\mathrm{F}$, thermostat for automatic control of large fan, $\mathrm{C}$; $\mathrm{G}$, small fan; $\mathrm{H}$, remote temperature indicator: $\mathrm{I}$, electrical connections to thermocouples at points 1 to $10 ; \mathrm{J}$. manometer tube; $\mathrm{K}$, small ice chamber; $\mathrm{L}$, lavatory; $\mathrm{M}$, wet- and dry-bulb thermometers; $N$, bathtub; $O$, sink; $P$, water pump; $Q$, water supply; R, roof rent; $\mathrm{S}$, spill basin; $\mathrm{T}$, thermometer; $\mathrm{U}$, immersion heater with thermostatic control; $V$, drain; $W$, water closet; $X$, air blower; $Y$, exhaust pipe; $Z$, overflow weir. 
temperature. In automatic device connected to the water closet flushed the closet at regular interrals of time. At the top of the stack an insulated cold chamber in the form of a cube approximately $3 \mathrm{ft}$ on a side (inside dimensions) surrounded the stack terminal or roof rent. This chamber was fitted with windows for making observations and with a rloor for maintenance of the test equipment located in the test chamber and for checking the accumulation of frost in the vent pipe. A rack was provided on which approximately $200 \mathrm{lb}$ of "drr ice" (solid carbon dioxide) could be placed. This provided the means by which a very low temperature could be maintained in the chamber.

A fan mounted above the dry ice, actuated by means of a thermostatic contiol unit mounter near the terminal of the stack, circulated air in the chamber whenerer required to maintain the temperature approximately constant at the value determined by the setting of the control unit. The control unit stopped the circulating fan whenever the temperat ure of the air in the chamber was reduced to the value to which the control unit ras adjusted.

A smaller fan nearer the stack was run continually in order to simulate a breeze blowing over the rooftop and to cause a more nearly uniform temperature distribution along the portion of the stack inside the cold chamber. A section of 3-in.diameter plastic pipe about $5 \mathrm{ft}$ long was set in the top of the cold chamber to provide means by which the air from the stack and the gaseous carbon dioxide from the dry ice could pass freely from the cold chamber to the external atmosphere; otherwise the chamber was made as nearly airtight as possible in order to prevent undue heat loss and to make it possible to measure the flow of air in the stack. This section of pipe contained an orifice for the purpose of measuring the rate of air flow through the system; and, since the orifice could be observed through the transparent plastic pipe, it could be kept free of frost in order that the readings might be reasonably accurate.

A closed chamber surrounded a perforated section of the house drain. A blower discharged air through a valve into this chamber, and by appropriate adjustment of this valve the desired pressure differential could be maintained and the rate of air flow through the system could be controlled. The air entered the house drain through a numbel of $3 / 8$-in.-diameter holes having a total crosssectional area equal to the cross-sectional area of the 3-in. house drain. In this way the frictional resistance due to the air entering the drain was probably greater than if it had entered through an open end of the 3-in. drain, since the entrance was through a number of small orifices in a direction at right angles to the direction of flow in the drain. This, of course, resulted in a head loss as a result of the change in direction of the inflowing air through an angle of $90^{\circ}$, similar to the effect of introducing the air through a $90^{\circ}$ elbow of small raclius of rurvature. In efferet, this arlangrenerst probably simulated a house drain and sewer of a length that might be expereted in service, but whirh space limitations prevented in the test installation.

Water occupied the part of the resamber below the drain. The temperature of the water was controlled by means of an immersion hester, so that any desired temperature ahove room tromperature coulf be maintainefl. Sorne of this hot water was pumperl up to the bathtub from which it flowed in a steady stream at a late of about 1.8 gal/min into the stack and retmined through the drain to the supply chamber.

A slot was cut in the bottom of the drain, so that the flow of hot water from the bathtub would be returned to the supply chamber without loss whereas a large flow of cold water, surch as thr discharge of the water closet, wonld for the most part pass on through the drain into the spill hasin so that there would be no great amount of corling of the warmer water in the supply chamber rlue to the addition of relatively large quantities of colrt water. The house drain terminated in a $90^{\circ}$ bent turned downward into the spill basin to form a water seal, which prevented the escape of air from the drain by this route.

During very hot weather it was found that it was impossible to keep the average temperature of the air in the stack as low as was desired in some of the tests, and, if the weather turnerl hot during a test run, it was sometimes impossible for the existing apparatus to keep the stack temperature at the value selected at the beginning of a run. Hence an arditional chamber was mounter near the blower and was filled with dry ice, so that by proper valve adjustment part of the air supplied by the blower passed through this chamber. By using this source of cooling, it was found possible to maintain the temperature of the air in the stack at the desired degree.

Inclined differential monometers were used to measure pressure differences between the pressure chamber enclosing the house drain and the chamber enclosing the roof rent and between oprosite sides of the orifice plate in the outlet tube from the cold chamber.

The concentration of carbon dioxids in the mixture of air and carbon dioxide passing through the orifice was measured by a dricice that operated on the principle of absorption of the artben dioxile from the mixture by means of a potassium hrelonide solution.

Temperatures inside the cold chanberl, at fiv" points in the air stram in the stack, at one point in the air stroam passing through the orition plate. and at two points in the wall of the sedtion of reme

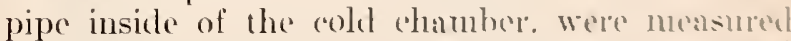
by means of a remote refording derite commerted to thermorouples placed at the ramious points sere

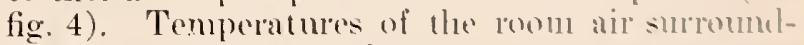
ing the test setup and water tomperatures were measured by meams of ordinary me'terty-in-ylass thermometers. Humblity determinations inside 
the stack were based on wet- and dry-bulb thermometer readings taken at a point about $5 \mathrm{ft}$ above the level at which the bathtub drain connected to the stack. These thermometers were fitted with rubber bushings, which were inserted into holes in the stack wall. Humidity determinations of the air in the room surrounding the installation were also based on wet- and dry-bulb thermometer readings.

In this connection, it is quite likely that the humidities obtained for the air in the stack were somewhat greater than the actual values, since the velocities in the stack probably were inadequate to lower the wet-bulb temperatures to their full extent. Howerer, this possibility was overlooked at the time the tests were made.

\subsection{Analysis of Test Installation}

There are three sets of conditions to consider in connection witl the test installation: (1) conditions outside of the system, (2) conditions inside of the system (1. e., inside of the stack and building drain), and (3) conditions in the manometer line (see fig. 5).

\section{a. Conditions Outside of System}

Corresponding to eq (1c) applying to the service system, the following equation applies to the test system:

$$
h_{\mathrm{at}}-h_{\mathrm{bt}}=r_{4 \mathrm{t}} L_{4 \mathrm{t}}+r_{2 \mathrm{t}}\left(L_{1 \mathrm{t}}+L_{3 \mathrm{t}}-L_{4 \mathrm{t}}\right)=\Delta h_{\mathrm{t}} .
$$

Howerer, in the tests made in this inrestigation the stack was mounted inside of a building at

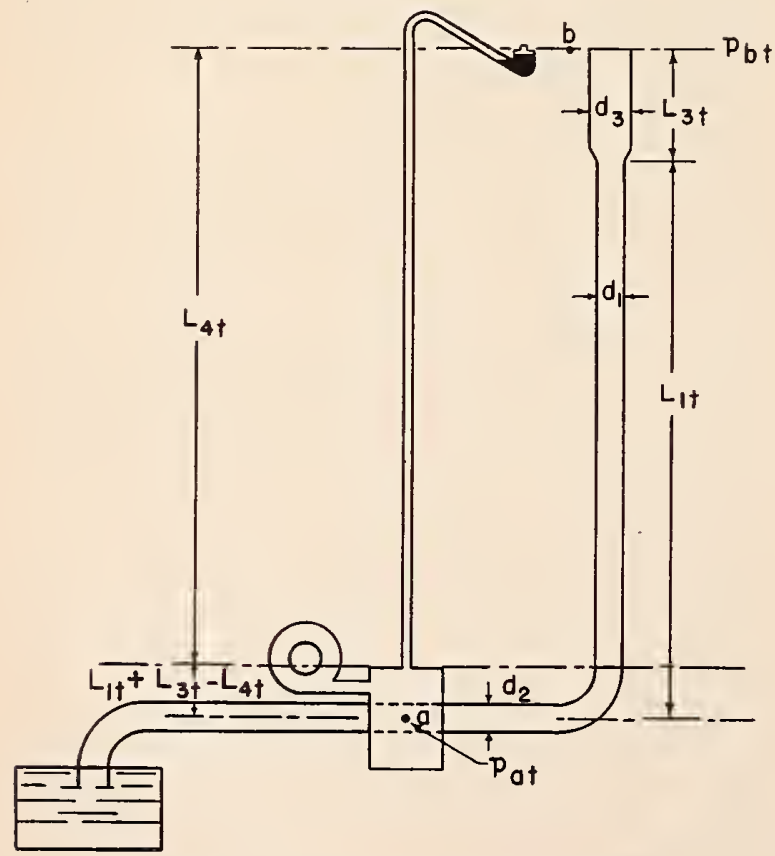

Figure 5. Analysis of test installation. ordinary room temperatures and thus was not subject to as great a difference in static head as would exist under service conditions in cold weather between the outlet of the building sewer and the top of the roof vent, owing to the lesser density of the air at room temperature compared with that of air at, say, $-30^{\circ} \mathrm{F}$. Hence, to produce a flow of air through the test system comparable to that which would occur in actual winter service, it was necessary to create artificially an additional difference in pressure head, $h_{\mathrm{e}}$, between points " $a$ " and " $b$ " through the stack. In the test installation this was done by means of a blower, as has been explained earlier. The head produced by the blower ranged from a few hundredths to a few tenths of an inch of water column. In order to produce the same difference in static pressure between points "a" and "b" as would exist in a similar installation in cold-weather service, the following relation must be satisfied:

$$
h_{\mathrm{at}}+h_{\mathrm{e}}-h_{\mathrm{bt}}=h_{\mathrm{as}}-h_{\mathrm{bs}}
$$

\section{b. Conditions Inside of System}

Corresponding to eq (3) for the service installation, we have for the test installation:

$$
h_{\mathrm{at}}+h_{\mathrm{e}}-h_{\mathrm{bt}}=h_{\mathrm{ft}}+r_{1 \mathrm{t}}\left(L_{1 \mathrm{t}}+L_{3 \mathrm{t}}\right) .
$$

We can substitute in this the value of $h_{\mathrm{at}}-h_{\mathrm{bt}}$ from eq (5) and solve for $h_{\mathrm{ft}}$, obtaining:

$$
h_{\mathrm{ft}}=\left(L_{1 \mathrm{t}}+L_{3 \mathrm{t}}-L_{4 \mathrm{t}}\right)\left(r_{2 \mathrm{t}}-r_{1 \mathrm{t}}\right)+L_{4 \mathrm{t}}\left(r_{4 \mathrm{t}}-r_{1 \mathrm{t}}\right)+h_{\mathrm{e}} .
$$

\section{c. Conditions in Manometer Line}

The auxiliary pressure created by the blower was measured by a manometer mounted on a level with the top of the roof vent. A relation between the reading $h_{\mathrm{m}}$ of the manometer and the pressure head $h_{\mathrm{e}}$ will next be derived. We can see in tuitively that $h_{\mathrm{e}}$ must be approximately equal to $h_{\mathrm{m}}$, but, if we wish to demonstrate this formally, we note from a consideration of figure 5 that the following relation holds for the manometer line:

$$
h_{\mathrm{at}}-h_{\mathrm{bt}}+h_{\mathrm{e}}=h_{\mathrm{m}}+r_{4 \mathrm{t}} L_{4 \mathrm{t}}+r_{2 \mathrm{t}}\left(L_{1 \mathrm{t}}+L_{3 \mathrm{t}}-L_{4 \mathrm{t}}\right) .
$$

Actually the value of $r_{4 t}$ inside of the manometer line will be a little greater than in the outside air because of the slightly higher pressure in the manometer line. Consideration of this pressure difference, using the gas law, shows, however, that the difference was not more than 0.1 percent in any of the tests, so the effect will be neglected. Hence, if we subtract eq (5) from eq (9), we obtain:

$$
h_{\mathrm{e}}=h_{\mathrm{m}} .
$$






FIGURE 6. Air-water density ratios for different temperatures.

Figure 6, giving the ralues of $r$ over the range of temperature in which we are interested, has been prepared for conrenience in computing. As has been stated. for the lower temperatures the air was assumed to be dry, while for the higher temperatures inside the stack the ail was assumed to be saturated.

\section{Friction Losses Involved in the Upward Flow of Air in the System}

In what follows it should be remembered that we are considering only the case in which no water is flowing in the drainage srstem. In order to eraluate the losses of head. $h_{\mathrm{fs}}$ and $h_{\mathrm{ft}}$, it is necessary to consider the drainage srstem in detail (see fig. 3).

The head losses in the system can be considered as belonging to three classes: (1) losses due to the frictional resistance to flow in straight pipes; (2) losses due to change in direction or to changes in cross-sectional area; and (3) losses required to create relocity of the air in the system. The first of these can be computed from the DarcyTeisbach equation:

$$
\lrcorner h=f \frac{L}{d} \frac{r^{2}}{2 g},
$$

where

$\Delta h=$ the head loss in terms of height of the fluid flowing-in this case, air

$f=$ the dimensionless Darcr-Teisbach friction coefficient

$L=$ the length of the pipe

$d=$ the internal diameter of the pipe

$x=$ the mean relocity of flow in the pipe

$g=$ the acceleration of gravity.

In order that $\Delta h$ may be measured in height of water column, it is necessary to multiply the right member by the ratio $r$ of the density of air under the assumed conditions to the density of water, since a water manometer was used to measure values of $\Delta h$. Thus, when $\Delta h$ is measured in height of water column, we have

$$
\lrcorner h=r f \frac{L}{d} \frac{v^{2}}{2 !} .
$$

The second class of losses can be expressed by a coefficient multiplied by the teelocity heard; $\rightarrow$, again multiplying by $r$ in order to oftstain $\Delta t_{\text {t }}$ in height of water column:

$$
\Delta h=r K \frac{v^{2}}{2 g},
$$

where $K$ is a constant.

The third type of loss is that due to the kinetir: energy of the air issuing from the roof rent arnd can be expressed by an equation similar to eq (12).

\subsection{Head Loss at Transition From Street Sewer to Building Sewer}

We assume that the energy loss, expressed as head of air, is equal to half the velocity hearl. as is customary where a square-cornered entrance is involved. 'The loss of head required to create the velocity $v_{2}$, the mean velocity of air flow in the building sewer and building drain, will not be added, since, if we take account of the energy losses (not transformations of energy) from point to point along the system, we need only to allow for the head loss required to create the relocity $v_{3}$ of the air issuing from the roof vent. Hence the loss of energy head at entrance to the building sewer is given by

$$
\Delta h=\frac{1}{2} r_{2} \frac{v_{2}^{2}}{2 g^{2}}
$$

or, since we shall find it convenient to express all losses in terms of the velocity hear in the stack:

$$
\Delta h=\frac{1}{2} r_{2}\left(\frac{d_{1}}{d_{2}}\right)^{4} \frac{i_{1}^{2}}{2 g}
$$

\subsection{Head Loss In Building Sewer and Drain}

Usually the building sewer and building drain comprise a single line of the same diameter and slope, being physically indistinguishable from each other. The distinction is made solety for administrative purposes. Hence, in what follows, they will be treated as a unit, the line having the limieter $d_{2}$ and the length $L_{2}$. The loss due to friction in this line is given by

$$
\Delta h=r_{2} f \frac{L_{2}}{d_{2}}\left(\frac{d_{1}}{d_{2}}\right)^{\frac{1}{2}} \frac{r_{1}^{2}}{2 j} .
$$

\subsection{Bend Loss at Entrance to Stack}

$$
\Delta h=r_{2} C_{b}\left(\frac{d_{1}}{d_{2}}\right)^{+} \frac{r_{i}^{2}}{2 !}
$$

\subsection{Head Loss at Contraction. Upper End of Bend}

In general the stack may be smaller in diamerer than the building drain. 'Then the loss date (1) 
contraction is

$$
\Delta h=r_{1} C_{\mathbf{c}} \frac{v_{1}^{2}}{2 g}
$$

$C_{c}$, the contraction coefficient, can be evaluated from tables given in various hydraulics textbooks, for example, Dodge and Thompson, Fluid mechan$i c s$, first edition, page 215 .

\subsection{Head Loss Due to Friction in Stack}

$$
\Delta h=r_{1} f \frac{L_{1}}{d_{1}} \frac{v_{1}^{2}}{2 g} \text {. }
$$

\subsection{Head Loss at Transition to Roof Vent}

The transition from the stack to the roof ventif they are not both of the same diameter-may be either a contraction or an expansion. If it is a contraction, the loss is given by

$$
\Delta h=r_{1} C_{c}\left(\frac{d_{1}}{d_{3}}\right)^{4} \frac{v_{1}^{2}}{2 g}
$$

and $C_{\mathrm{c}}$ can be evaluated as explained above. If it is an expansion, it is given by

$$
\Delta h=r_{1} C_{e} \frac{v_{1}^{2}}{2 g}
$$

where $C_{e}=\left[1-\left(d_{1} / d_{3}\right)^{2}\right]^{2}$.

\subsection{Head Loss Due to Friction in Roof Vent}

$$
\Delta h=r_{1} f \frac{L_{3}}{d_{3}}\left(\frac{d_{1}}{d_{3}}\right)^{4} \frac{v_{1}^{2}}{2 g}
$$

where $d_{3}$ is the diameter of the opening in the vent, which depends on the thickness of the layer of frost, if such a layer is present.

\subsection{Head Loss at Outlet of Roof Vent}

Because the outlet is square-cornered, it will be assumed that all of the kinetic energy of the issuing air is lost. That is, there is no recovery of head at exit. However, we must include in the equation. for the loss of head in the system the velocity liead of the air issuing from the roof vent because a loss of head was required to create this velocity.

Hence

$$
\Delta h=r_{1}\left(\frac{d_{1}}{d_{3}}\right)^{4} \frac{v_{1}^{2}}{2 g} .
$$

This procedure is not strictly correct because some of the changes of velocity in the system occur at the temperature $\theta_{2}$ and some at temperature $\theta_{1}$, under the assumptions made. However, the differences involved are so small as to be neglibible in the problem.

The total loss of head in the system is the sum of the above head losses, or

$$
\begin{aligned}
h_{\mathrm{f}} & =\Sigma \Delta h=\left[r_{2}\left\{\frac{1}{2}\left(\frac{d_{1}}{d_{2}}\right)^{4}+f \frac{L_{2}}{d_{2}}\left(\frac{d_{1}}{d_{2}}\right)^{4}+C_{\mathrm{b}}\left(\frac{d_{1}}{d_{2}}\right)^{4}\right\}\right. \\
& +r_{1}\left\{C_{\mathrm{c}}+f \frac{L_{1}}{d_{1}}+C_{\mathrm{e}}+f \frac{L_{3}}{d_{3}}\left(\frac{d_{1}}{d_{3}}\right)^{4}\right. \\
& \left.\left.+\left(\frac{d_{1}}{d_{3}}\right)^{4}\right\}\right] \frac{v_{\mathrm{1}}^{2}}{2 g}
\end{aligned}
$$

(In this equation, $C_{\mathrm{e}}$ is to be replaced by $C_{\mathrm{c}}\left(d_{1} / d_{3}\right)^{4}$ if there is a contraction instead of an expansion. If neither, $C_{\mathrm{e}}$ and $C_{\mathrm{e}}$ are both equal to zero.)

Now, inserting the proper values for the density ratios, the lengths, the diameters, and the coefficients, and computing $h_{\imath}$ from eq (4), we can solve eq (14) for $v_{1}$.

The following assumptions are made in the computations that follow: The diameters of the house sewer, the house drain, the stack, and the roof vent are all the same and will be represented by $d_{1}$. Of course, as the vent frosts up, its diameter will decrease, and, under these conditions will be represented by $d_{3}$. The total length of house sewer and drain is $50 \mathrm{ft}$. We adopt the following

TABLE 1. Pressure differentials $h_{f}$ in feet of water column tending to produce convection in stacks of different heights

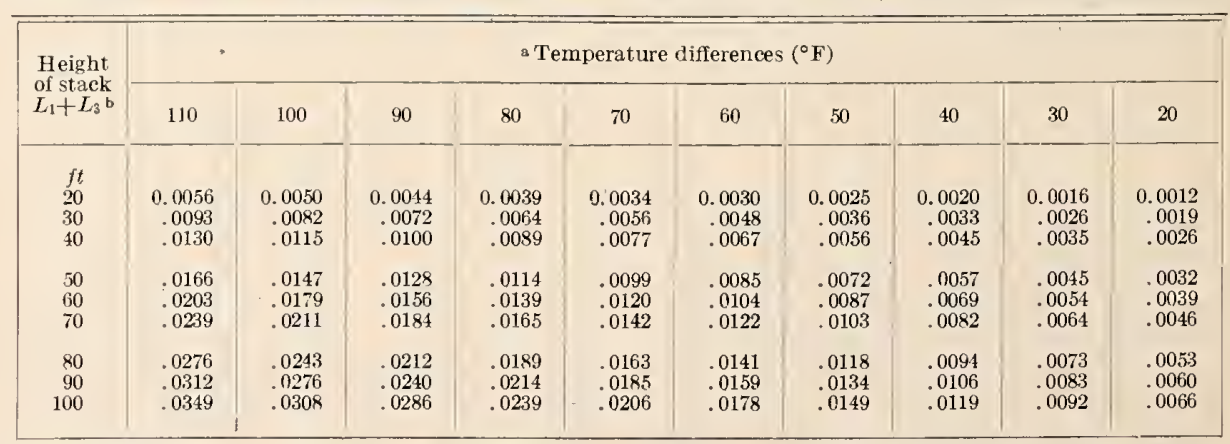

a Temperature of the air in the stack and vent is taken as $60^{\circ} \mathrm{F}$. Temperature of the air in the street sewer, manhole building sewer, and building drain is taken as $50^{\circ} \mathrm{F}$. The temperature difference is the algebraic difference between the temperature of the air in the stack and that of the outside air.

berature or the air $L_{1}+L_{3}-L_{4}=5 \mathrm{ft}$. 


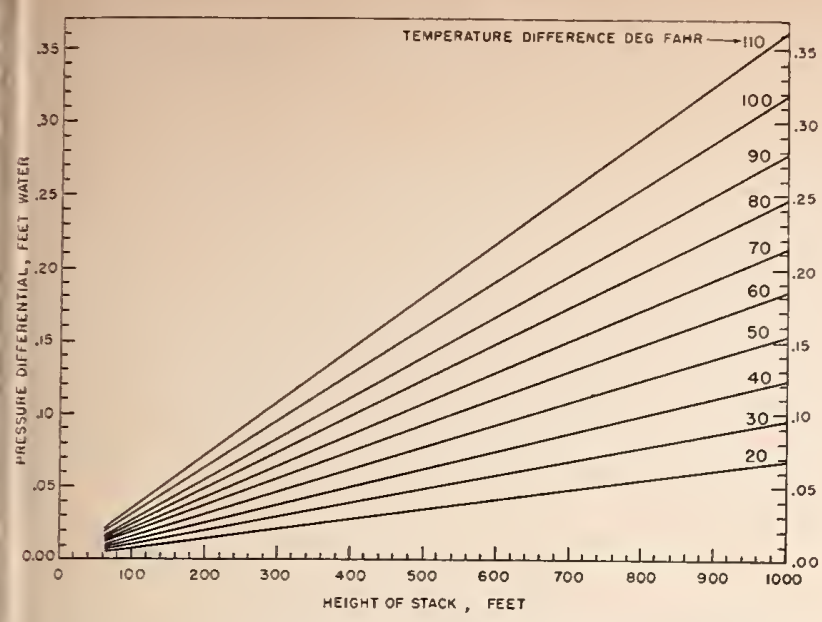

FIGLRE 7. Pressure differentials tending to cause convection due to temperature difference between outside air and air in stack.

(See footnote to table 1 for air temperatures assumed.)

values: $f=0.03, C_{\mathrm{b}}=0.23$, and $g=32.2 \mathrm{ft} / \mathrm{sec}$ squared.

Values of $h_{1}$ computed from eq (4) are tabulated in table 1 and are plotted in figure 7 for various differences in temperature between that of the outside air and the air in the stack and for heights of stack up to $1,000 \mathrm{ft}$.

Table 2 gives velocities of air flow in systems in which the building sewer, building drain, stack, and roof vent are all 3 in. in diameter for stacks up to $60 \mathrm{ft}$ in height and for temperature differences ranging from 30 to 90 deg $F$. In this and all the following cases for which computed velocities are giren, it is assumed that the total length of building drain is $50 \mathrm{ft}$. The temperature of the air in the building drain and sewer is assumed to be $50^{\circ} \mathrm{F}$. and that in the stack is assumed to be $60^{\circ} \mathrm{F}$. Outside air temperatures are selected to gire the desired temperature differences.

Tables 3, 4, 5, and 6 give air velocities in 4-in., 6-in., 8-in., and 12-in. systems for stack heights up to $1,000 \mathrm{ft}$ in the case of the 8 -in. and $12-\mathrm{in}$. stacks.

TABLE 2. Air velocities in stacks due to convection Pipe diameter throughout system, 3 in. ${ }^{\text {a }}$

\begin{tabular}{|c|c|c|c|c|c|c|c|}
\hline \multirow{2}{*}{$\begin{array}{l}\text { Height of } \\
\text { stack } \\
L_{1}+L_{3}\end{array}$} & \multicolumn{7}{|c|}{ Temperature difference $\left({ }^{\circ} \mathrm{F}\right)$} \\
\hline & 30 & 40 & 50 & 60 & 70 & 80 & 90 \\
\hline $\begin{array}{l}f t \\
20 \\
40 \\
60\end{array}$ & $\begin{array}{r}f p s \\
2.9 \\
3.8 \\
4.4\end{array}$ & $\begin{array}{c}\int p s \\
3.2 \\
4.4 \\
5.0\end{array}$ & $\begin{array}{c}\int p s \\
3.6 \\
4.9 \\
5.6\end{array}$ & $\begin{array}{r}f p s \\
3.9 \\
5.3 \\
6.1\end{array}$ & $\begin{array}{c}f p s \\
4.2 \\
5.7 \\
6.5\end{array}$ & $\begin{array}{r}f p s \\
4.5 \\
6.1 \\
7.0\end{array}$ & $\begin{array}{r}f p s \\
4.8 \\
6.5 \\
7.4\end{array}$ \\
\hline
\end{tabular}

s Length of house sewer and house drain, $50 \mathrm{ft}$.
TABLE 3. Air velocities in stacts diue to convection Pipe diameter throughout. system, 4 in. ${ }^{3}$

\begin{tabular}{|c|c|c|c|c|c|c|c|}
\hline \multirow{2}{*}{$\begin{array}{l}\text { Height of } \\
\text { stack } \\
L_{1}+L_{3}\end{array}$} & \multicolumn{7}{|c|}{ Temperature difference $\left({ }^{\circ} \mathrm{F}\right)$} \\
\hline & 30 & 40 & 50 & (i) & 70 & 8i) & (a) \\
\hline$f t$ & $f \rho s$ & $f p s$ & $f p s$ & 108 & $f p s$ & $f(p)$ & $f p s$ \\
\hline 20 & 3. 2 & 3. 6 & 4. 1 & 4. 4 & 4.7 & 5. 1 & 5,1 \\
\hline 40 & 4.3 & 4.9 & 5.5 & 6.0 & f. 4 & f. 9 & 7.3 \\
\hline 60 & 4.9 & 5. 6 & 6.3 & 6.9 & 7.4 & $x .0$ & $x .4$ \\
\hline 80 & 5.4 & 6. 1 & f. 8 & 7.5 & 80 & \&. fi & 9. 2 \\
\hline 100 & 5.7 & 6. 4 & 7. 2 & 7.9 & 8.5 & 0.1 & 3. 7 \\
\hline
\end{tabular}

a Length of house sewer and house drain, sift.

TABLE 4. Air velocities in stacks due to convertion Pipe diameter throughout syst. $m$ was 6 in. ${ }^{\text {a }}$

\begin{tabular}{|c|c|c|c|c|c|c|c|}
\hline \multirow{2}{*}{$\begin{array}{l}\text { Height of } \\
\text { stack } \\
L_{1}+L_{3}\end{array}$} & \multicolumn{7}{|c|}{ Temperature difference $\left({ }^{\circ} \mathrm{F}\right)$} \\
\hline & 30 & 40 & 50 & 60 & 70 & $30)$ & (A) \\
\hline$f t$ & $f p s$ & $f p s$ & $\int p s$ & $\int p 8$ & $f p .8$ & fps &  \\
\hline 50 & 5.5 & 6.3 & 7.0 & $\frac{7}{7} .6$ & 8. 2 & 8.8 & 9.4 \\
\hline 100 & 6.8 & 7.7 & 8.6 & 9.4 & 10.1 & 10. 9 & 11. 5 \\
\hline 200 & 7.7 & 8.8 & 9.8 & 10.8 & 11.6 & 12.5 & 13. 2 \\
\hline 300 & 8.1 & 9.3 & 10. 4 & 11.3 & 12.2 & 13. 2 & 13.9 \\
\hline 400 & 8.4 & 9.6 & 10. 7 & 11.7 & 12.6 & 13.6 & 14.4 \\
\hline 500 & 8.5 & 9.7 & 10.9 & 11. 9 & 12.8 & 13.8 & 14. 6 \\
\hline
\end{tabular}

a Length of house sewer and house drain, $50 \mathrm{ft}$.

TaBle 5. Air velocities in stacks due to convection Pipe diameter throughout system, 8 in. a

\begin{tabular}{|c|c|c|c|c|c|c|c|}
\hline \multirow{2}{*}{$\begin{array}{l}\text { Height of } \\
\text { stack } \\
L_{1}+L_{3}\end{array}$} & \multicolumn{7}{|c|}{ Temperature difference $\left({ }^{\circ} \mathrm{F}\right)$} \\
\hline & 30 & 40 & 50 & 60 & 70 & 80 & 90) \\
\hline$f t$ & $f p s$ & $f \underline{p s}$ & $f p s$ & $f p s$ & fps & $f p s$ & $\int p s$ \\
\hline & 6.1 & 7.0 & 7.8 & 8.5 & 9.1 & 9. 9 & 10.4 \\
\hline 100 & 7. 6 & 8.6 & 9.7 & 10.5 & 11.4 & 12. 2 & 13.0 \\
\hline 200 & 8.8 & 10.0 & 11. 2 & 12. 2 & 13. 2 & 14.2 & 15. 0 \\
\hline 300 & 9.3 & 10.6 & 11.8 & 12.9 & 13. 9 & 15.0 & 15. 9 \\
\hline 400 & 9.6 & 10.9 & 12. 2 & 13.4 & 14.4 & 15.5 & 16.4 \\
\hline 500 & 9.8 & 11. 1 & 12.5 & 13. 6 & 14. 7 & 15.5 & 16. : \\
\hline 600 & 9.9 & 11.3 & 12.6 & 13.8 & 14.9 & 16.0 & 17.0 \\
\hline 700 & 10.0 & 11.4 & 12.8 & 13.9 & 15.0 & 16. . & 17. 1 \\
\hline 800 & 10.1 & 11.5 & 12.9 & 14.0 & 15.1 & 16.3 & 17.3 \\
\hline 900 & 10.1 & 11.5 & 12.9 & 14. 1 & 15. 2 & 16.4 & 174 \\
\hline 1,000 & 10.2 & 11.6 & 13. 0 & 14. 2 & 15.3 & 16. 5 & 175 \\
\hline
\end{tabular}

a Length of house sewer and house drain, $50 \mathrm{ft}$.

TABLE 6. Air velocities in stacks due to contection Pipe diameter throughout system, 12 in. *

\begin{tabular}{|c|c|c|c|c|c|c|c|}
\hline \multirow{2}{*}{$\begin{array}{c}\text { Height of } \\
\text { stack } \\
L_{1}+L_{3}\end{array}$} & \multicolumn{7}{|c|}{ Temperature difference $\left({ }^{\circ} \mathrm{F}\right)$} \\
\hline & 30 & $\$ 0$ & 50 & 60 & 70 & (i) & (4) \\
\hline$f t$ & $f p s$ & fps & $f p s$ & $f p s$ & $f p s$ & fpr & $i p s$ \\
\hline 50 & 7.1 & 8.0 & 8.9 & 9. 8 & 10.5 & ili. 3 & 120 \\
\hline 100 & 8.9 & 10.1 & 11.3 & 12.3 & 13.3 & 14.3 & $1 \mathrm{~N} 1$ \\
\hline 200 & 10.4 & 11.8 & 13.3 & 14.5 & 15. 6 & 16. & 17. \\
\hline 300 & 11.1 & 12.6 & 1.2 .2 & 15.5 & 16. : & (N.) & 1!1 i) \\
\hline 400 & 11.5 & 13.1 & 14.7 & lit. 0 & 17.3 & IS 6 & 19. 7 \\
\hline 500 & 11.8 & 13.4 & 15.0 & iti. $t$ & 17.7 & 19.1 & 211.2 \\
\hline 600 & 12.0 & 13. 6 & 15.3 & $1 t i .7$ & I. 0 & 19. & 71.5 \\
\hline 700 & 12.1 & 13.8 & 15.4 & 1ti. 9 & IS: : & 19.8 & 2117 \\
\hline 800 & 12.2 & 13.9 & 15.6 & 17. 0 & 153 & $19=$ & 21.0 \\
\hline 900 & 12.3 & 14.0 & 15.7 & 17.1 & 15. 5 & [!? & 211 \\
\hline 1,000 & 12.4 & 14.1 & 15.5 & 17.2 & 18. 6 & (1). (1) & $: 12$ \\
\hline
\end{tabular}

a Length of house sewer and house drain, solf. 
TABLE 7. Air velocities in stacks due to convection Data from Gray

\begin{tabular}{|c|c|c|c|c|c|c|}
\hline $\begin{array}{c}\text { Tempera- } \\
\text { Teme } \\
\text { ture } \\
\text { differ- } \\
\text { ence }\end{array}$ & $\begin{array}{c}\text { Height of } \\
\text { stack }\end{array}$ & \multicolumn{5}{|c|}{ Stack diameter (in.) } \\
\cline { 5 - 8 } & & 2 & 3 & 4 & 5 & 6 \\
\hline deg $F$ & $f t$ & $f p s$ & $f p s$ & $f p s$ & $f p s$ & $f p s$ \\
20 & 20 & 1.88 & 2.25 & 2.47 & 2.80 & 3.17 \\
20 & 50 & 2.78 & 3.55 & 3.90 & & $\ldots$ \\
25 & 20 & 1.97 & 2.52 & 2.77 & 3.12 & 3.53 \\
25 & 50 & 3.07 & 3.97 & 4.37 & 4.95 & 5.58 \\
30 & 20 & 2.15 & 2.75 & 3.02 & 3.42 & 3.87 \\
30 & 50 & 3.40 & 4.33 & 4.78 & 5.42 & 6.12 \\
\hline
\end{tabular}

By comparison, the data given by Gray [3] on the velocity of flow of air in stacks due to convection are given in table 7 . He does not state all of the assumptions he made in computing these values, but it will be observed that his results fit very well the results given in the tables referred to above.

It should be emphasized that the values given in tables 2 to 6 , inclusive, apply only when no water is being discharged into the stack and when there is no closure of the rent by frost. In addition, these values have been computed on the assumption of straight stacks without horizontal branch or vent comnections. Obviously these assumptions give computed velocities somewhat greater than those that occur sometimes in service. However, owing to the many variables inherent in the many types of plumbing drainage systems in service, it is necessary to make certain simplifying assumptions in connection with such computations. It is believed that the values in the tables above give at least a rough estimate of the maximum convective velocities to be expected in stacks.

\section{Physics of Frost Closure of Roof Vents}

\subsection{General Considerations}

The closure of a roof vent by the formation of a layer of frost on the inner surface of the vent is a complicated process which it is not feasible to discuss with any great degree of accuracy. However, the general physics of the process is quite clear and leads to certain conclusions, some of which are at variance with commonly accepted ideas today. The process will be discussed at considerable length here, therefore, both for the purpose of achieving a clear understanding of the principles involved in the process and for pointing out the way in which any further investigation might best be carried out.

The partial or complete closure of a roof vent by frost in cold weather requires that a more or less steady current of warm moist air flow up through the stack and roof vent. If the system does not contain a house trap, then this air comes from the street sewer and is relatively moist and warm. If there is a house trap in the building drain, then a fresh-air inlet is ordinarily required on the house side of the trap; and in this case the current of air flowing up the stack is much cooler than in the first-mentioned case and is less pronounced. It is also much drier when it enters the system.

When water is discharged intermittently from fixtures that drain into the stack, the upward current of air may become quite erratic, and, at times when considerable water is discharging, its direction may be reversed. However, during many hours of each day little or no use is made of the plumbing fixtures, and the upward current is fairly steady.

The air flowing upward through the stack, partially or completely saturated with water vapor, is chilled by heat loss to the cold interior surface of the roof vent. This causes condensation $\mathrm{or}^{\prime}$ deposition of water on or the adhering of ice particles to the surface. If the inner surface of the rent is below $32^{\circ} \mathrm{F}$, the water freezes or the ice particles adhere, forming an ice or frost deposit; if it is above $32^{\circ} \mathrm{F}$, the deposited water runs down the inner surface of the stack. The temperature of the inner surface of the vent, exposed to the current of air flowing upward in the stack, is thus a controlling factor in the formation of a frost deposit. Under steady conditions of outdoor weather and air temperature in the stack, the temperature of the inner surface of the vent depends on the temperature of the outside air and the wind velocity, on the insulating effect of the vent pipe and the frost deposit, and on the temperature and velocity of the air flowing in the rent pipe.

As the frost deposit builds up, it acts as insulation to reduce the flow of heat from the stack air to the outdoor air and consequently to raise the temperature of the frost deposit exposed to the stack air. If the ice-air surface rises in temperature to $32^{\circ} \mathrm{F}$, further moisture deposits will remain liquid and will drain down the stack, and the frost deposit will not thicken any further. The calculations presented in this paper are for the purpose of estimating for any particular stack vent under steady temperature conditions the extent to which frost deposits may be expected to build up in the rent pipe.

The rate at which moisture or frost particles may be deposited, and, therefore, the rate at which a frost deposit may thicken, increases, other things being equal, as the humidity of the air stream increases. Whether a given vent will freeze closed during a particular spell of cold weather may thus depend on the rate of moisture deposition and so, to a considerable extent, on the humidity of the stack air.

The exposed length of the vent pipe is of obvious importance in connection with this phenomenon, since the available area for chilling the stack air and, therefore, for abstracting its accompanying moisture, is increased with increased length of vent, 
while the effect of conduction of heat upward in the wall of the rent pipe from the warmer length below is reduced.

\subsection{Heat Transfer in a Roof Vent}

It is assumed that warm air at the temperature $\theta_{1}$, saturated with water rapor, is flowing upward through the rent with relocity $r_{3}$. From the standpoint of heat transfer, the general problem is that of a warm fluid flowing in a crlindrical pipe or shell, with heat transfer to the shell, and thence through the shell to the colder air or wind beyond it. The heat transfer phenomenon is a complicated one, partly because of the existence of a boundary layer near the pipe wall in the air stream and partly because changes of state occur in the air stream as it loses its moisture in passing through the rent.

It has already been stated that, as the saturated or nearly saturated air chills while passing up through the roof vent, some of the water condenses to form drops of moisture. Under some conditions some of this moisture may freeze while still in the air stream. As the layer of ice in the vent increases in thickness, the resistance that the vent offers to the flow of air increases, with the result that there is a decrease in the relocity of the air stream in the stack, but an increase in the relocity of the air stream in the rent (see fig. 8). When this happens, a smaller amount of moisture passes through the rent in a given time than when the latter is unobstructed, but, on the other hand, the area of the surface on which moisture can deposit is reduced to a greater extent than is the volume of flow.

Owing to these facts and to the further fact that there are two changes in state occurring in the vent pipe, i. e., from rapor to liquid and from liquid to

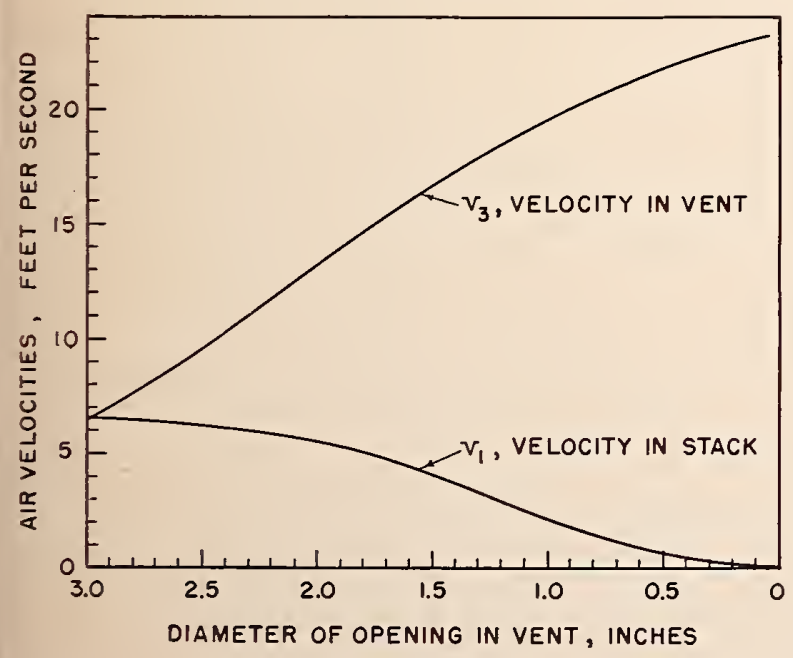

FIGCRE 8. Changes in air velocities in a 3 -in. stack and vent as the vent freezes up.

Height of stack, $40 \mathrm{ft}$; Jength of vent affected by frost, $1 \mathrm{ft}$; and temperaHeight of stack, $40 \mathrm{ft}$; Jength of vent affected by frost, $1 \mathrm{ft}$; and tempera-
ture difference, $90 \mathrm{deg}$ F. (See footnote to table 1 for air temperature assumed.) solid, with consequent releass of heat, it is obrions that it would be an extremely difficult and romplicated task to compute acrurately the rate of heat transfer from the air stream to the inner wal] of the vent, nor do the practical aspecets of thro problem warrant such an attempt. However, formulas are available for the transfer of heat from an air stream to a chilled pipe wall when no changes of state occur, and one of these formulas will be used here, an estimate being inclucled for the effect of the changes of state that occur. Figure 9 , showing the cross section of a vent, gives the nomenclature used in what follows.

\section{a. Transfer of Heat From Air Stream in Vent to} Inner Wall of Vent

The general equation for the transfer of heat from the air stream to the wall is $[4$, p. 3]:

$$
q=K S \Delta \theta
$$

where

$q=$ the rate of heat transfer through the surface involved

$K=$ the coefficient of heat transfer, which varies with the velocity of air flow and other quantities (see eq 17 and 24)

$S=$ the area of the surface in question

$\Delta \theta=$ the rifference in temperature producing the flow of heat.

Applying this equation to the transfer of heat from the stream of air in the vent to the wall of the pipe or to the ice surface, as the case may be, we write eq (15) as follows:

$$
q_{\mathrm{s} 3}=K_{\mathrm{s} 3} S_{3} \theta_{\mathrm{s} 3}=2 \pi r_{3} K_{\mathrm{s} 3} \theta_{\mathrm{s} 3},
$$



Figure 9. Nomenclature used in heat transfer amolists. 
where

$q_{s 3}=$ the rate of heat transfer from the air stream to the wall

$K_{83}=$ the coefficient of heat transfer from the air strcam to the wall

$r_{3}=$ the radius of the cylindrical opening in the vent

$S_{3}=$ the area of the inner wall $=2 \pi r_{3}$, since unit length of vent is being considered

$\theta_{\mathrm{s} 3}=$ the difference in temperature between the wall and the air stream.

To evaluate $K_{83}$, the equation given by McAdam applying to this case is used [4, p. 168]:

$$
\frac{K_{s 5} d_{3}}{k}=0.023\left(\frac{d_{3} \rho_{1} v_{3}}{\mu}\right)^{0.8}\left(\frac{c_{p} \mu}{k}\right)^{0.4}
$$

the notation bcing adapted to the present problem. In this equation

$d_{3}=$ the diameter of the cylindrical opcning in the vent, in feet

$k=$ the coefficient of thermal conductivity of the air, in Btu/(hr) (ft) (deg F)

$c_{\mathrm{p}}=$ the specific heat of the air at constant pressure, in Btu/(lb) air (deg F)

$\rho_{1}=$ the weight density of the air in the stack and vent, in $\mathrm{lb} / \mathrm{ft}^{3}$

$\mu=$ the absolute viscosity of the air in $\mathrm{lb} /(\mathrm{hr})$ (ft)

$v_{3}=$ the velocity of air flow through the vent in $\mathrm{ft} / \mathrm{hr}$.

Equation 17 gives the value of the coefficient of heat transfer $K_{\mathrm{s} 3}$ for the case of a fluid flowing through a chilled pipe, under the conditions that the viscosity of the fluid is not more than twice that of water and for Reynolds numbers excecding 2,100 , in other words, for turbulent flow. These two conditions are fulfilled in the problem under consideration, except that, for very low velocities in the smallest vents, the Reynolds number. might be somewhat less than the value specified
above.

$A$ value of 0.78 can be taken as an average for $c_{\mathrm{p}} \mu / k$. Substituting this in $\mathrm{eq}(17)$, we obtain

$$
K_{\mathrm{8} 3}=0.027 \frac{c_{\mathrm{p}}\left(\rho_{1} v_{3}\right)^{0.8} \mu^{0.2}}{d_{3}^{0.2}}
$$

which is in agreement with McAdam [4, p. 174]. The coefficient 0.027 will be increased to $0.030 \mathrm{ar}$ bitrarily in an attempt to allow for heat generated by the changes in state referred to earlier. If this change is made, an average value of 0.0435 is assumed for $\mu$, and a value of 0.25 is assumed for $c_{\mathbf{p}}$,
eq (18) reduces to the form

$$
K_{\mathrm{s} 3}=\frac{0.004\left(\rho_{1} v_{3}\right)^{0.8}}{d_{3}^{0.2}}
$$

If this value of $K_{\mathrm{s} 3}$ is substituted in eq (16), the following expression is obtained:

$$
q_{\mathrm{s} 3}=0.004 S_{3} \frac{\left(\rho_{1} v_{3}\right)^{0.8}}{d_{3}^{0.2}} \theta_{83}=0.004 \pi\left(\rho_{i} v_{3} d_{3}\right)^{0.8} \theta_{\mathrm{s} 3} \text {. }
$$

This last equation gives the rate of heat transfer between the air stream in the vent and the inside surface of the vent (metal or ice) in British thermal units per hour per foot lengtli of vent.

\section{b. Transfer of Heat Through Ice Layer and Pipe Wall}

The equation for the transfer of heat through a cylindrical shell is $[4, p .8]$ :

where

$$
q=\frac{2 \pi k_{\mathrm{m}} L}{\ln \left(x_{\mathrm{o}} / x_{\mathrm{l}}\right)} \Delta \theta
$$

$k_{\mathrm{m}}=$ the mean thermal conductivity of the material of the shell

$L=$ the length of the cylindrical surface of the shell

$x_{0}, x_{1}=$ the radii of the outer and inner walls, respectively, of the shell

$\Delta \theta=$ the difference in temperature between the inner and outer walls of the shell.

Using eq (21), and taking the length of the cylinder, $L$, as unity, $q_{31}$, the rate of heat transfer through the ice layer, becomes, per unit length of cylinder:

$$
q_{31}==\frac{2 \pi k_{31}}{\ln \left(r_{1} / r_{3}\right)} \theta_{31}
$$

Similarly, $q_{10}$, the rate of heat transfer through the pipe wall, becomes

$$
q_{\mathrm{io}}=\frac{2 \pi k_{10}}{\ln \left(r_{\mathrm{o}} / r_{1}\right)} \theta_{10^{\circ}}
$$

\section{c. Transfer of Heat From Outer Wall of Vent to Outer}

The roof vent, extending vertically upward from a flat roof, may be looked upon as a single heated cylinder in a stream of cooler air flowing at right angles to its axis. The flow of air thus represents the wind blowing past the vent. For this condition McAdam $[4, p, 221]$ gives a curve of the relation betwcen $K d_{0} / k$ plotted against the Reynolds number, $d_{0} v_{4} \rho_{4} / \mu$, which applies to this case and extends to nearly the highest values of the Reynolds number that will be involved in the following computations. In the above Reynolds number, $v_{4}$ is the velocity of the wind in feet per hour, and $\rho_{4}$ is the weight density of the outcloor air in pounds per cubic foot. This curve was used in the computations that follow, and the relation that it gives can be represented by the equation,

$$
K_{\mathrm{os}}=\frac{k}{d_{0}} \psi\left(\frac{d_{0} v_{4} \rho_{4}}{\mu}\right),
$$

where $\psi$ is a functional symbol. 
Substituting the value of $K_{0 \mathrm{a}}$ given by aq (24) in eq (15), we bare for the rate of heat transfer from the outer wall of the vent pipe to the outer atmosphere:

$$
q_{\mathrm{os}}=S_{\mathrm{o}} \frac{k^{2}}{d_{\mathrm{o}}} \psi\left(\frac{d_{0} v_{4} \rho_{4}}{\mu}\right) \theta_{\mathrm{oa}}=2 \pi r_{\mathrm{o}} K_{\mathrm{os}} \theta_{\mathrm{oa}}
$$

where $q_{\text {os }}$ and $\theta_{\text {oa }}$ are the rate of heat transfer per unit length of pipe, snd the temperature difference between the outer wall and the air, respectively, $S_{0}$ is the area of the surface of unit length of the outer wall of the ront, $d_{0}$ is the outside diameter, and $r_{0}$ the outside adius of the vent.

\section{d. Computation of the Temperature of the Ice-Air Surface in the Vent}

The problem is to compute the variation of the temperature of the ice-air surface in a given vent for any set of assumen conditions as the vert freezes up. If, at any stage of the icing process, the temperature of this surfare rises to : $32^{\circ} \mathrm{F}$. the freezing will not continue further, and the pipe will remain only partly elosed. If , on the r,ther hand, the temperature of this surfare does not rise as high as $32^{\circ} \mathbf{F}$ during the process of frecring, then the freeging will continue to complete closure, provided the conditions remain corrstant for a sufficiently long period.

The computations will be given in detail for a 3-in. vent in what follows. We assurne a particular system in which the building drain and sewer, the stack, and the vent are all ? in. in diameter. It will be assumed that the building sewer and drain together are $50 \mathrm{ft}$ long and that the stack, including the roof vent, is $40 \mathrm{ft}$ high. For the sake of concreteness, it will be further assumed that the vent projects I ft above the roof, although this assumption is not essential to the problem. The ail temperature in the

TABLE 8. Computation of coefficient of heat transfer from air stream in 3-in. vent to inner wall of vent Temperature of air in vent, $60^{\circ} \mathrm{F}$; weight density of air in vent, $\rho_{1}, 0.075 \mathrm{lb} / \mathrm{ft}^{3} ; K_{\mathrm{\theta}}=0.004 \frac{\left(3,600 \rho_{1} v_{3}\right)^{0.8}}{\left(d_{3}\right)^{0.2}}$.

\begin{tabular}{|c|c|c|c|c|c|c|c|c|c|}
\hline \multicolumn{2}{|c|}{$\begin{array}{c}\text { Diameter opening in } \\
\text { vent, } \boldsymbol{d}_{3}\end{array}$} & \multirow{2}{*}{$\begin{array}{c}\begin{array}{c}\text { Tempera- } \\
\text { ture of } \\
\text { outside air }\end{array} \\
\end{array}$} & \multirow{2}{*}{$\begin{array}{c}\begin{array}{c}\text { Velocity of } \\
\text { air in vent }\end{array} \\
\\
f p s \\
6.49 \\
6.13 \\
5.75 \\
5.31 \\
4.90 \\
4.35\end{array}$} & \multirow{2}{*}{$\begin{array}{l}3,600 \rho_{i} v_{3} \\
l b / f t 2 h \tau \\
1,750 \\
1,655 \\
1,555 \\
1,435 \\
1,325 \\
1,175\end{array}$} & \multirow{2}{*}{$\begin{array}{c}\left(3,600 \rho_{1} v_{3}\right)^{0.8} \\
\\
\\
395 \\
375 \\
360 \\
335 \\
315 \\
285\end{array}$} & \multirow{2}{*}{$\begin{array}{l}\left(d_{3}\right)^{0.2} \\
0.762 \\
.762 \\
.762 \\
.762 \\
.762 \\
.762\end{array}$} & \multirow{2}{*}{$\begin{array}{l}K_{\mathrm{e} 3} \\
\\
\\
2.08 \\
2.00 \\
1.89 \\
1.78 \\
1.66 \\
1.50\end{array}$} & \multirow{2}{*}{$\begin{array}{c}\frac{r_{3}}{r_{0}} \\
0.877 \\
.877 \\
.877 \\
.877 \\
.877 \\
.877\end{array}$} & \multirow{2}{*}{$\begin{array}{l}\frac{r_{3}}{r_{i}} \\
1.00 \\
1.00 \\
1.00 \\
1.00 \\
1.00 \\
1.00\end{array}$} \\
\hline $\begin{array}{l}\text { in. } \\
3.07 \\
3.07 \\
3.07 \\
3.07 \\
3.07 \\
3.07\end{array}$ & $\begin{array}{c}f t \\
0.256 \\
.256 \\
.256 \\
.256 \\
.256 \\
.256\end{array}$ & & & & & & & & \\
\hline $\begin{array}{l}2.5 \\
2.5 \\
2.5 \\
2.5 \\
2.5 \\
2.5\end{array}$ & $\begin{array}{l}.208 \\
.208 \\
.208 \\
.208 \\
.208 \\
.208\end{array}$ & $\begin{array}{r}-30 \\
-20 \\
-10 \\
0 \\
+10 \\
+20\end{array}$ & $\begin{array}{l}9.23 \\
8.80 \\
8.25 \\
7.57 \\
6.92 \\
6.22\end{array}$ & $\begin{array}{l}2,490 \\
2,375 \\
2,230 \\
2,045 \\
1,870 \\
1,680\end{array}$ & $\begin{array}{l}520 \\
500 \\
475 \\
450 \\
415 \\
380\end{array}$ & $\begin{array}{l}.731 \\
.731 \\
.731 \\
.731 \\
.731 \\
.731\end{array}$ & $\begin{array}{l}2.85 \\
2.73 \\
2.60 \\
2.44 \\
2.28 \\
2.08\end{array}$ & $\begin{array}{l}.714 \\
.714 \\
.714 \\
.714 \\
.714 \\
.714\end{array}$ & $\begin{array}{r}0.814 \\
.814 \\
.814 \\
.814 \\
.814 \\
.814\end{array}$ \\
\hline $\begin{array}{l}2.0 \\
2.0 \\
2.0 \\
2.0 \\
2.0 \\
2.0\end{array}$ & $\begin{array}{l}.16 \overline{7} \\
.16 \bar{\gamma} \\
.16 \overline{7} \\
.16 \overline{7} \\
.16 \overline{1} \\
.16 \overline{7}\end{array}$ & $\begin{array}{r}-30 \\
-20 \\
-10 \\
0 \\
+10 \\
+20\end{array}$ & $\begin{array}{r}12.85 \\
12.15 \\
11.30 \\
10.50 \\
9.62 \\
8.63\end{array}$ & $\begin{array}{l}3,470 \\
3,280 \\
3,050 \\
2,835 \\
2,600 \\
2,330\end{array}$ & $\begin{array}{l}680 \\
650 \\
615 \\
580 \\
540 \\
495\end{array}$ & $\begin{array}{l}.699 \\
.699 \\
.699 \\
.699 \\
.699 \\
.699\end{array}$ & $\begin{array}{l}3.90 \\
3.72 \\
3.52 \\
3.32 \\
3.09 \\
2.84\end{array}$ & $\begin{array}{l}.571 \\
.571 \\
.571 \\
.571 \\
.571 \\
.571\end{array}$ & $\begin{array}{l}.651 \\
.651 \\
.651 \\
.651 \\
.651 \\
.651\end{array}$ \\
\hline $\begin{array}{l}1.5 \\
1.5 \\
1.5 \\
1.5 \\
1.5 \\
1.5\end{array}$ & $\begin{array}{l}.125 \\
.125 \\
.125 \\
.125 \\
.125 \\
.125\end{array}$ & $\begin{array}{r}-30 \\
-20 \\
-10 \\
0 \\
+10 \\
+20\end{array}$ & $\begin{array}{l}17.25 \\
16.15 \\
15.15 \\
14.10 \\
12.90 \\
11.60\end{array}$ & $\begin{array}{l}4,660 \\
4,360 \\
4,090 \\
3,810 \\
3,480 \\
3,130\end{array}$ & $\begin{array}{l}860 \\
820 \\
775 \\
730 \\
680 \\
625\end{array}$ & $\begin{array}{l}.6600 \\
.660 \\
.660 \\
.660 \\
.660 \\
.660\end{array}$ & $\begin{array}{l}5.20 \\
+.96 \\
+.68 \\
4.42 \\
4.12 \\
3.88\end{array}$ & $\begin{array}{r}+429 \\
+429 \\
+429 \\
+429 \\
.299 \\
.429\end{array}$ & $\begin{array}{r}.489 \\
.489 \\
.489 \\
.489 \\
.489 \\
.459\end{array}$ \\
\hline $\begin{array}{l}1.0 \\
1.0 \\
1.0 \\
1.0 \\
1.0 \\
1.0\end{array}$ & $\begin{array}{l}.0833 \\
.0833 \\
.0833 \\
.0833 \\
.0833 \\
.0833\end{array}$ & $\begin{array}{r}-30 \\
-20 \\
-10 \\
0 \\
+10 \\
+20\end{array}$ & $\begin{array}{l}20.55 \\
19.35 \\
18.15 \\
16.80 \\
15.40 \\
13.75\end{array}$ & $\begin{array}{l}5,550 \\
5,225 \\
4,900 \\
4,535 \\
4,160 \\
3,720\end{array}$ & $\begin{array}{l}990 \\
945 \\
895 \\
815 \\
785 \\
720\end{array}$ & $\begin{array}{l}.608 \\
.608 \\
.608 \\
.608 \\
.608 \\
.608\end{array}$ & $\begin{array}{l}6.51 \\
6.21 \\
5.88 \\
5.56 \\
5.16 \\
4.74\end{array}$ & $\begin{array}{l}2866 \\
.2260 \\
.286 \\
286 \\
286 \\
286\end{array}$ & $\begin{array}{l}326 \\
.326 \\
.326 \\
.326 \\
.326 \\
326\end{array}$ \\
\hline $\begin{array}{r}0.75 \\
.75 \\
.75 \\
.75 \\
.75 \\
.75\end{array}$ & $\begin{array}{l}.0625 \\
.0625 \\
.0625 \\
.0625 \\
.0625 \\
.0625\end{array}$ & $\begin{array}{r}-30 \\
-20 \\
-10 \\
0 \\
+10 \\
+20\end{array}$ & $\begin{array}{l}21.40 \\
20.20 \\
18.75 \\
17.55 \\
16.10 \\
14.30\end{array}$ & $\begin{array}{l}5,780 \\
5,455 \\
5,065 \\
4,740 \\
4,350 \\
3,860\end{array}$ & $\begin{array}{r}1,025 \\
975 \\
920 \\
875 \\
815 \\
710\end{array}$ & $\begin{array}{l}.575 \\
.575 \\
.575 \\
.575 \\
.575 \\
.575\end{array}$ & $\begin{array}{l}7.12 \\
6.78 \\
6.40 \\
6.18 \\
5.68 \\
5.15\end{array}$ & $\begin{array}{l}214 \\
2214 \\
.214 \\
214 \\
214 \\
214\end{array}$ & $\begin{array}{l}244 \\
244 \\
244 \\
244 \\
241 \\
241\end{array}$ \\
\hline $\begin{array}{l}.50 \\
.50 \\
.50 \\
.50 \\
.50 \\
.50\end{array}$ & $\begin{array}{l}.0417 \\
.0417 \\
.0417 \\
.0417 \\
.0417 \\
.0417\end{array}$ & $\begin{array}{r}-30 \\
-20 \\
-10 \\
0 \\
+10 \\
+20\end{array}$ & $\begin{array}{l}22.10 \\
20.80 \\
19.35 \\
18.10 \\
16.60 \\
14.85\end{array}$ & $\begin{array}{l}5,970 \\
5,615 \\
5,225 \\
4,890 \\
4,485 \\
4,010\end{array}$ & $\begin{array}{r}1,050 \\
1,000 \\
945 \\
895 \\
835 \\
765\end{array}$ & $\begin{array}{l}.530 \\
.530 \\
.530 \\
.530 \\
.530 \\
.530\end{array}$ &  & $\begin{array}{l}143 \\
143 \\
143 \\
14.13 \\
1.13 \\
143\end{array}$ & 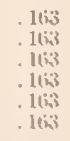 \\
\hline $\begin{array}{l}.25 \\
.25 \\
.25 \\
.25 \\
.25 \\
.25\end{array}$ & $\begin{array}{l}.0208 \\
.0208 \\
.0208 \\
.0208 \\
.0208 \\
.0208\end{array}$ & $\begin{array}{r}-30 \\
-20 \\
-10 \\
0 \\
+10 \\
+20\end{array}$ & $\begin{array}{r}22.60 \\
21.20 \\
19.95 \\
18.45 \\
16.95 \\
5.35\end{array}$ & $\begin{array}{l}6,100 \\
5,725 \\
5,390 \\
4,985 \\
4,580 \\
4,145\end{array}$ & $\begin{array}{r}1,070 \\
1,015 \\
965 \\
910 \\
850 \\
785\end{array}$ & $\begin{array}{l}4(11 \\
4(11 \\
.461 \\
4 t i 1 \\
4(t 1) \\
461\end{array}$ & $\begin{array}{l}4.25 \\
8.52 \\
8.36 \\
7.30 \\
7.36 \\
6.2 .2\end{array}$ & $\begin{array}{r}0714 \\
.0714 \\
.014 \\
.0714 \\
.0714 \\
.0714\end{array}$ & 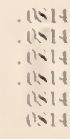 \\
\hline
\end{tabular}


building sewer and drain will be taken as $50^{\circ} \mathrm{F}$ and that in the stack as $60^{\circ} \mathrm{F}$.

With these assumptions we can compute the velocity of air flow upward through the vent for different degrees of closure of the vent, once we have assumed the temperature of the outdoor air. This temperature will be given successive values ranging from $-30^{\circ} \mathrm{F}$ to $+20^{\circ} \mathrm{F}$ by 10 -deg steps.

The first step in the computation is to determine values of $v_{3}$ for these different outdoor air temperatures for different degrees of closure of the vent. In order to do this we first compute the corresponding values of $v_{1}$ by using eq (14), which takes on the following simple form for the case assumed:

$h_{\mathrm{f}}=\left[r_{2}\left\{\frac{1}{2}+f \frac{L_{2}}{d_{1}}+C_{\mathrm{b}}\right\}+r_{1}\left\{\frac{L_{1}+L_{3}}{d_{1}}+1\right\}\right] \frac{v_{1}^{2}}{2 g}$

Once the value of $v_{1}$ has been computed, $v_{3}$ can be found from the relation:

$$
v_{3}=\left(\frac{d_{1}}{d_{3}}\right)^{2} v_{1}
$$

The results of this computation for an outdoor air temperature of $-30^{\circ} \mathrm{F}$ are given in figure 8 .

In computing the value of $K_{\mathrm{s} 3}$ from eq (19), $v_{3}$ must be expressed in feet per hour, whereas in the computations dealing with pipe friction, the relocities have been expressed in feet per second. Hence we multiply the values of $v_{3}$ taken from figure 8 and similar figures not shown, by 3,600 . The successive steps of the computation are given in table 8 .

The value of $k_{31}$, the coefficient of thermal conductivity of the ice was taken as $1.0 \mathrm{Btu} /(\mathrm{hr})(\mathrm{ft})$ $(\operatorname{deg} \mathrm{F})$ for ice that is assumed to be part granular and part solid. It seems probable that the layer of ice in the vent is neither entirely solid nor entirely granular; and a computation based on the assumption that the ice was solid, in which case $k_{31}$ would be about $1.3 \mathrm{Btu} /(\mathrm{hr})(\mathrm{ft})(\mathrm{deg} \mathrm{F})$, gave temperature curves that seemed to be too low. Furthermore, a computation based on a value of $k_{31}=0.6 \mathrm{Btu} /(\mathrm{hr})(\mathrm{ft})(\operatorname{deg} \mathrm{F})$, which would be approximatcly correct for granular ice, gave curves that were too high to agree well with the Winnipeg data used later in this paper as a check on the analysis. No allowance was made for the small effect of temperature on the value of $k_{31}$.

In order to compute $K_{\text {oa }}$, the coefficient of heat transfer from the outer wall of the pipe to the wind blowing past it, the curve given by McAdam [4, fig. 111] was used. Values of $3,600 \rho_{4} v_{4}$ were first computed for various wind velocities $v_{4}$ and outdoor temperatures $\theta_{4}\left(\right.$ or $\left.\theta_{0}\right)$. Values of the Reynolds number, $\left.3,600 d_{0} \rho_{4} v_{1} / \mu\right)$, were next computed under the assumption that $\mu$ has the constant value, $0.0435 \mathrm{lb} /(\mathrm{hr})(\mathrm{ft})$, regardless of the temperature. Next, values of $\psi\left(d_{0} \rho_{4} v_{4} / \mu\right)$ were read from McAdam's curve and were multiplied by $k / d_{0}$. The values of $k$ used for the different assumed air temperatures are indicated in table 9 , together with the details of the computation of the values of $K_{\mathrm{oa}}$ for the 3 -in. vent.

TABLE 9. Computation of coefficient of heat transfer from outer wall of 3-in. vent to wind stream

\begin{tabular}{|c|c|c|c|c|c|c|c|}
\hline $\begin{array}{l}\text { Outdoor } \\
\text { aira tem- } \\
\text { pera- } \\
\text { ture, } \theta_{\mathrm{a}}\end{array}$ & 3,600 & $\begin{array}{l}\text { Wind } \\
\text { veloc- } \\
\text { ity, } v_{4}\end{array}$ & $3,600 \rho_{4} v_{4}$ & $\frac{3,600 d_{\circ} \rho_{4} v_{4}}{\mu}=F$ & $\psi\left(F^{\prime}\right)$ & $\frac{k}{d_{0}}$ & $K_{O B}$ \\
\hline $\begin{array}{l}{ }^{\circ} F \\
-30 \\
-30 \\
-30 \\
-30 \\
-30 \\
-30 \\
-30\end{array}$ & $\begin{array}{l}l b / f t^{3} \\
334.8 \\
334.8 \\
334.8 \\
334.8 \\
334.8 \\
334.8 \\
334.8\end{array}$ & $\begin{array}{r}f p s \\
2 \\
5 \\
10 \\
20 \\
40 \\
60 \\
100\end{array}$ & $\begin{array}{r}670 \\
1,675 \\
3,350 \\
6,695 \\
13,390 \\
20,290 \\
33,480\end{array}$ & $\begin{array}{r}4,490 \\
11,215 \\
22,430 \\
44,860 \\
89,725 \\
134,600 \\
224,310\end{array}$ & $\begin{array}{l}37.5 \\
60.2 \\
88.0 \\
137.0 \\
227 \\
312 \\
470\end{array}$ & $\begin{array}{r}0.0429 \\
.0429 \\
.0429 \\
.0429 \\
.0429 \\
.0429 \\
.0429\end{array}$ & $\begin{array}{c}1.61 \\
2.58 \\
3.78 \\
5.88 \\
9.75 \\
13.4 \\
20.1\end{array}$ \\
\hline $\begin{array}{l}-20 \\
-20 \\
-20 \\
-20 \\
-20 \\
-20 \\
-20\end{array}$ & $\begin{array}{l}327.6 \\
327.6 \\
327.6 \\
327.6 \\
327.6 \\
327.6 \\
327.6\end{array}$ & $\begin{array}{r}2 \\
5 \\
10 \\
20 \\
40 \\
60 \\
100\end{array}$ & $\begin{array}{r}655 \\
1,640 \\
3,275 \\
6,550 \\
13,100 \\
19,660 \\
32,750\end{array}$ & $\begin{array}{r}4,390 \\
10,975 \\
21,950 \\
43,900 \\
87,800 \\
131,700 \\
219,500\end{array}$ & $\begin{array}{r}37.1 \\
59.5 \\
87.0 \\
134.0 \\
223 \\
307 \\
460\end{array}$ & $\begin{array}{l}.0435 \\
.0435 \\
.0435 \\
.0435 \\
.0435 \\
.0435 \\
.0435\end{array}$ & $\begin{array}{r}\text { 1. } 61 \\
2.59 \\
3.79 \\
5.83 \\
9.70 \\
13.4 \\
20.0\end{array}$ \\
\hline $\begin{array}{l}-10 \\
-10 \\
-10 \\
-10 \\
-10 \\
-10 \\
-10\end{array}$ & $\begin{array}{l}320.4 \\
320.4 \\
320.4 \\
320.4 \\
320.4 \\
320.4 \\
320.4\end{array}$ & $\begin{array}{r}2 \\
5 \\
10 \\
20 \\
40 \\
60 \\
100\end{array}$ & $\begin{array}{r}640 \\
1,600 \\
3,205 \\
6,410 \\
12,820 \\
19,225 \\
32,040\end{array}$ & $\begin{array}{r}4,295 \\
10,730 \\
21,470 \\
42,930 \\
85,870 \\
128,800 \\
214,670\end{array}$ & $\begin{array}{r}36.8 \\
59.0 \\
86.1 \\
132.0 \\
220 \\
298 \\
453\end{array}$ & $\begin{array}{l}.0442 \\
.0442 \\
.0442 \\
.0442 \\
.0442 \\
.0442 \\
.0442\end{array}$ & $\begin{array}{r}1.63 \\
2.61 \\
3.81 \\
5.84 \\
9.72 \\
13.2 \\
20.0\end{array}$ \\
\hline $\begin{array}{l}0 \\
0 \\
0 \\
0 \\
0 \\
0 \\
0\end{array}$ & $\begin{array}{l}313.2 \\
313.2 \\
313.2 \\
313.2 \\
313.2 \\
313.2 \\
313.2\end{array}$ & $\begin{array}{r}2 \\
5 \\
10 \\
20 \\
40 \\
60 \\
100\end{array}$ & $\begin{array}{r}625 \\
1,525 \\
3,130 \\
6,260 \\
12,530 \\
18,800 \\
31,320\end{array}$ & $\begin{array}{r}4,195 \\
10,500 \\
20,980 \\
41,970 \\
83,940 \\
125,900 \\
209,850\end{array}$ & $\begin{array}{l}36.4 \\
58.3 \\
84.7 \\
131.0 \\
215 \\
294 \\
443\end{array}$ & $\begin{array}{r}.0453 \\
.0453 \\
.0453 \\
.0453 \\
.0453 \\
.0453 \\
.0453\end{array}$ & $\begin{array}{c}1.65 \\
2.64 \\
3.83 \\
5.93 \\
9.74 \\
13.3 \\
20.1\end{array}$ \\
\hline $\begin{array}{l}+10 \\
+10 \\
+10 \\
+10 \\
+10 \\
+10 \\
+10\end{array}$ & $\begin{array}{l}306.4 \\
306.4 \\
306.4 \\
306.4 \\
306.4 \\
306.4 \\
306.4\end{array}$ & $\begin{array}{r}2 \\
5 \\
10 \\
20 \\
40 \\
60 \\
100\end{array}$ & $\begin{array}{r}612 \\
1,530 \\
3,060 \\
6,120 \\
12,240 \\
18,360 \\
30,600\end{array}$ & $\begin{array}{r}4,100 \\
10,250 \\
20,500 \\
41,000 \\
82,000 \\
123,000 \\
205,000\end{array}$ & $\begin{array}{r}36.0 \\
57.5 \\
84.0 \\
128.0 \\
212 \\
290 \\
437\end{array}$ & $\begin{array}{l}.0459 \\
.0459 \\
.0459 \\
.0459 \\
.0459 \\
.0459 \\
.0459\end{array}$ & $\begin{array}{r}1.65 \\
2.64 \\
3.86 \\
5.88 \\
9.74 \\
13.3 \\
20.1\end{array}$ \\
\hline $\begin{array}{l}+20 \\
+20 \\
+20 \\
+20 \\
+20 \\
+20 \\
+20\end{array}$ & $\begin{array}{l}298.8 \\
298.8 \\
298.8 \\
298.8 \\
298.8 \\
298.8 \\
298.8\end{array}$ & $\begin{array}{r}2 \\
5 \\
10 \\
20 \\
40 \\
60 \\
100\end{array}$ & $\begin{array}{r}598 \\
1,495 \\
2,990 \\
5,980 \\
11,950 \\
17,930 \\
29,900\end{array}$ & $\begin{array}{r}4,005 \\
10,010 \\
20,020 \\
40,040 \\
80,080 \\
120,200 \\
200,200\end{array}$ & $\begin{array}{l}35.6 \\
56.3 \\
82.8 \\
127.0 \\
208 \\
284 \\
430\end{array}$ & $\begin{array}{l}.0470 \\
.0470 \\
.0470 \\
.0470 \\
.0470 \\
.0470 \\
.0470\end{array}$ & $\begin{array}{r}1.67 \\
2.64 \\
3.88 \\
5.97 \\
9.77 \\
13.3 \\
20.2\end{array}$ \\
\hline
\end{tabular}

Assumed characteristics of outdoor air:

\begin{tabular}{|c|c|c|c|}
\hline$\theta_{\mathbf{3}},\left(\theta_{4}\right)$ & $\rho_{4}$ & k & $\mu$ \\
\hline $\begin{array}{r}{ }^{\circ} F \\
-30 \\
-20 \\
-10 \\
0 \\
+10 \\
+20\end{array}$ & $\begin{array}{c}l b / f t^{3} \\
0.093 \\
.091 \\
.089 \\
.087 \\
.085 \\
.083\end{array}$ & $\begin{array}{c}\text { Btu/(hr)(ft) } \\
(\text { deg F }) \\
0.0125 \\
.0127 \\
.0129 \\
.0132 \\
.0134 \\
.0137\end{array}$ & $\begin{array}{c}l b /(h r)(f t) \\
0.0435 \\
.0435 \\
.0435 \\
.0435 \\
.0435 \\
.0435\end{array}$ \\
\hline
\end{tabular}

$d_{0}=3.5$ in.$=0.2917 \mathrm{ft} ; S_{0}=0.916 \mathrm{ft}^{2}$.

With the required values of $K_{\mathrm{s} 3}, k_{31}, k_{10}$, and $K_{\text {oa }}$ determined, ${ }^{4}$ the procedure of computing the temperatures of the ice-air surface under various assumed conditions is as follows: First, eq (20,

$4 \mathrm{Eq}(19)$ and (24) give the methods for determining $K_{\mathrm{e} 3}$ and $K_{\mathrm{OA}}$, respectively. $k_{3 \mathrm{i}}$ is assumed to be $1.0 \mathrm{Btu} /(\mathrm{hr})(\mathrm{ft})(\mathrm{deg} \mathrm{F})$ for partly granular ice. $k_{\text {io }}$ is about $0.3 \mathrm{Btu} /(\mathrm{hr})(\mathrm{ft})(\mathrm{deg} \mathrm{F}$ ) for asbestos cement, and about $30 \mathrm{Btu} /$ (hr) (ft) (deg F) for steel or cast iron. 
22. 23. and 25) are adopted in the form

$$
\begin{aligned}
& q_{\mathrm{s} 3}=2 \pi r_{3} K_{\mathrm{s} 3} \theta_{\mathrm{s} 3}, \\
& q_{3 \mathrm{i}}=\left(2 \pi k_{31}\right) / \ln \left(r_{1} / r_{3}\right) \theta_{3 \mathrm{l}}, \\
& q_{10}=\left(2 \pi k_{10}\right) / \ln \left(r_{0} / r_{1}\right) \theta_{10}, \\
& q_{0 \mathrm{o}}=2 \pi r_{0} K_{\mathrm{oa}} \theta_{02} .
\end{aligned}
$$

These equations are next written in the form

$$
\begin{aligned}
& \frac{\theta_{\mathrm{s} 3}}{q_{\mathrm{s} 3}}=R_{\mathrm{s} 3}=\frac{1}{2 \pi r_{3} K_{\mathrm{s} 3}}, \\
& \frac{\theta_{31}}{q_{31}}=R_{31}=\frac{\ln \left(r_{1} / r_{3}\right)}{2 \pi k_{31}}, \\
& \frac{\theta_{10}}{q_{10}}=R_{10}=\frac{\ln \left(r_{\mathrm{o}} / r_{1}\right)}{2 \pi k_{10}}, \\
& \frac{\theta_{\mathrm{oa}}}{q_{\mathrm{va}}}=R_{\mathrm{oa}}=\frac{1}{2 \pi r_{0} K_{\mathrm{oa}}} .
\end{aligned}
$$

Adding:

$\sum \frac{\theta}{q}=\Sigma R=\frac{1}{2 \pi}\left[\frac{1}{r_{3} K_{\mathrm{s} 3}}+\frac{\ln \left(r_{1} / r_{3}\right)}{k_{31}}+\frac{\ln \left(r_{\mathrm{o}} / r_{\mathrm{t}}\right)}{k_{\mathrm{lo}}}+\frac{1}{r_{\mathrm{o}} K_{\mathrm{oa}}}\right]$.

Since $q_{\mathrm{s} 3}=q_{31}=q_{\mathrm{io}}=q_{\mathrm{os}}$ and $\theta_{\mathrm{s} 3}+\theta_{31}+\theta_{\mathrm{10}}+\theta_{\mathrm{oa}}=\theta_{\mathrm{sa}}=$ $\theta_{\mathrm{s}}-\theta_{\mathrm{a}}$, then

$$
\theta_{\mathrm{s} 3}=\theta_{\mathrm{s}}-\theta_{3}=\left(\theta_{\mathrm{s}}-\theta_{\mathrm{a}}\right) \frac{R_{\mathrm{s} 3}}{\mathrm{\Sigma} R}
$$

where

$\theta_{\mathrm{s}}=$ the temperature of the airstream in the rent in degrees Fahrenheit

$\theta_{\mathrm{a}}=$ the temperature of the outdoor air in regrees Fahrenheit $\left(=\theta_{4}\right)$

$\theta_{3}=$ the temperature of the ice-air surface in the vent in degrees Fahrenheit.

From eq (28) and (29) the following expression is obtained:

$$
\begin{aligned}
& \frac{\theta_{\mathrm{s}}-\theta_{3}}{\theta_{\mathrm{s}}-\theta_{\mathrm{a}}}=\frac{R_{\mathrm{s} 3}}{\mathrm{~s} R}=\mathrm{N} \\
& \quad=\frac{1}{\frac{\ln \left(r_{1} / r_{3}\right)}{k_{31}}+\frac{\ln \left(r_{\mathrm{o}} / r_{1}\right)}{k_{10}}+\frac{1}{r_{3} K_{\mathrm{8} 3}}+\frac{1}{r_{\mathrm{o}} K_{\mathrm{o} a}}} \cdot \frac{1}{r_{3} K_{83}},
\end{aligned}
$$

and

$$
\begin{aligned}
\frac{1}{N} & =r_{3} K_{\mathrm{s} 3}\left[\frac{\ln \left(r_{1} / r_{3}\right)}{k_{31}}+\frac{\ln \left(r_{\mathrm{o}} / r_{1}\right)}{k_{\mathrm{lu}}}+\frac{1}{r_{3} K_{\mathrm{s} 3}}+\frac{1}{r_{\mathrm{o}} K_{\mathrm{oa}}}\right] \\
& =\frac{r_{3} K_{\mathrm{s} 3}}{k_{31}} \ln \left(r_{1} / r_{3}\right)+\frac{r_{3} K_{\mathrm{s} 3}}{k_{\mathrm{to}}} \ln \left(r_{\mathrm{o}} / r_{\mathrm{1}}\right)+1+\frac{r_{3} K_{\mathrm{s} 3}}{r_{\mathrm{o}} K_{\mathrm{oa}}}
\end{aligned}
$$

Then

$$
\begin{aligned}
\frac{1}{N^{T}}-1=\frac{\theta_{3}-\theta_{\mathrm{a}}}{\theta_{\mathrm{s}}-\theta_{3}}=\left(r_{3} / r_{1}\right) r_{1} K_{\mathrm{s} 3} & {\left[\frac{1}{k_{31}} \ln \left(r_{1} / r_{3}\right)\right.} \\
+ & \left.\frac{1}{k_{\mathrm{10}}} \ln \left(r_{\mathrm{o}} / r_{1}\right)+\frac{1}{r_{0} K_{\mathrm{oa}}}\right]
\end{aligned}
$$

\begin{tabular}{|c|c|c|c|c|c|c|}
\hline $2 r_{3}$ & $\theta_{B}$ & $K_{83}$ & $K_{o a}$ & $\frac{\theta_{3}-\theta_{\mathrm{B}}}{\theta_{3}-\theta_{3}}$ & $\theta_{3}$ & $r_{3} r_{4}$ \\
\hline $\begin{array}{l}\text { in. } \\
3.07 \\
\text { 3. } 07 \\
\text { 3. } 07 \\
\text { 3. } 07 \\
\text { 3. } 07 \\
\text { 3.07 }\end{array}$ & $\begin{array}{r}\circ F \\
-30 \\
-20 \\
-10 \\
0 \\
+10 \\
+20\end{array}$ & $\begin{array}{l}2.08 \\
2.00 \\
1.89 \\
1.78 \\
1.66 \\
1.50\end{array}$ & $\begin{array}{l}3.78 \\
3.79 \\
3.81 \\
3.83 \\
3.86 \\
3.88\end{array}$ & $\begin{array}{r}0.482 \\
.463 \\
.435 \\
.407 \\
.377 \\
.339\end{array}$ & $\begin{array}{r}\circ F \\
-0.7 \\
+5.3 \\
11.2 \\
17.4 \\
23.7 \\
30.1\end{array}$ & $\begin{array}{l}1.00 \\
1.00 \\
1.00 \\
1.00 \\
1.00 \\
1.00\end{array}$ \\
\hline $\begin{array}{l}2.50 \\
2.50 \\
2.50 \\
2.50 \\
2.50 \\
2.50\end{array}$ & $\begin{array}{r}-30 \\
-20 \\
-10 \\
0 \\
+10 \\
+20\end{array}$ & $\begin{array}{l}2.85 \\
2.73 \\
2.60 \\
2.44 \\
2.28 \\
2.08\end{array}$ & $\begin{array}{l}3.78 \\
3.79 \\
3.81 \\
3.83 \\
3.86 \\
3.88\end{array}$ & $\begin{array}{r}.600 \\
.574 \\
.543 \\
.508 \\
.771 \\
.428\end{array}$ & $\begin{array}{r}+3.7 \\
9.2 \\
14.6 \\
20.2 \\
26.0 \\
32.0\end{array}$ & $\begin{array}{r}0.914 \\
.814 \\
.814 \\
.814 \\
.814 \\
.814\end{array}$ \\
\hline $\begin{array}{l}2.00 \\
2.00 \\
2.00 \\
2.00 \\
2.00 \\
2.00\end{array}$ & $\begin{array}{r}-30 \\
-20 \\
-10 \\
0 \\
+10 \\
+20\end{array}$ & $\begin{array}{l}3.90 \\
3.72 \\
3.52 \\
3.32 \\
3.09 \\
2.84\end{array}$ & $\begin{array}{l}3.78 \\
3.79 \\
3.81 \\
3.83 \\
3.86 \\
3.88\end{array}$ & $\begin{array}{l}.731 \\
.697 \\
.651 \\
.617 \\
.568 \\
.520\end{array}$ & $\begin{array}{r}+8.0 \\
12.9 \\
17.6 \\
22.9 \\
29.1 \\
33.7\end{array}$ & $\begin{array}{l}.651 \\
.651 \\
.651 \\
.651 \\
.651 \\
.651\end{array}$ \\
\hline $\begin{array}{l}1.50 \\
\text { 1. } 50 \\
1.50 \\
\text { 1. } 50 \\
\text { 1. } 50 \\
\text { 1. } 50\end{array}$ & $\begin{array}{r}-30 \\
-20 \\
-10 \\
0 \\
+10 \\
+20\end{array}$ & $\begin{array}{l}5.20 \\
4.96 \\
4.68 \\
4.42 \\
+.12 \\
3.88\end{array}$ & $\begin{array}{l}3.78 \\
3.79 \\
3.81 \\
3.83 \\
3.86 \\
3.88\end{array}$ & $\begin{array}{l}.828 \\
.786 \\
.738 \\
.692 \\
.644 \\
.601\end{array}$ & $\begin{array}{r}+10.8 \\
15.2 \\
19.7 \\
24.6 \\
29.6 \\
35.0\end{array}$ & 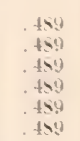 \\
\hline $\begin{array}{l}\text { 1. } 00 \\
\text { 1. } 00 \\
\text { 1. } 00 \\
\text { 1. } 00 \\
\text { 1. } 00 \\
\text { 1. } 00\end{array}$ & $\begin{array}{r}-30 \\
-20 \\
-10 \\
0 \\
+10 \\
+20\end{array}$ & $\begin{array}{l}6.51 \\
6.21 \\
5.88 \\
5.56 \\
5.16 \\
4.74\end{array}$ & $\begin{array}{l}3.78 \\
3.79 \\
3.81 \\
3.83 \\
3.86 \\
3.85\end{array}$ & $\begin{array}{r}.795 \\
.761 \\
.715 \\
.675 \\
.623 \\
.569\end{array}$ & $\begin{array}{r}+9.9 \\
14.6 \\
19.0 \\
24.2 \\
297.2 \\
34.5\end{array}$ & 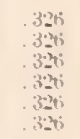 \\
\hline $\begin{array}{r}0.75 \\
.75 \\
.75 \\
.75 \\
.75 \\
.75\end{array}$ & $\begin{array}{r}-30 \\
-20 \\
-10 \\
0 \\
+10 \\
+20\end{array}$ & $\begin{array}{l}7.12 \\
6.78 \\
6.40 \\
6.08 \\
5.68 \\
5.16\end{array}$ & $\begin{array}{l}3.75 \\
3.79 \\
3.81 \\
3.83 \\
3.86 \\
3.35\end{array}$ & $\begin{array}{l}715 \\
.615 \\
642 \\
6415 \\
565 \\
.512\end{array}$ & $\begin{array}{r}+7.5 \\
+12.4 \\
17.4 \\
73.5 \\
33.5\end{array}$ & $\begin{array}{l}244 \\
244 \\
344 \\
2+4 \\
24 t \\
24\end{array}$ \\
\hline $\begin{array}{l}.50 \\
.50 \\
.50 \\
.50 \\
.50 \\
.50\end{array}$ & $\begin{array}{r}-30 \\
-20 \\
-10 \\
0 \\
+10 \\
+20\end{array}$ & $\begin{array}{l}7.92 \\
7.56 \\
7.12 \\
6.7 t \\
6.25 \\
5.76\end{array}$ & $\begin{array}{l}\text { 3. } \pi \\
\text { 3. } 79 \\
3.51 \\
\text { 3.s. } \\
\text { 3.s } \\
\text { 3.s }\end{array}$ & $\begin{array}{l}611 \\
571 \\
.5316 \\
.511 \\
.171 \\
.130\end{array}$ & 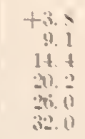 & $\begin{array}{r}163 \\
16 i \\
.163 \\
.163 \\
16 i 3 \\
.1633\end{array}$ \\
\hline $\begin{array}{l}.25 \\
.25 \\
.25 \\
.25 \\
.25 \\
.25\end{array}$ & $\begin{array}{r}-30 \\
-20 \\
-10 \\
0 \\
+10 \\
+20\end{array}$ & $\begin{array}{l}9.25 \\
8.32 \\
3.36 \\
7.91 \\
7.36 \\
\text { (i...22 }\end{array}$ & 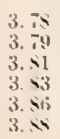 & $\begin{array}{l}+15 \\
397 \\
375 \\
335 \\
335 \\
340\end{array}$ & 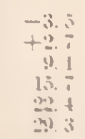 &  \\
\hline
\end{tabular}

since, from eq $(30), N=\left(\theta_{\mathrm{s}}-\theta_{3}\right) /\left(\theta_{\mathrm{g}}-\theta_{\mathrm{a}}\right)$.

For a given $\theta_{\mathrm{s}}$ and $\theta_{\mathrm{a}}$, freezing will continue, and $r_{3} / r_{1}$ will decrease, until $\theta_{3}$ increases to $32^{\circ} \mathrm{F}$. That is, the vent will continue to frefze up until $N$ decreases bolow a value,

$$
N=\left(\theta_{\mathrm{s}}-32\right) /\left(\theta_{\mathrm{s}}-\theta_{\mathrm{a}}\right) \text {. }
$$

The temperature of the ice-air surface can now be computer from eq (32) for any assumed conditions. The results of this computation for a 3 -in. metal vent are given in table 10 for a wind velocity TABLE 10. Computation of temperature of ire-air surface in 3-inch vent. $r_{0}=1.75 \mathrm{in} .=0.146 \mathrm{ft} ; \theta_{\mathrm{n}}=60^{\circ} \mathrm{F} ; r_{\mathrm{i}}=1.53$ in. $=0.128 \mathrm{ft} ; k_{3 \mathrm{i}}=1.0 \mathrm{Btu} /(\mathrm{hr})(\mathrm{ft})$ (deg
F) $\iota_{4}=10 \mathrm{fDs}$. 
of $10 \mathrm{ft} / \mathrm{sec}$ and are plotted in figure 11 . Similar temperature curves are shown in figures 10,12 , 13,14 , and 15 for $1 \frac{1}{2}, 4,6,8$, and 12 -in. vents, respectively. The numbers appearing on the curves refer to the corresponding outdoor temperatures in degrees Fahrenheit. Because of the high thermal conductivity of a metallic vent and the negligible temperature drop through the wall of such a vent, the term $\left(1 / k_{10}\right) \ln \left(r_{\mathrm{o}} / r_{\mathrm{i}}\right)$ in eq (32) can be omitted without appreciable error. 'This has been done in computing the temperature curves shown in the above-mentioned figures. The heights of stack and vent assumed for diameters of $1 \frac{1}{2}, 4,6,8$, and 12 -in. stacks were 30,60 , 100,150 , and $200 \mathrm{ft}$, respectively. The total length of the building sewer and building drain was taken as $50 \mathrm{ft}$ in all cases. The assumed air temperatures in the building sewer, drain, and stack were the same as for the 3-in. stack.

Returning now to figure 11 , it will be observed that the curve for an outside air temperature of $20^{\circ} \mathrm{F}$ crosses the line representing a temperature of $32^{\circ}$ for the ice-air surface. Hence the vent would frost up until the diameter of the opening corresponds to the ratio, $r_{3} / r_{i}$, for which this occurs. The moisture deposited on the ice surface

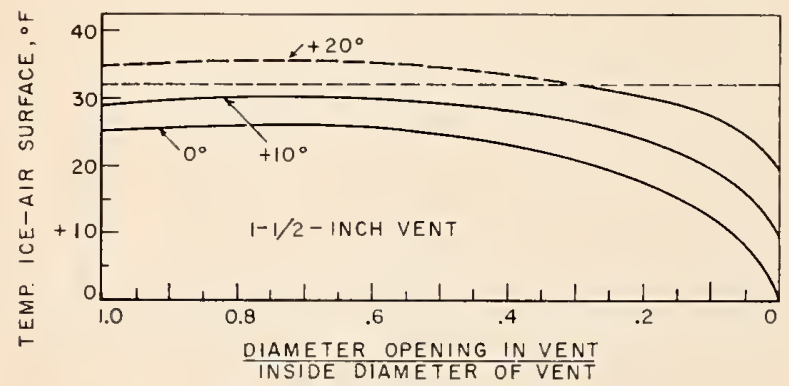

FIGURE 10. Temperatures of the ice-air surface in a $1 \frac{1}{2}$-in. vent for different outside air temperatures and for a wind velocity of $10 \mathrm{ft} / \mathrm{sec}$ as the vent freezes up.

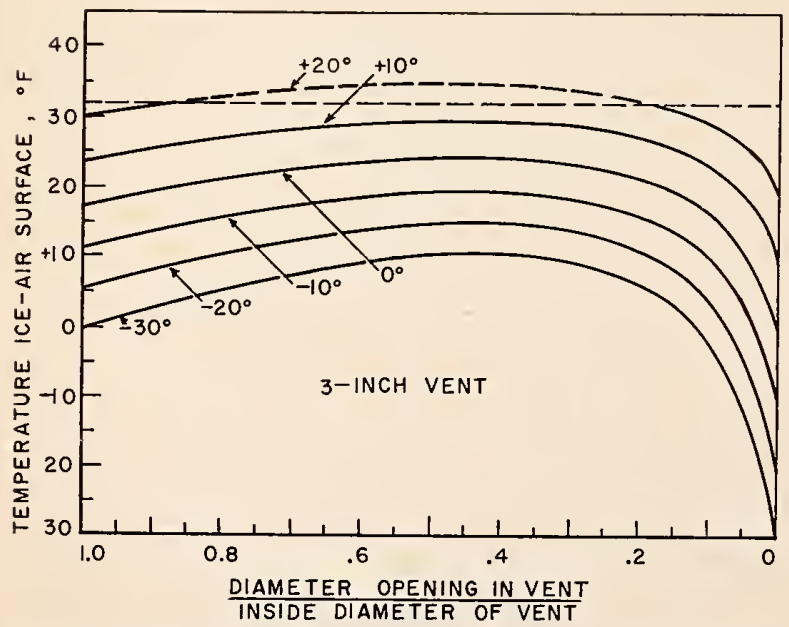

FIGURE 11. Temperatures of the ice-air surface in a 3-in. vent for different outside air temperatures and for a wind velocity of $10 \mathrm{ft} / \mathrm{sec}$ as the vent freezes $u p$. thereafter will not freeze but will run down the surface. Thus the dashed portion of the curve lying above the intersection of the $20^{\circ}$ curve with the $32^{\circ}$ line represents conditions that are physically impossible. In fact, the solid portion of the curve lying to the right of the dashed portion is also physically impossible for a vent that is freezing up. However, it may represent physical facts for a vent that is thawing.

To illustrate the effect of different wind velocities on the temperature of the ice-air surface as the vent freezes up, figure 16 was prepared for a 3 -in. vent, an outside air temperature of $-30^{\circ}$ $\mathrm{F}$ and different wind velocities from 2 to $90 \mathrm{ft} / \mathrm{sec}$

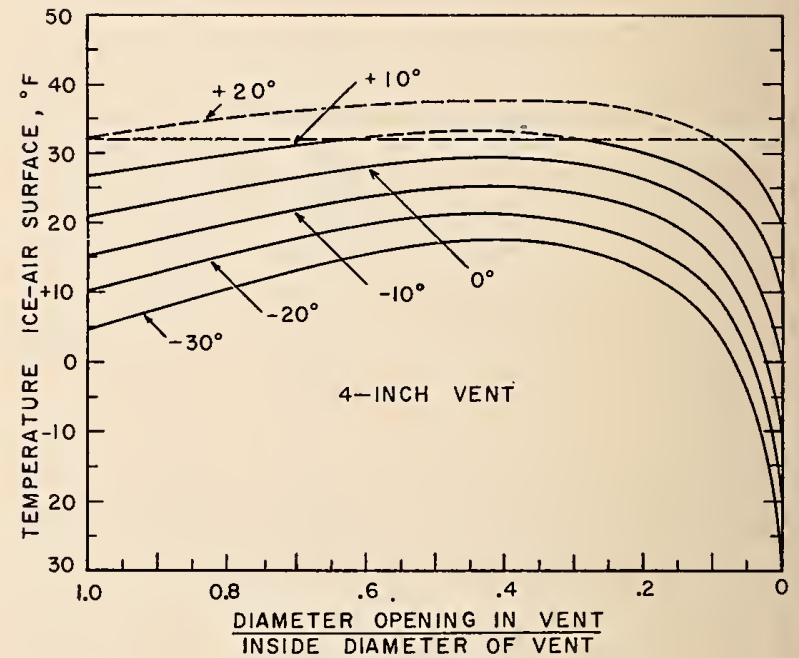

Figure 12. Temperatures of the ice-air surface in a 4-in. vent for different outside air temperatures and for a wind velocity of $10 \mathrm{ft} / \mathrm{sec}$ as the vent freezes up.

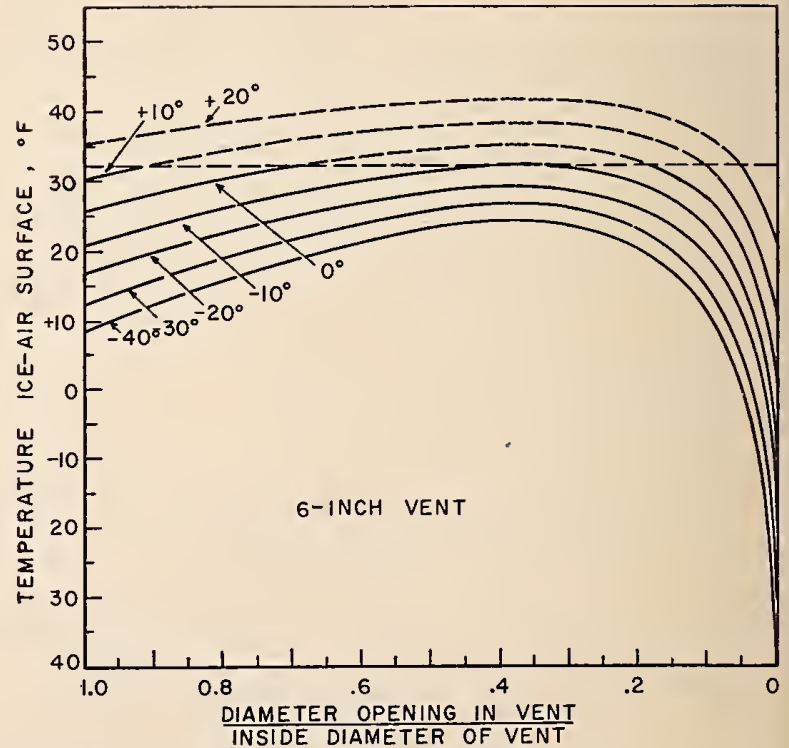

Figure 13. Temperatures of the ice-air surface in a 6-in. vent for different outside air temperatures and for a wind velocity of $10 \mathrm{ft} / \mathrm{sec}$ as the vent freezes $u p$. 
being asssumed. None of these curves crosses the $32^{\circ} \mathrm{F}$ line; hence it is concluded that, given an outside air temperature of $-30^{\circ} \mathrm{F}$, a 3 -in. vent will always freeze up solid, given sufficient time.

Finally, in order to show the effect of using for the vent pipe a material offering considerable resistance to the flow of heat, instead of the customary metal pipe, there are shown in figure 17 curves of the temperature of the ice-air surface in a 4 -in. vent, first when the rent pipe is metal, and second when it is asbestos-cement. Asbestos-

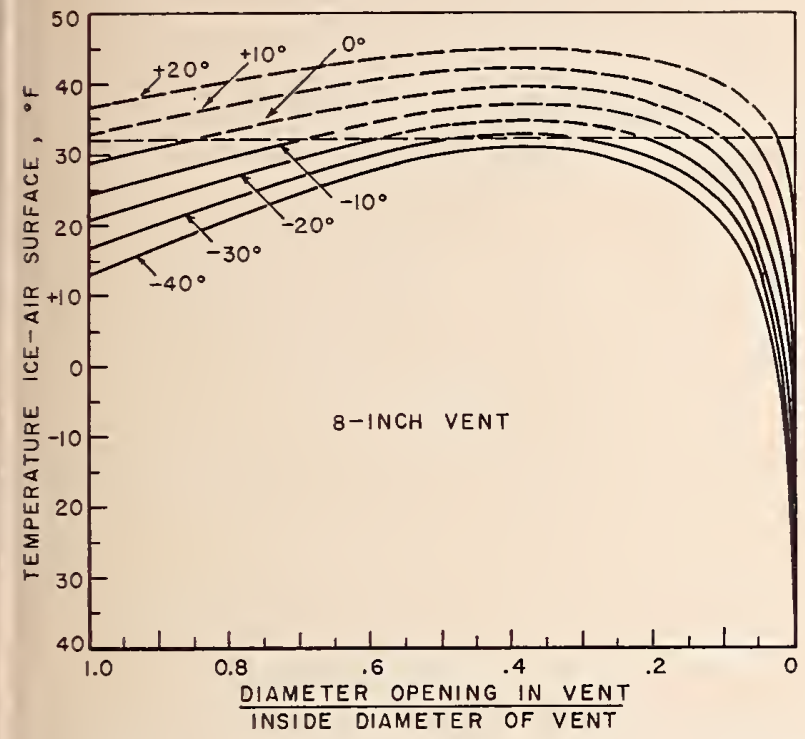

FIGURE 14. Temperatures of the ice-air surface in an 8-in. vent for different outside air temperatures and for a wind velocity of $10 \mathrm{ft} / \mathrm{sec}$ as the vent freezes up.



FIGURE 15. Temperatures of the ice-air surface in a 12-in. vent for different outside air temperatures and for a wind velocity of $10 \mathrm{ft} / \mathrm{sec}$ as the vent ferezes up. cement, having a theimal conductivity of ().; $\mathrm{Btu} /(\mathrm{hr})(\mathrm{ft})(\operatorname{deg} \mathrm{F})$, was userl for this comprarison because this pipe is roming into usr for olry vents. In romputing the temperature eurves for ashestroscement, it was necessar to take into acrount the second term in the brarket in erf (32) involving the heat transfer through the wall of the vont pipe. The improvement in ronditions attainerl by using this material in place of steel or cast iron (or any other metal) is definite. Evirlently very heavy thermal insulation is necessary if romplete protection against frost rlosure is to be achieved by this means, however.

The temperature curves bring out one puzzling feature of the phenomenon. The frost in a completely closer vent will presumably begin to thaw outwaid from the center when the outside air

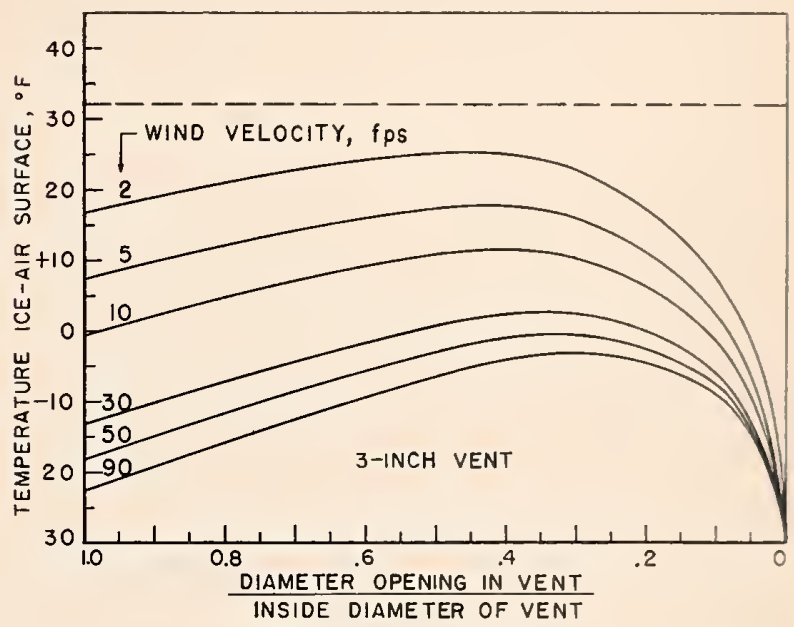

FiruRE 16. Temperatures of the ice-air surface in a 3-in. vent for an outside air temperature of $-30^{\circ} F$ and for different wind velocities as the vent freezes up.

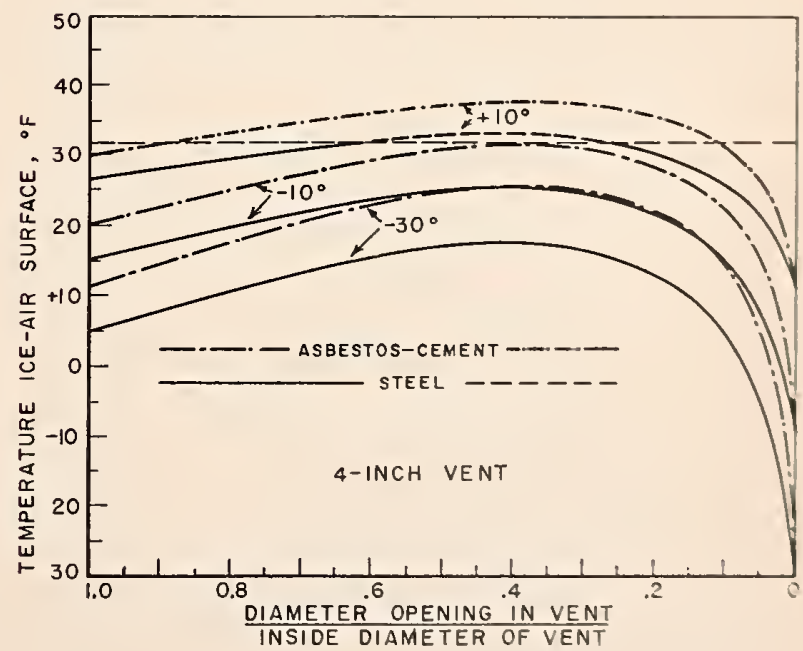

FifURE 17. Temperatures of the ice-air surferes in a $p=0$. vent for different outside air temperatures ind for a tormet velocity of $10 \mathrm{ft} / \mathrm{sec}$.

Comprison of sted and asbestosecunent vent pips. 
temperature rises. For example, refering to figure 12, which gives the temperature of the ice-air surface in a 4 -in. vent for different outside air temperatures and for a wind velocity of 10 $\mathrm{ft} / \mathrm{sec}$, it is clear that, if the outside air temperature is $-10^{\circ} \mathrm{F}$, for example, frosting will continue until complete closure results, given sufficient time, because the temperature of this surface remains below $32^{\circ} \mathrm{F}$ for all degrees of closure of the vent.

Now suppose that the outside air temperature rises to and remains at $20^{\circ} \mathrm{F}$. Since, when the vent is completely filled with frost, the temperature of the frost in the vent is equal to the temperature of the outside air, the temperature of the frost will rise with the outside air temperature to $20^{\circ} \mathrm{F}$ and should remain there. Thus it would seem at first sight as if the vent should not start to thaw out until the temperature of the outside air had risen above $32^{\circ} \mathrm{F}$. Yet there is evidence that this is not the case. The data from Winnipeg, presented earlier in this paper, appear to contradict this.

Further consideration of the problem leads to a possible explanation of the phenomenon. It is very likely that there does not exist in the exposed part of the vent a layer of ice of uniform thickness. When the vent is completely closed for some distance down from the top, it is likely that the thickness of the layer of ice tapers off in the downward direction, as shown in figure 18. Whether there exists a very small opening through the vent when what has been assumed to be complete closure exists is not known. However, when the experimental vents that were presumably completely closed were inspected visually from the top, a small opening was seen, which apparently tapered off to zero a short distance down from the top. It may be, however, that this small opening merely deviated sidewise until it was lost to view.

If figure 18 represents the actual conditions, then there would be a current of warm air rising in the center of the rent, coming in contact with

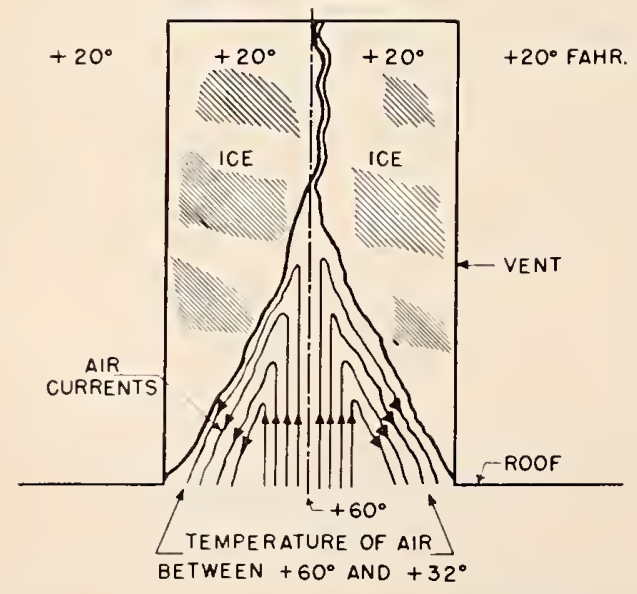

Figure 18. Conjectured form of so-called complete closure of a roof vent by frost. the ice, chilling, and then flowing downward in the neighborhood of the ice layer. A condition of approximate equilibrium would be attained as long as the outside air temperature remained low, say $-10^{\circ} \mathrm{F}$, with the ice in the portion of the vent that is frozen up completely attaining this same temperature.

Suppose now that the outside air temperature rises to $20^{\circ} \mathrm{F}$. Then the ice in the completely frozen part of the vent would soon attain this latter temperature (see fig. 18). The condition of equilibrium that had been established would then be upset, and the current of warm air would begin to melt some of the ice with which it comes in contact. The upper point of the conical cavity shown in figure 18 would move upward until a clear opening might be established, air would then begin to pass upward and out of the vent, and the conditions assumed earlier for the freezing of vents in general would be established once more. Under these conditions, presumably the appropriate curve shown by the solid line at the right-hand edge of the appropriate figure (fig. 12 for a 4-in. vent) would be valid.

The Winnipeg data shown in figure 2 afford a rough check on the analysis made in this paper. The comparison is shown in figure 19. The curves in this figure were obtained as follows: From figure 11 we see that the $20^{\circ} \mathrm{F}$ curve for the 3 -in. vent crosses the $32^{\circ} \mathrm{F}$ line at a value of the ratio $r_{3} / r_{i}$ of approximately 0.86 , or for a diameter of opening of $2.6 \mathrm{in}$. That is, if the outside air temperature is $20^{\circ} \mathrm{F}$, the vent would freeze to this point and then stop. 'This establishes the point plotted on the line in figure 19 for the 3 -in. vent. Furthermore, it is estimated from figure 11 that, if the temperature of the outside air should fall to about $14^{\circ} \mathrm{F}$, the temperature curve (if plotted in figure 11) would just miss reaching a temperature of

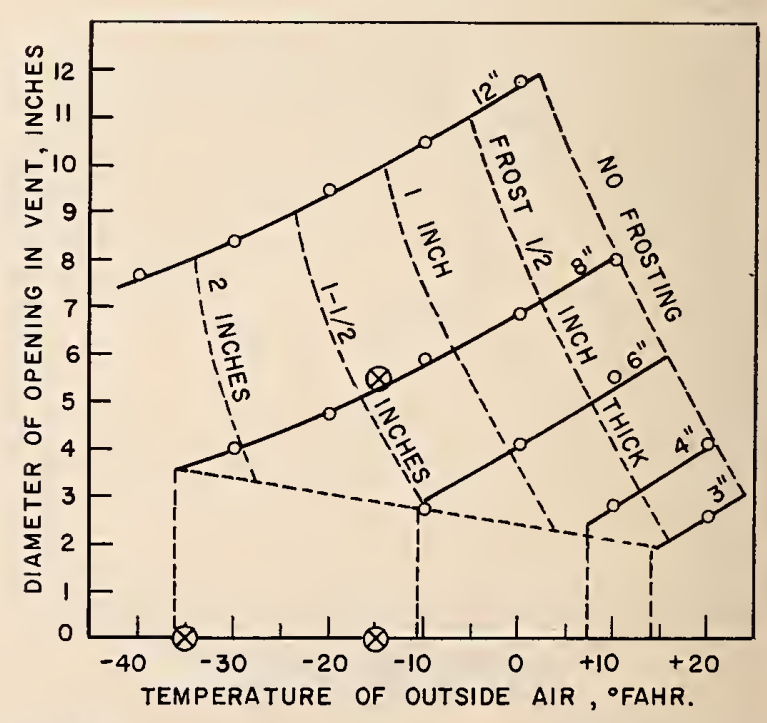

Figure 19. Comparison of computed temperatures of ice-air surface with data from Canada for 6-and 8-in. vents. 
$32^{\circ} \mathrm{F}$ at its highest point. In other works, the vent would freeze up completely for air temperatures of $14^{\circ} \mathrm{F}$ and below, given sufficient time. This is indicated by the vertical line drawn in figure 19 through a temperature of $14^{\circ} \mathrm{F}$

Similarly, we see from figure 12 for the 4 -in. rent that the rent barely starts to freeze if the temperature of the outside air is $20^{\circ} \mathrm{F}$. This establishes a point on the line for the 4 -in. rent in figure 19. Another point is established by observing that, if the temperature of the outdoor air is $10^{\circ} \mathrm{F}$, the vent will stop freezing when the ratio $r_{3} r_{i}$ takes on a value of about 0.73 (diameter of opening about $3.0 \mathrm{in.}$.). This establishes the other point plotted in figure 19 for this diameter vent. The note also from figure 12 that the highest outdoor air temperature for which the curve (if plotted) would miss touching the $32^{\circ} \mathrm{F}$ line is about $\delta^{\circ} \mathrm{F}$. This establishes the vertical line through the temperature of $8^{\circ} \mathrm{F}$, connecting with the curve for the 4-in, vent. The significance of these rertical lines is that, as we move downward and to the left along the curve for any given vent, when the conditions corresponding to the intersection of the rertical lime and the curve are reached, freezing will continue until complete closure results. The other curves for vents 6,8 , and 12 in. in diameter in figure 19 were obtained in this same way.

Now, considering figure 2, we note that the S-in. stack on the Grain Exchange was found to be completely closed on January 6 , when the minimum daily temperature was $-35^{\circ} \mathrm{F}$. This is represented by a large circle plotted on the base line of figure 19. Had the agreement been perfect, it would have coincided with the vertical line for the 8 -in. rent. Obriously the agreement is quite good-better than might have been anticipated.

The next consider the obserration of the same vent on Februarr 17. On this date the opening in the rent was found to be about $5.5 \mathrm{in}$. in diameter, and the daily minimum air temperature at that time was about $-15^{\circ} \mathrm{F}$. It can be seen from figure 19 that this point also agrees verr well with the computed curre.

The consider also the observation for the 6-in stack at the Grain Exchange on January 29, at which time the stack or vent was observed to hare closed up when the daily minimum temperature was about $-15^{\circ} \mathrm{F}$. This point, when plotted in figure 19, lies a little to the left of the line plotted for the 6 -in. vent. Thus the agreement is still good, if not quite as satisfactory as for the 8-in. vent.

Although these three available observations show good agreement with the computed curves and hence will be taken as reasonably good justification for the computed temperature curves given in this paper, too much reliance should not be placed on the exactness with which the computed curves fit the actual conditions. It should be remembered that we do not have adequate information in regard to the Winnipeg data. We to not know the exart day on whirh the veuts (losed up because the observations were marle only at infrequent intervals, and heres: we are not sure of the daily minimum temperature or the aetual day of closure. Whe do not know the daily average temperatures, but only the minimum temperatures. We do not know hew the wind velocity varied during the periort in guestion. Hence the comparison should be lookerl upors merely as a rough verification.

Curves similar to those shown in figures 10,11 $12,13,14$, and 15 were computed, using a value of $0.6 \mathrm{Btu} /(\mathrm{hr})(\mathrm{ft})\left(\mathrm{deg}\right.$ F) for $k_{3 t}$ for the ire (corresponding to completely granular ire), anrl these curves looked more reasonable for the small-diameter vents than do those shown in the above-mentioned figures, but they diul not agree at all with the Winnipeg data. "Further experimental investigation and more detailed fielr data are needed to study the matter further.

\section{Test Procedure}

For the purpose of studying frost closure. plumbing systems may be considered as romprising two broad classes. The first class will include systems having a water seal in the drain downstream from the stack without a rent to the atmosphere on the house side of the water seal. This condition mav exist if a running house trap without a fresh-air inlet is used (or in case the fresh-air inlet is plugged or closed off), or it mar occur if the street sewer is so full that the outlet end of the house sewer is submerged. It is much more likely, however, that the second class of installation will be found in service. In this class the house drainage system is connected directly to the street sewer or a septic tank without any water seal in the horizontal drain from the base of the stack. Here the air and sewer gises may pass directly through the house drainage sistem in response to whatever forces are causing the flow to take place. An installation having is fresh-air inlet to the house trap might also be placed in this class, as far as the flow of air through the stack is concerned, although ail entering through the house trap will have relatirely low humidity, and hence in this respect it will tosnl to promote less frosting of the roof rent than if it were saturated. Also the air strean up thromgh the system will be colder, and the rate of flow will be less than if there were a commection between the street sewer and the building srstent

Tests were made by using the haboratory sotup shown in figure 4 , with the temperature of the ali surrounding the top of the stack maintained at at constant value during each run. The tempersiture was about $-30^{\circ} \mathrm{F}$ in most of the tests. althourgh a few rums were made at a lower temperatmes.

For those tests in which the 'ise' of all murented house trap was simulated, a trap wis installed in the house drain near the bise of the stack. Wam water was introdueed thromerh the bithtuh at al 
rate of about $1.8 \mathrm{gal} / \mathrm{min}$, and the water closet was flushed at regular intervals of time. The roof vent was observed periodieally (once or twice daily) for evidence of frosting.

In most of the testing, however, no trap was used in the house drain, and air was forced through the system by a blower at the base of the stack, simulating the convective air eurrent that would exist in a service installation.

An important eonsideration in connection with the tests was that of maintaining approximately a constant pressure differential a vailable for produeing air flow through the system. For a given height of stack in service and a given temperature difference between the air inside of the stack and the outside air, the differential can be approximated from table 1 or figure 7 , or it ean be computed from eq (4). In the test installation, it was possible to attain flow eonditions approximating those that would be expected in service for the same staek by adjusting the blower so that a pressure reading $\left(h_{\mathrm{m}}=h_{\mathrm{e}}\right)$ was obtained on the inclined manometer shown in figure 4 , such that $h_{\text {ft }}$ computed from eq (8) was equal to $h_{\mathrm{fs}}$ eomputed fiom eq (4).

It ean be seen readily that, in order to simulate flow conditions closely, not only must the pressure differential for overeoming friction be maintained in the test setup at the same value as in the service installation simulated for the given tempcrature conditions, but also that the physical dimensions, or at least the overall flow resistance, of the setup must be the same as in the colresponding service installation. When these eonditions are not attained, it may be that either more or less air flow is actually produced in the test installation than in any particular service installation, even though the pressure available for producing air flow be made the same in the two cases. In addition, for a given pressure differential $h_{\mathrm{f}}$ through the system and for a given roof vent, the greatel the frictional resistance of the staek, building drain, and building sewer, the less will be the relative effect of a given degree of frosting of the roof vent on the volumetric rate of air flow through the system.

The importance of the factors mentioned in the above paragraph was not fully appreciated at the time when these tests were made. Aetually, many of the tests were made using purely arbitrary settings for the pressure differential; hence it is unfortunate that flow conditions identical to those that would oceur during frosting in service with the same setup were not produeed.

It was necessary to make frequent calculations and adjustments in order to make available approximately a constant pressure differential for producing air flow as each test run progressed because the accumulation of frost and changes in room temperature would in a short time result in a differential differing from that which was desired. In making a complete cycle of computation, temperature and pressure differential readings, and adjustment every hour during the tests, it is believed that the effect of this tendency for the test setup to get out of adjustment was minimized, although it was soon evident that highly accurate control over the pressure differential could not be maintained with the test setup used.

Air and water temperatures were measured at points shown in figure 4 . The water discharging into the stack was maintained at a constant temperature during each run, being as high as $120^{\circ} \mathrm{F}$ in a few runs, although a temperature of from $70^{\circ}$ to $80^{\circ} \mathrm{F}$ was used in most of the tests, since higher temperatures were evidently not needed to maintain a high humidity in the air stream.

The average stack temperature was computed from readings of the air temperatures inside of the stack, these temperatures being measured by a remote-rccording device. The average temperature in the stack was maintained as nearly constant as possible during each run. The temperature of the air around the roof vent was also maintained approximately constant.

The thickness of the accumulation of frost inside the vent was observed once or twice a day. Relative humidities in the stack and in the room in which the test installation was located were obtained from wet and dry-bulb temperature readings. The rate of flow of air through the system was determined from readings of the pressure drop across the orifice through which the mixture of air and carbon dioxide escaped to the atmosphere. The ratio of carbon dioxide to air was determined by the special device mentioned earlier and was taken into account when the rate of flow of air through the system was calculated.

During intervals when the apparatus was not in use overnight or on weekends, the top of the roof vent and the outlet to the cold chamber were plugged, and the chamber was filled with dry ice. In this way the accumulation of frost in the vent was apparently preserved fairly well in most instances unt il the next work day, when the test was continued. However, these interruptions may have changed the nature of the surface of the ice from a porous condition to a solid condition and hence may have influenced the further freezing of the vent. An effort was made to continue each test run until the vent ceased to accumulate frost. In some instances this meant carrying the test to complete closure of the vent.

The primary object of the tests was to ascertain if roof vents $1 \frac{1}{2}, 3$, and $4 \mathrm{in}$. in diameter could be frozen up completely. However, in some of the tests the effect of varying the rate of air flow through the vent was investigated, while in other tests the effect of varying the temperature inside the stack was studicd. Maintenance of relatively low humidity in the stack was found to be too difficult to warrant an investigation of this factor; and, in any event, low humidity would tend to decrease the rate of frosting of the vent. The humidity in the stack approached saturation at all times during the tests, apparently because of 
the continual flow of water into the stack. Howerer, as mentioned earlier in the paper, the humidit $\mathrm{r}$ measurements made in the stack possibly indicated a greater degree of humidity than may actually have existed. Evidence has been found from observations in Canada that, when hot water is discharged into the stack, there is an increased tendency to frost closure, apparently because of the high humidity thus created.

The dimensions of the rent exposed to low temperature in the cold chamber were varied. In addition to tests on a 3 -in. stack, which continued undiminished in diameter into the cold chamber,


pipe mounted on top of the 3 -in. stack. The $1 \frac{1}{2}$-in. pipe was $38 \mathrm{in}$. long and extended $15 \mathrm{in}$. up into the cold chamber in most of the runs, but in a few tests only 6 in. of its lengtl extended up into the chamber. A few runs were made on a 4-in. roof vent $38 \mathrm{in}$. long extending $15 \mathrm{in}$. into the cold chamber.

\section{Test Results}

\subsection{Tests on System With House Trap}

A few tests were made in which a house trap without a fresh-air inlet was installed in the louse drain. In these tests no attempt was made to create a forced draft through the system. The unrented house trap eliminated the normal conrective draft. The temperature of the air surrounding the upper $15 \mathrm{in}$. of the 3 -in.-diameter roof rent was approximately $-30^{\circ} \mathrm{F}$ in most of these tests, and the mean temperature of the air in the stack varied from $65^{\circ}$ to $78^{\circ} \mathrm{F}$. Runs varying in length from 3 to $24 \mathrm{hr}$ were made. A constant fiow of warm water was introduced to the stack throughout the tests, and the water closet was flushed at 1-hr intervals. In no case was there more than a slight surface coating of frost in the roof vent at any time.

\subsection{Tests on System With Air Flow up Stack}

This case corresponds to a service system in which there is free passage of air from the street sewer up through the stack and vent to the outer air. The tests were made on a test installation in which an upward flow of air in the stack was maintained by means of a blower at a rate reasonably representative of service conditions. In these tests partial or complete closure of the vent occurred in most instances. Four different vent conditions were tested: (a) 1/1/2-in. vent on a 3-in. stack, with a length of 15 in. exposed to the low temperature, (b) the same, but with a length of $6 \mathrm{in}$. exposed to the low temperature, (c) the 3 -in. stack unchanged in diameter and having a 15 -in. exposure, and (d) the vent enlarged to $4 \mathrm{in}$. and extending $15 \mathrm{in}$. up into the cold chamber. The test data relating to temperature and flow conditions for the $1 \frac{1}{2}$-in. vent are given in table 11 , and
TABLE 11. Temperatures and flow comditions existong in frost-riosure tests

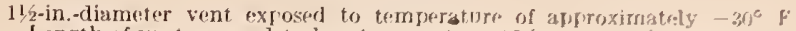
Length of vent exposad to low teminerature 15 in fexcest in rung 15 , if and 17 , in which tho length was fin.

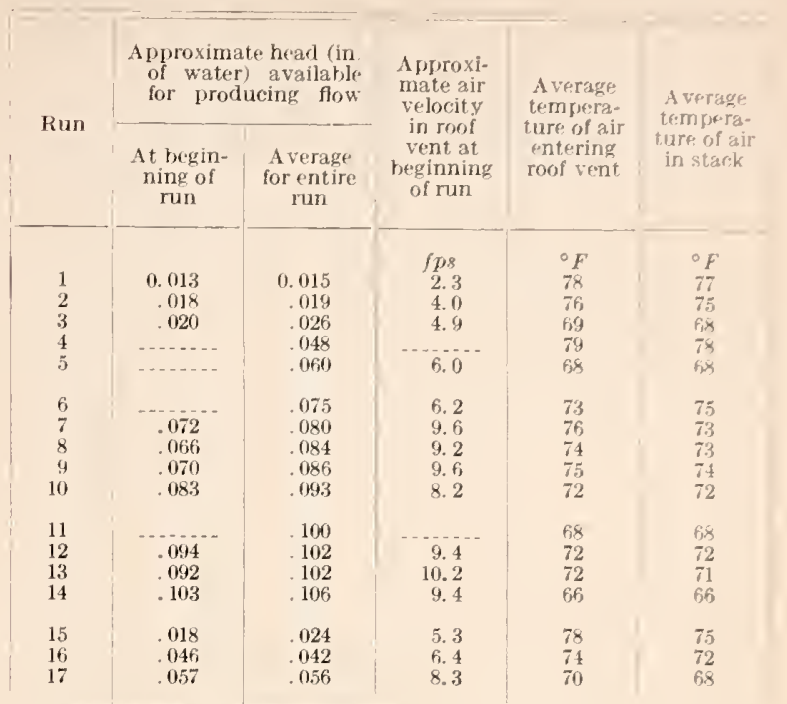

TABLE 12. Temperatures and flow conditions existing in frost-closure tests

3- and 4-in.-diameter roof vents exposed for a length of 15 in. to a temperature of approximately $-30^{\circ} \mathrm{F}$
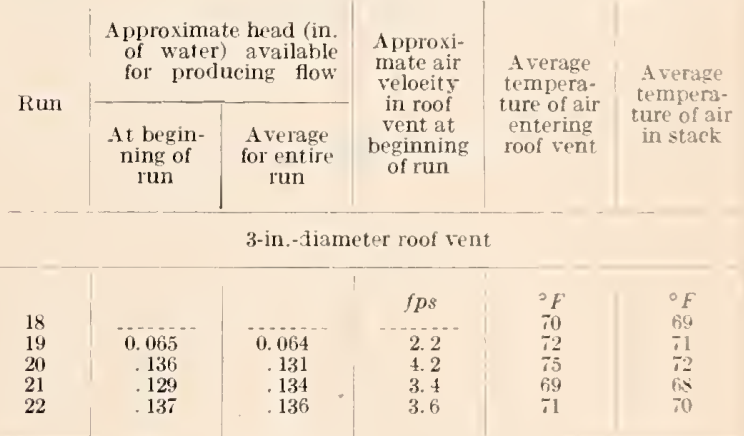

\begin{tabular}{|c|c|c|c|c|c|}
\hline \multicolumn{6}{|c|}{ 4-in.-diameter roof rent } \\
\hline $\begin{array}{l}23 \\
24 \\
25\end{array}$ & $\begin{array}{r}0.064 \\
.066 \\
.105\end{array}$ & $\begin{array}{r}0.065 \\
.066 \\
.096\end{array}$ & $\begin{array}{l}2.1 \\
1.7 \\
2.6\end{array}$ & $\begin{array}{l}74 \\
75 \\
-3\end{array}$ & $\begin{array}{l}73 \\
73 \\
71\end{array}$ \\
\hline
\end{tabular}

the data for the 3 -in. and 4 -in. vents ane sriven in table 12 .

One interesting obscrvation applying to most of the data obtained from tests in this investigation is that the freezing up of the veluts-that is. the increase in thickness of the ice or brest latyer apparently was approximately linear with time. There is, howerer, no reason to heliere that this would always be the catse: in fact. there is reison to believe that, for "eltain temperitture enentitions. and especially for larere stateks, there would be al decreasing rate of frost closure with inclesest

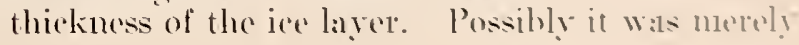


a coincidence that the tests reported here vielded results indicating that closure is linear with time, or it may be that this is actually true generally in the case of small diameter roof vents. These matters have not been investigated adequately.

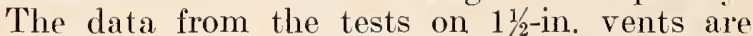
shown in figure 20. From this figure and the data in table 11 , it is apparent that there is no consistent correlation of rate of freezing with stack temperature or rate of air flow. However, in this connection a number of runs (not shown in the above data) were made, using appreciably higher rates of air flow than existed in the tests shown in figure 20, other conditions being similar. In nearly all instances in which the mean air velocity in the $1 \frac{1}{2}-\mathrm{in}$. vent at the beginning of a run exceeded about $10 \mathrm{ft} / \mathrm{sec}$, little or no frost accumulation was noted. This was possibly due in part to the air stream not being cooled sufficiently when passing through the vent at high velocity to permit freezing in the vent to take place. Another explanation suggested by the operator of the test apparatus is that apparently a high-velocity air flow scours the frost accumulation off the wall as fast as it can form. It was noted in the tests at the higher air velocities that a more or less continuous spray of frost particles issued from the roof vent, indicating confirmation of one or both of the above suppositions.

Probably there is a gradual increase in rate of frosting with increase in rate of air flow, starting from zero flow and continuing up to a certain

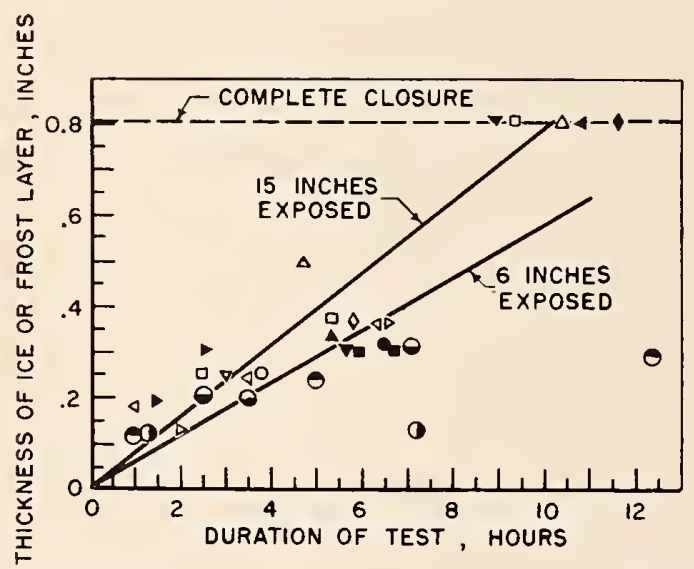

Figure 20. Experimentally determined rates of frost closure for a 1/2-in.-diameter roof vent exposed to outside air temperatures of approximately $-30^{\circ} \mathrm{F}$.

\begin{tabular}{|c|c|c|c|}
\hline Symbol & Run & Symbol & Run \\
\hline - & $\begin{array}{l}1 \\
2 \\
2\end{array}$ & 4 & $\begin{array}{r}9 \\
10\end{array}$ \\
\hline 量 & $\begin{array}{l}3 \\
3 \\
4\end{array}$ & $\nabla$ & ${ }_{12}^{11}$ \\
\hline $\bar{\Delta}$ & 6 & 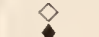 & 13 \\
\hline 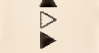 & $\begin{array}{l}7 \\
8 \\
8\end{array}$ & 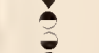 & $\begin{array}{l}15^{*} \\
16^{*}\end{array}$ \\
\hline & & 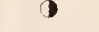 & $17^{*}$ \\
\hline
\end{tabular}

${ }^{*} 6$-in. length of vent exposed. All other runs, 15 in. exposed. intermediate range of flow rates, beyond which there is a sharp decrease in rate of frosting to near zero. Probably this curve is rather flat at intermediate flows, which may account for the fact that only inconclusive correlation of rate of frosting with air velocity was measured in tests at intermediate flows.

Summarizing the results on $1 \frac{1 / 2}{2}$ in. vents (fig. 20 ), we find that in the case of the 15 -in. exposure, where all observations are given equal weight and the temperatures are averaged (stack temperature approximately $72^{\circ} \mathrm{F}$, temperature of the air entering the roof vent approximately $73^{\circ} \mathrm{F}$, and the temperature of the air surrounding the exposed portion of the roof vent approximately $\left.-30^{\circ} \mathrm{F}\right)$, the overall average rate of frosting was $0.080 \mathrm{in}$./hr. It is interesting to note that if only the 5 points that represent the runs leading to complete closure are considered, again an average rate of frosting of $0.080 \mathrm{in}$./lir is obtained. It will be explained here that by rate of frosting is meant the rate of increase in thickness of the frost or ice layer adhering to the inner surface of the roof vent, not the decrease in diameter, which would be double the rate specified. It is realized that this is not a definite dimension, but that the frost layer is very likely to be very irregular in thickness and in general will probably be thickest at some distance from the base of the roof vent, undoubtedly near the top in the case of a relatively short roof vent. In the data taken in the present investigation, an attempt was made to record the average thickness of the frost layer at the section of minimum opening. It is undoubtedly true that this method of estimating by visual inspection gave rise to appreciable errors.

The data obtained showed slightly better correlation of rate of frosting as affected by the temperature of the air entering the roof vent. The lowest air temperatures gave rates of frosting greater than did the highest air temperatures, there being a difference of about 8 to $10 \mathrm{deg} F$ in the temperatures compared (comparison of runs 3,5 , and 11 with runs 1, 2, and 4). Nevertheless, because the results are so erratic in this respect, especially for the intermediate stack temperstures, little else can be inferred from the result:i. Probably the erratic nature of the phenomenon of frosting of vents, the unavoidable variations in flow and temperature conditions during the test runs, the limited range of stack temperatures and pressure differentials covered, the fact that partial loss of the frosted layer or changes in the nature of the layer took place in some of the runs when it was necessary to shut down the apparatus over night or over a holiday before continuing the run, and last, but not least, the very rough method employed in observing frost accumulation, all may have contributed to the inconclusiveness of the data on the effects of temperature and air flow.

Only limited data were obtained on the effect of roof-vent length on rate of closure. The data 
for the 6 -in. exposure are shown in figure 20 as runs 15,16 , and 17 . The data are badly seattered; hence detailed conclusions are not warranted. However, averaging all observations given, the arerage rate of closure was $0.059 \mathrm{in.} / \mathrm{hr}$, when the average stack temperature was approximately $72^{\circ} \mathrm{F}$, and the average temperature of the ais entering the roof rent was approximately $74^{\circ} \mathrm{F}$. This rate is about 26 percent less than was obtained with a 15 -in. exposure under substantially the same conditions.

The data for five tests on the 3 -in. vent with a 15-in. exposure are shown in figure 21. For the only test that was carried te complete closure, run 19 , the average rate of closure was $0.069 \mathrm{in}$. $/ \mathrm{hr}$, which is about 14 percent less than the rate found for the $1 \frac{1}{2}$-in. vent having the same exposure length. In this run the average stack temperature was approximately $71^{\circ} \mathrm{F}$. and the average temperature of the air entering the roof vent was approximately $72^{\circ} \mathrm{F}$. It will be noted that figure 21 does not show run 19 going to complete closure but shows only the first two observations. The reason for this omission is that sometime after the 13 th hr of the run, the temperaturecontrol system failed, resulting in a partial loss of the ice layer in the vent. As the exact length of the period during which the ice layer had suffered reduction is unknown, we do not know just when the ice layer was restored to its original thickness, this having been accomplished after the apparatus was repaired. Thereafter apparent complete closule occurred within a few hours. The average rate of closure of $0.069 \mathrm{in}$./hr given above is based on the two observations shown in figure 21 .

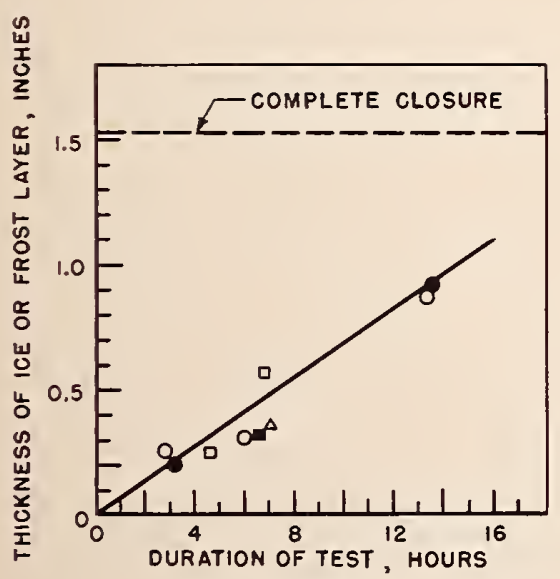

Figure 21. Experimentally determined rates of frost closure for a 3-in.-diameter roof vent exposed $15 \mathrm{in}$. to outside air temperatures of approximately $-30^{\circ} \mathrm{F}$.

\begin{tabular}{|c|c|}
\hline Symbol & Run \\
\hline 8 & $\begin{array}{l}18 \\
19 \\
20 \\
21 \\
22\end{array}$ \\
\hline
\end{tabular}

Unfortunately none of the three russ shown in figure 22 for the 4 -in. vent was earrief to eomplete closure. Averaging all observations gives a rate of closure of $0.063 \mathrm{in}$. hr. The averages startk temperature was approximately $73^{\circ} \mathrm{F}$, arrol the avelage temperature of the air cntering the ronf vent was approximately $74^{\circ} \mathrm{F}$. The late of closure of $0.063 \mathrm{in} . / \mathrm{hr}$ is about 21 perrent les; than was obtained in the ease of the $1 \frac{1}{2}$-in. Tent under similar conditions.

Plotting the rates of closure given above against values of $l / d$ (where $l$ is the exposed length of loof vent, and $d$ is the full internat diameter of the vent, both in the same units) on logarithmir. paper yields the interesting result that the flata obtained in this investigation ean be represented closely by the empirical relationship,

$$
R_{c}=0.04\left(\frac{l}{d}\right)^{0.3}
$$

where $R_{c}$ is the rate of closure in inches per hour. Here $R_{c}$ represents the rate of increase in thickness of the ice layer, not the rate of decrease of diameter of opening. Although this equation gires results that are generally in fair agreement with the average results obtained in the investigation, it is limited in application to the conditions existing in the tests and hence eannot be applied generally.

An attempt was made to compute rates of closure approximately, making use of the temperature curves for the ice-air surface given in the paper, but the number of unknowns was too great to permit any worthwhile attempt of this sort. Hence no attempt is made in the paper,

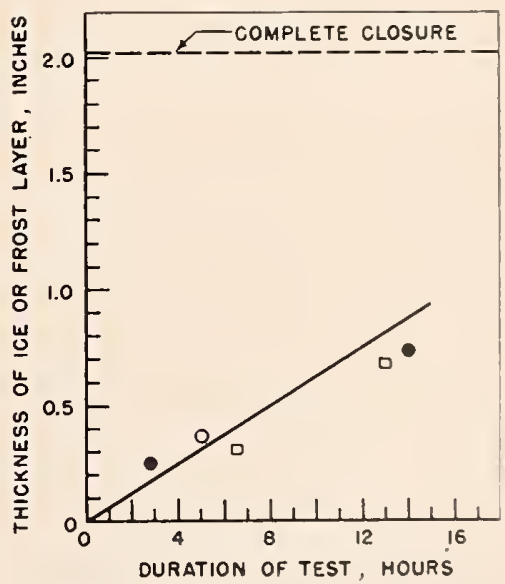

Figure 22. Experimentally determined rates of frost closure for " f-in.-diameter roof lent exposed 1.5 in. to outside air temperatures of approximately $-30^{\circ} \mathrm{F}$.




other than the computations made in connection with figures 20,21 , and 22 to eraluate the time factor in the process of the freezing of a rent. The results presented purport to make it possible to predict roughly to what extent any giren rent projecting above a roof will freeze up under given conditions, but not how fast it will freeze up.

\section{Discussion of Frost Closure-Field Reports}

There are two forms of frost closure that appear to occur in actual installations, provided the outside air temperature becomes and remains sufficiently low, say lower than perhaps $10^{\circ} \mathrm{F}$. The first comprises a concentric layer of frost on the inside wall of the rent pipe that increases in thickness up to some particular value or to complete closure. It is this form that lias been analyzed in this paper and that was observed in the laboratory tests. The second form comprises the building up of a frost cap on top of the roof vent, starting at the rim of the vent. There are several variations of this form of closure.

Field reports seem to indicate that this is the more common form of closure, but this mar be due to the fact that it is the more easily observed of the two. One report from Canada indicates that both forms are likely to occur simultaneously.

Presumably the form first mentioned is more likely to oceur when the exposed length of rent is relatively great. In this case the layers of air close to the cold wall of the vent commence to chill when the warm air is still a considerable distance from the outlet of the rent. This gives the drops of moisture more opportunity to come in contact with the wall of the rent and to freeze there than if the exposed length of the rent is short

In the laboratory tests made in the investigation reported here, the exposed length of vent was 15 in. in the great majority of the cases tested. 'Thus the length/diameter ratios for the $1 \frac{1}{12}, 3$, and 4 -in. vents were 10,5 , and 3.75 , respectively, based on the nominal diameters. In all of the tests in which frost formed, it alwars occurred as a layer on the inner wall of the vent, although in a few instances it was observed that a cap also started to form over the top of the vent. In some instances it was noted that true ice, rather than frost, formed on the wall of the stack. Unfortunately not enough data were obtained to clarify this point.

The manner in which the second form of frost closure comes about seems to be fairly clear. Particles of water and frost are being carried upward out of the vent in the air stream. Some of the water particles strike the cold rim of the vent and freeze there. Other particles of frost and water strike the frost that has first formed on the rim of the vent and adhere, with the result that a porous mass of frost gradually builds upward and inward until a columnar mass roughly crlindrical in shape with an axial opening forms. In extreme cases this formation may possibly close completely at the top. Photographs of the development of such a frost cap in the Report of Proceedings, 1913 and 1914 Conventions of the Canadian Institute of Sanitar $r$ Engineers [1] for the 6 -in. vent on the Civie Curling Rink in Winnipeg unfortunately are not clear enough to reproduce here.

The photographs in the reference [1] show that on February 3 , following a period of weather with minimum daily temperatures ranging from $-5^{\circ}$ to $-15^{\circ} \mathrm{F}$, a rim of frost had started to build up around the upper edge of the vent, with a very ragged contour. The daily minimum temperatures then dropped steadily, reaching a low of about $-40^{\circ} \mathrm{F}$ on February 10, then oscillated up and down during the remainder of the month. A photograph taken on February 10 showed that the body of frost had built up to a height of perhaps 6 to 8 in., but the opening had scarcely diminished in size. On February 25 this annular column of frost had grown to a lieight of about 18 in., but still the opening had not decreased perceptibly.

It will be noted from figure 2 that the exposed length of rent was very small, and it appears from the report that a special roof jack was installed around the vent in an attempt to retard frost closure. Unfortunately no information is available as to the trpe of closure that occurred with the other 6 - and 8 -in. vents shown in figure 2.

The Committee on Research of the American Society of Sanitary Engineering made a report [5] on the subject of frost closure in which it presented facts regarding the occurrence of frost closure and the means taken to combat it and gave information obtained from various eities in the United States. Excerpts that seem to be pertinent follow.

Elmira, N. $\quad$. Considerable hoar frost. No knowledge of complete closure.

Sioux Falls, $S . D$. Some trouble with vents frosting but the city has no ordinance. Trouble occurs not more than 3 or 4 days at a time and only in very cold weather.

Milwaukee, Wis. During long stretches of very cold weather sometimes have many complaints. All vent pipes less than 4 inches in diameter must be increased to 4 inches and increaser must be about 18 inches below roof.

Springfield, Mass. In zero weather occasionally a stack closes. Require that no soil or vent pipe shall be smaller in diameter than 4 inches where it passes through the roof.

St. Joseph, Mo. Do not increase main vent stack through roof but permit nothing less than 2 inches internal diameter for any vent or revent pipe through roof. Top of vent stack rarely closes. When weather is above zero, no frost at all is noted.

Davenport, Iowa. Do not have any cases of frost closure. Increase stacks 2 inches where they go through roof.

Elizabeth, N.J. Have short cold spells when the temperature drops from 2 above to 4 below zero. Find that all pipes smaller than 4 inches were almost closed by frost. Specify that no vent pipe shall be smaller than 4 inches in diameter coming through roof. 
Rock Island, Ill. Increase all vents going through roof 2 inches and do not allow them to extend more than 12 inches above the roof, so as to keep the length of the increaser below the roof. Fery little trouble with frost closure and have no ordinance.

Columbus, Ohio. state Plumbing Code require. that all pipes be increased to $t$ inches when passing through the roof. Obvious that in our northern cities all soil stacks should be increaseck one full size at least 1 foot below the roof.

Pittsburgh. Pa. Hare a great deal of trouble in the Pit tsburgh District from frost clostre. Yo provision in code. Allowed to run pipes outside of building-.

Dayton, Ohio. On very cold days the rent stacks above the roof have been closed by hoar frost to such an extent that it eventually formed a solid inass of ice, thereby closing the stack until the weather moderated and thamed it out. Has caused siphonage of traps in plumbing fixtures, causing sewer gas to permeate the interior of building. Law calls for all rent pipes to be increased through roof.

Buffalo, N. $Y$. To complaints. Ordinance requires all vent pipes to be increased one size or connected to main rent stack before passing through the roof.

Traterloo, Iowa. Require that no pipes less than 4 inches in diameter shall pass through roof. Pipes $t$ inches and larger shall be increased two sizes. Even with this, find that many pipes freeze up if zero weather persists for several months without thawing spells in betrieen.

Grand Rapids, Wich. Have no trouble with frost. fllow no increaser less than $t$ inches, and every stack is increased one size at roof. Used to have trouble before fresh-air trap was abolished, but do not now, since warm air from semer passes through.

Waterbury, Conn. Where the house trap is used, the liability of closure is reduced. Waterbury provides against the closure by installing the house trap. It is a matter of ordinance.

Recommendations of the Committee. Naturally in territories where climatic conditions are mild, the question of frost closure need not be considered. In many of our northern towns there are occasional case. of trouble from frost closure, but they do not seem to be sufficient to compel an ordinance on the subject. The believe it nould be a good idea from the data contained in this paper to frame an ordinance concerning frost closure and methods of installation to prevent it. which can be generally adopted throughout the country by towns and cities requiring this protection. There seems to be considerable agreement in the main points of installation, and it should not be difficult to construct such an ordinance. Some attention should be given also in the discussion as to whether the house trap should be considered a legitimate means of prevention or whether the remedy should in every case be found in the terminal construction of the vent line. If the vent line construction can be unanimously adopted as being satisfactory in it provisions against frost closure, we would suggest that a rariation of the practice could be effectively done away with by dispensing with the suggested house trap remedy.

The following quotations in regard to the subject of frost closure have been drawn from various sources and are given, partly because of the factual information included and partly because of the suggestive ideas that some of them contain.

James Smith, Chief Plumbing Inspector, Winnipeg, Canada, [6], states:

In the Prairie Provinces of Western Canada we claim to have overcome this trouble to a very great extent at least by simply increasing the pipe before it passes through the roof and limiting the extent to which the pipe projects above the roof to a minimum of 1 inch and a maximum of 3 inchen. Thi- boster axpedient was first suggesterd and experimenterl with hy a very keen student of plumbing problemrs, the lat plumbing inspector of Sa-katorn, Saskatchewir This method of treating pipe terminal ha- Iors joa--rot the experimental stage and is now common prartice in Thestern Canada. Frozen pipe terminals were at orir. time a very common condition, and while evers thes inethod I have described is subject to frost closurs: it is only under very exceptional and munsually conditions. In this connection it may interes know that wherever possible we reconnect verit pipos to the stack before it pastes through the roof and in this way provide a circulation of air thronghont the sistem and so prevent syphonic action. In recent years we have gone a step further and requirerl that the pipe terminal shall conform to the pitch of the roof, and for this purpose terminals are made having a $45^{\circ}$ and $60^{\circ}$ pitch, as well as the ordinary increaser used in a building having a flat roof. All increasers have hubs and are finished with a lead flashing.

The following opinions in regard to the use of increasers at the roof were expressed in discussion reported in the Proceedings of the 1913 and 1914 Conventions of the Canadian Institute of Sanitary Engincers [1]:

(1) When the diameter of the pipe is increased below the roof, the velocity of the outflowing air is retarderl. and this promotes the deposition of moisture. The le-metal in the increaser, the less is the tendency to freczing. (2) If the diameter of the pipe is increased at a considerable distance below the roof, the velocity of the outflowing air will be retarded, but, if the increarer is made as short as possible, the stream of air does not have an opportunity to expand fully within the increaser, and hence the moist air escapes without coming in contact with the wall of the pipe and this tends to prevent freezing. (3) The larger in diameter the increaser is made, the heavier the body of cold air that must be displaced by the warm air noring up the stack. (4) Experience at Edmonton, Canada, has shown that when the vent pipes are cut off at the roof complete frost closure did not occur. The result when an increaser was used, have been practically the same. (5) In St. Boniface, Canada, it was found that increasing the exposed length of the rent termina! above the roof increased the trouble from frost closure. Their experience leads them to be heartily in favor of using increasers. (6) A great deal depend on the exposure of the terminal. Less trouble is experienced with southern exposures than with other exposures. Woisture that freezes falls over on the outside of the vent in the direction of the wind and builds up there (7) At Winnipeg it was found that the increaser did not help matters any.

The following recommendations were subnitted to the Convention referred to abore and undoults edly represent the thinking on the subject of frost closure prevalent in Canada at the time (1914)

Winnipeg Recommendations. All terminals of soil. waste, and rentilating pipes of $t$ inclies in dinnefer or less shall be increased 2 inches in dimmeter before passing through the roof of the prentives and all perminats of such pipes shall project to the oufer air not less than 1 inch and not more than 2 inches stures on the high side where pasing through a pischert rowe and not less than 3 inches or nore than 5 incles above where passing through a tlat roof. provided that the portion of atl such pipe terminals above the rent shatl have a hub of a size in proportion to which the pipe is increased, and the same shall be miate weatlerprowe by means of a lead tlashing. All stloh lead usut for this purpose shall be in weight at lesst (i pomds men square foot and shall be worked over and into the 
hub with not less than 5 inches of cover on the roof on either side of the pipe terminal, and it shall be finished with a cast or wrought iron ring properly caulked into the hub which shall in no case project above such terminal.

All terminals of soil, waste, and ventilating pipes shall where passing through a pitched roof be carried to a point within 2 feet of the ridge or peak of the roof and shall be located not less than 10 feet from or 2 feet above any window, door, or other opening in the same or adjoining premises, provided that in all cases a roof with a pitch of 6 inches or more in 12 inches shall be considered as a pitched roof.

Saskatoon Rccommendations. That all vent pipes terminate not more than 1 inch above the pitch of roof on the higli side and have a lead flasling turned down I inch all around inside the top of pipe dressed in tight and secured with a inslleable iron ring.

All vent pipes to be carried up to roof and to terminate the same size unless the vent line is less than 4 inches in dianeter, when it shall be increased to 4 inches, at least 3 feet below roof.

We claim that by elimination of the roof jack and increaser and the consequent decreased surface, we lessen the radiation and therefore the deposition of moisture which congeals thereon.

All branch veuts shall be carried back into the main stack before passing through roofs. This will reduce the number of roof terminals.

Edmonton Recommendations. All soil, waste, and vertilating pipes shall be located inside the premises; and all roof terminals of such pipes shall be located not less than 10 feet distant from any opening door, window, etc., in the same or any adjoining premises, nor shall a perpendicular from any roof terminal to the grade be nearer than 10 feet to the side line of the lot; the roof terminal shall project 1 inch and no more above the highest point on the roof where such roof terminal intersects the roof.

All vent pipes of 4 inch dianeter or less shall be increased at least 2 inches before passing through the roof, and no roof terminal shall be less than 4 inches where the same passes through roof and shall terminate with a hub and shall be flashed with sheet lead turned dow $n$ and caulked into the hub.

\section{Methods of Retarding or Preventing Closure of Roof Vents by Frost}

Experience and the principles presented in this paper indicate that means of retarding the closure of roof vents by frost include factors that affect the vent terminal itself and factors that are independent of the vent terminal.

Of the former, we may list (1) limit the height of exposed length of vent above the roof to the extreme minimum that can be permitted, (2) enlarge the vent just before it passes through the roof, (3) use a substitute material having a high resistance to the transfer of heat in place of the usual metallic vent pipe, (4) put thermal insulation around the exposed length of the vent, and (5) in extreme cases provide means for heating the outer surface of the exposed length of the vent electrically or by means of steam or hot water.

In the latter category we may list the use of a house trap, either with or without a fresh-air vent. If the discharge of hot water into the stack can be prevented, this should help reduce the oceurrence of frost closure.

The simplest, most obvious, and probably most effective way of preventing or minimizing the frosting up of roof vents is to reduce the length of vent exposed to the low temperature to a minimum. In Canada it is quite customary to limit the length of vent projecting above a sloping roof to from 1 to $2 \mathrm{in}$. on the high side.

Figure 23 shows a typical design of roof terminal that has come into use at Saskatoon, Canada, and has been found successful in resisting frost closure [1]. Note that the terminal is a special pipe with the upper rim at an angle to fit approximately the slope of the roof. This pipe is $2 \mathrm{ft}$ long measured from the rim on the lower side.

There seems to be no valid reason for objecting to a flush opening or a very short extension on a sloping roof. Snow may occasionally block a vent pipe, but the snow is porous and thus permits the passage of some air and furthermore such closure, which will occur only during heavy snow storms, is short-lived. It would seem that any amount of water that might enter a vent that is flush with the roof would be inconsequential. The situation on a flat roof, however, might be quite different, since, if the strainer's at the storm leader's should become blocked with trash, the roof might become flooded, and hence discharge an undue amount of water down the roof vent.

Correspondence with various persons in Canada who have had experience with frost closure elicited considerable interesting information, the most pertinent of which follows:

Earle O. Turner of the University of New Brumswick, Fredericton, states:

From my own experience, the only phenomenon of this kind in this climate is the formation of a frost cap over rents in soil pipes in buildings. This will only take place at temperatures below zero Fahrenheit and will not persist after the temperature rises.

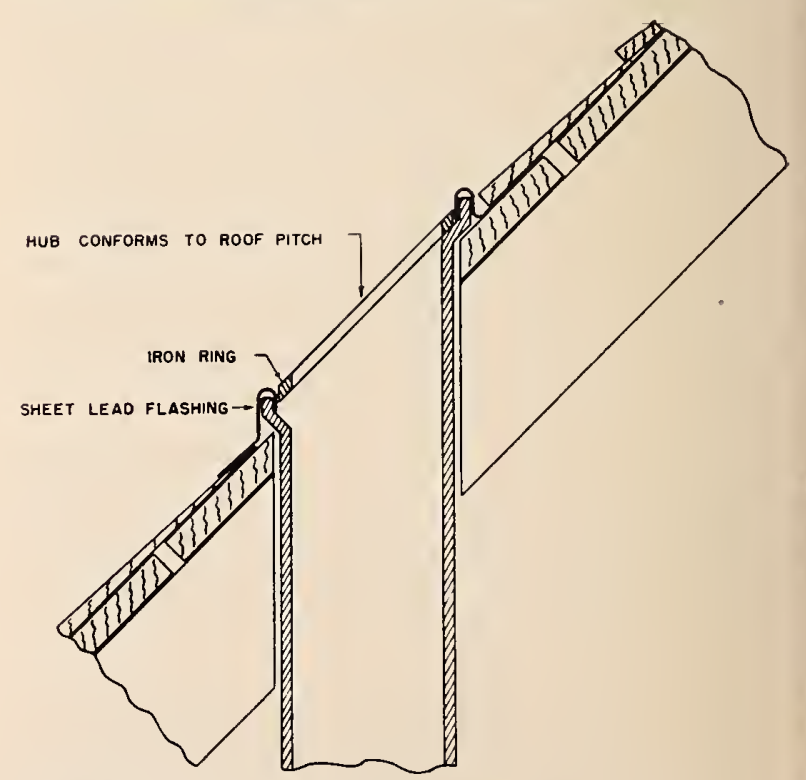

Figure 23. Design of roof terminal used at Siashatoon, Canada. 
L. P. Cabana. Superintendent, Division of Sanitary Inspection, City of Montreal, Canada, writes:

We have experienced the formation of ice at the outlet of vents on roofs, but not to the extent of complete closure. There is always in extreme cases a oneinch opening except during a snow storm, when this opening may be blocked temporarily with snow.

He states that the city does not permit house traps and that the rents are always 1 inch larger in diameter than are the stacks.

\section{Tr. D. Cameron, Plumbing Inspector, Kirkland} Lake, Canada, states:

I must say we do have difficulty to some extent up here with vent stacks during the extreme cold weather which varies from zero to 55 degrees below during the winter months. ITe have made some experiments from time to time on this subject, and up to six years ago our code called for a 12 -inch extension above the roof on the highest side. This was found to be too great an exposure, so we cut it down to 8 inches and insulated the vent pipe from the roof to the ceiling joists. Which did help some, but in numerous cases could not be done where the stack was carried up the corner of the building and where it was impossible to extend the stack up the roof to any other point.

TTe have come to the conclusion now, that by increasing all vent stacks to 4 inches from a point approximately 2 feet below the roof to 4 inches above on the highest side, we have gained the most satisfaction, and where necessary, insulate the 2 feet below the roof. Although this does not entirely eliminate the ice condition, it does not completely ice up solid under extreme conditions.

I must mention with reference to our plumbing srstem here that we do not permit a main trap on the sewer line between the main trunk sewer in the street and the house, therefore, we have a straight vent line from the street through the roof on each building. The do not permit anything less than 2inch extensions through the roof; this we find is the smallest size we can permit without completely icing up solid.

This freezing or icing which occurs here only happens during the very lowest temperatures, perhaps from 15 to 45 degrees below zero and forms an icing on the side of the pipe to a depth of approximately 1 inch. Then there forms a cone or light ice cap somewhat heavier than a hoar frost and extends straight upwards to a height of from 6 to 8 inches and remains there until the temperature rises, which usually happens about noon each day, or more often until the heat from the building increases sufficiently to break this light ice cap and force an opening in the top, permitting the escape of the vapour. As for the wind extending this cone or ice cap to one side of the vent, we do not have the wind here when the temperature is at a low degree, for during such temperatures even the smoke from the chimneys rises straight up and a heary fog occurs.

H. E. Roseborough, Building Inspector, Sudbury, Ontario, Canada, writes:

Hoar frost very seldom extends more than 6 inches from the top of the vent stack and is of very even consistency. It generally forms in a cone shape above the top of the stack and extends some 4 or 5 inches. The wind seems to have very little effect on the shape of the cone of frost.

During the second Great War restrictions were put on the use of 4 -inch soil pipe, and at that time we changed our by-laws to permit the use of a 3 -inch stack for a two-family house. We carry our vent pipe qpproximately 6 to 8 inches above the roof level, and we do not lise any interceptor tray at then entrance to our builcling, therefore each stack is a partial vest to our main sewer.

Previous to 1938 we have had ar odd caste of a 4-inch stack closing with hoar frost, but since nsing the 3-inch, only on one or two occasions, even with the temperature at 47 degrees below zero, have w\% had any trouble.

During the past week our temperature ranged from 47 below to 26 below for four days, and riot one case was reported to this office. Te have harl ro trouble whatever with a 6-inch stack freezing over

Gordon Park Jackson, Medical Officer of Health, 'Toronto, Canada, furnisher the following information:

The closure of vent stacks by frost in this City happens infrequently. In the very few places where this has occurred, it apparently was the result of the excessive use of hot water. For example, when there is a large fire in a heating furnace containing a domestic hot-water coil, the water becomes overheated and discharges into the drain. Winter temreratures in this City are usually below the freezing point, and we frequently have temperatures below zero extending over a period of three or four days. Vent stacks less than 3 inches in diameter where they extend through the roof are not permitted.

V. S. Baker, Secretary-Treasurer of the Ontario Association of Plumbing Inspectors and Affiliates writes (referring to the City of London, Ontario, Canada):

In the City of London the average winter temperature is around 10 to 20 degrees, with occasional temperatures of 10 to 15 degrees below zero for a day or two. We receive a few conplaints each winter from frost closure on 4 -inch vents and also on 3 -inch. On the average, the stacks that freeze are on the north or west sides of dwellings... We have also noted that the 1/4-inch sink vent in the cold portion of the attic space freezes when the building is insulated. In the western sections of the country increasers are used at the roof and very short terminals or nearly flush.

In reply to further questions Mr. Baker furnished the additional information that in the area referred to, in general, stacks freeze with frost caps. Also that in the case of the $1^{1 / 4}-\mathrm{in}$. vents in the atties of insulated lomes, it was not certain whether the pipes froze solidly or whether they were filled with a spongy ice.

J. A. McDonald, City Engineer, Edmonton, Alberta, Canada, furnished the following information in response to specific questions:

The City of Edmonton does not pernit house traps to be installed. The stack is not pernitted to extend more tlian 1 incli above the roof. Relatively. few cases of frost closure have been experienced there. but those that have been observed were of the iripe that form on the interior wall of the pipe. Vio vent smaller than 4 inclues is permitted, and in any case, the stack is increased a minimun of 1 inch in diameter where it passes tlirougl the roof. Edmonton fre quently has periods of from one to three weeks when the temperature ranges from 20 to 50 degrees below zero continuously.

Guy S. Franks, Plumbing Inspector, Calgary Alberta, Camada, states in response to speritio questions: 
A certain amount of frost closure is experienced. Every terminal of a soil, waste, or ventilating pipe three inches, four inches, or five inches, shall be increased one inch in diameter, and each under three inches shall be increased to four inches before passing through the roof, by means of an increaser and shall project to the outer air not less than 1 inch nor more than 3 inches above the roof and shall be made weatherproof by means of a lead flashing. All lead used for this purpose shall be in weight at 6 pounds per square foot and shall be worked over and into the hub of the increaser at least 1 inch with not less than 6 inches of cover on either side of the roof terminal, and it shall be finished with cast or wrought iron ring properly caulked with lead in the hub thereof . . . We have extreme low temperatures, lasting sometimes for days. Maximum 10 below zero and minimum of 30 below zero. Not the general rule.

An unusual type of frost closure, caused by inoisture outside of the vent instead of moisture inside, is reported by $\mathrm{R}$. E. Andrews, Sanitary Inspector, Niagara Falls City. He writes:

In view of the fact that Niagara Falls City is so geographically situated, we have practically no rimeing of vent stacks even in the $11 / 2$-inch size. We do, however, have an icing condition caused by spray from the Falls being carried over the City by a South or South-East wind. In that portion of the City and suburbs so affected, we stress the need for a 4-inch vent stack or the existing vent to be increased immediately below the roof and carried through by 6 inches. This serves the purpose in the majority of eases, bnt we have exceptions where we have had the vents encircled by 1/4-inch copper pipe carrying hot water or steam and the whole installation lagged with hair felt and leaded over. This latter method has proved effective and we are able to prevent blocking by ice.

The following information was received from A. E. Berry, Director, Sanitary Engineering Division, Department of Health, Toronto, Canada:

We liave beer giving a good deal of corsideration to the question you have sulmitted. It is a problem in this country, and unfortunately there are varying opinions regarding it. In some municipalitics they report that closures do take place, while in other's they find no difficulty, even with a 3 -inch vent. Under extrome cold weather conditions there would probably be some closures, but even in the northern part of this province, where the temperature quite frequently goes down to -40 or 50 degrees below, no particular difficulty appears to be involved. Probably it is due to the fact that these cold spells do not last for any great length of time.

We have been giving consideration to the development of a plumbing code for the Province of Ontario, and the comnittee that was at work on this canvassed the situation somewhat carefully, with the result that they did not feel any special precautions were necessary to prevent closures.

Edward Pretious of the University of British Columbia, Vancouver, Canada, wrote as follows:

Prior to this arrangement (see figure 24A) there was no house trap, and the sewer cover was closed. The warm sewer gases escaped through the roof vent, and freezing was prevalent. The present scheme (shown in figure $24 \mathrm{~B}$ ) appears to obviate this condition.

He also remarks that when the roof vent is flush with the roof, freezing does not occur.
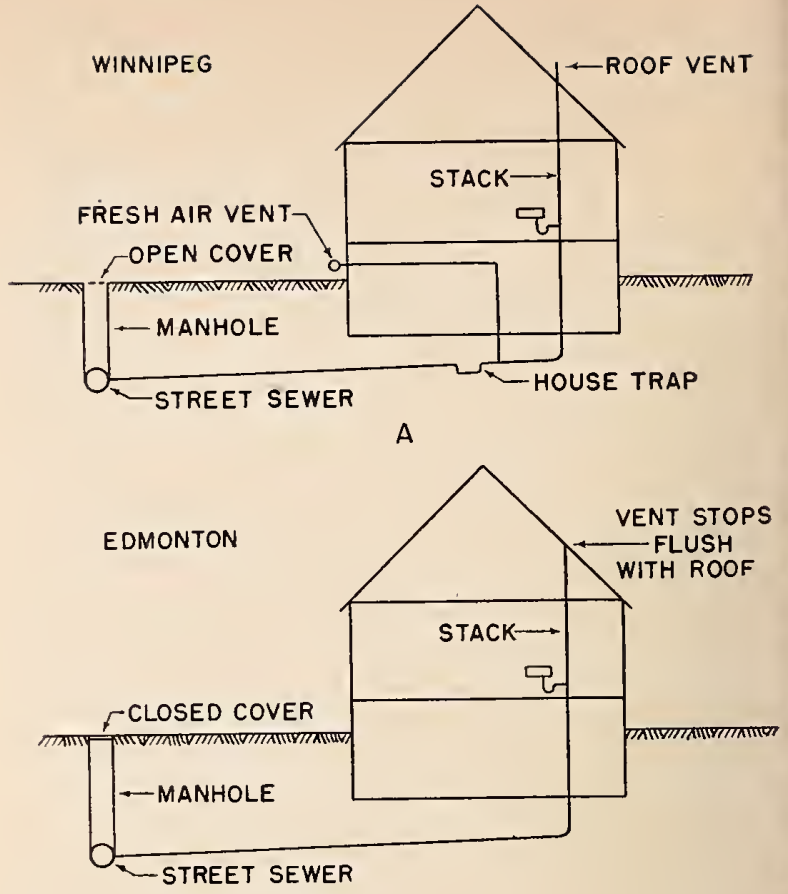

B

FIGTRE 24. Systems used at Winnipeg and Edmonton, Canada

\section{Conclusions}

1. The roof vents of building drainage systems may become partially or completely closed by frost in very cold weather under certain conditions. Among the factors that affect frost closure are: (a) temperature of the outside air, (b) temperature and humidity of the air passing up the stack and vent, (c) wind velocity, (d) length of vent that is exposed to the outside atmosphere, (e) diameter of vent, (f) thermal insulation, if any, of the exposed part of the vent, or the use of a vent pipe of some material that is highly resistant to the transmission of heat, (g) whether or not a house trap is inserted in the building drain, either with or without a fresh-air vent, (h) whether or not the diameter of the vent is greater than that of the stack, and the distance to which such expansion extends below the roof, (i) the temperature conditions in the air space below the roof, $(j)$ the exposure, whether northern, southern, etc., and (k) the velocity of air flow upward through the vent.

2. Frost closure has been observed in two general forms: (1) as a concentric layer that builds up on the inner wall of the vent, and (2) as a cap that builds up from the rim of the vent at its outlet. The latter form is the one that has been the morc 
frecfucntly- reported, possibly because it is the more easily observed of the two. sometimes the two forms oecur simultaneously.

3. In general, it appears that there is lit tle likelihood of trouble from frost closure unless the outside air temperature falls below about $10^{\circ} \mathrm{F}$ and remains there for at least several days.

4. Reducing the length of the exposect portion of the rent as much as possible appears to be the most certain way of reducing or preventing frost closure.

5. Uninsulated small-diameter rents in unheated attics may freeze solid unless protected by insulation.

6. The discharge of hot water into the stack, particularly" at night, when the upward convective air current is most pronounced, tends to increase the humidity of the air passing up the stack and thus increases the tendency to frost closure.

7 . The larger the diameter of the rent, the less likely it is to close completely because: (1) a longer period of cold weather is required to create the necessary thickness of ice, and (2) because, with the larger diameter rents, the temperature of the ice-air surface in the rents is generally higher for a given thickness of ice laver than with the smaller diameter vents. (See figs. 10 to 15 ). Freezing stops when a temperature of $32^{\circ} \mathrm{F}$ is attained at the ice-air surface.

8. As the air from the street sewer is relatively moist and warm, the use of a house trap to prevent this moist air from passing up the stack should reduce the tendener to frost closure. Even if a fresh-air inlet is provided on the house side of the trap, this provides a source of relatively cold dry air that carries with it less moisture to condense out and freeze in the vent.

9. Snow storms may close the vent temporarily, but the snow is porous, and evidence seems to be available that this does not cause any serious difficulty.

10. Reconnecting vent pipes to the stack before it passes up through the roof has been found to reduce or prevent siphonage of trap seals when the rent was completely closed by frost.

11. Increasing the diameter of the vent above that of the stack may help in two ways: (1) It affords the advantage of a larger diameter of vent, so that it requires a longer time for the vent to freeze up completely, and (2) it would seem that, if the length of the expanded portion of the vent is relatively short, the stream of air passing up through the vent may not expand soon enough to reach the chilled wall of the vent, and hence less moisture reaches the wall than would otherwise be the case, so that the tendency to freeze is decreased.

12. The greater the wind velocity, the greater the tendency to closure. In general, however, the lower the temperature, the smaller is the wind velocity. Less trouble seems to be experienced when a vent has a southern exposure (in the northern hemisphere) than when it is exposed on the shady side of the roof.
13. The use of a material for the vent pipe that has a higher resistane to the flow of heat thar does stecl has a favorable effect.

14. As a rough estimate of the rate at which the thickness of the ice layer in a vent may increase in cold weather, we may take a value of 0.07 in./hr, or roughly $1 \frac{1 / 2}{2}$ in./ day, assuming that the convective current of air persists rluring the greater part of the day. 'This value was obtained hy laboratory experiments on 3-in. vents for an outdoor air temperature of $-30^{\circ} \mathrm{F}$ and with the air passing up through the vent saturated with moisture at a temperature of about $70^{\circ} \mathrm{F}$. Values of about 0.08 and $0.06 \mathrm{in}$./hr were obtained for $1 \frac{1}{2}$-in. and 4-in. vents, respectively.

Acknowledgment is made to the Housing and Home Finance Agency for its support of the experimental part of this investigation. Credit is due John L. French for planning and directing the early stages of the investigation and to James $\mathrm{L}$. Johinson, Jr., for his painstaking work in developing the experimental apparatus and in planning the details of the tests. Particular acknowledgment is made of the advice and assistance given by Henry E. Robinson. He suggested to the author's and outlined for them the method used in the paper to compute the temperature of the icc-air surface in the vent as a substitute for the equally accurate but more cumbersome method they used originally. The author's also express their thankto Victor Brame, Jr., and Anthony L. Lembeck for their careful experimental work and to Clarence E. Bardsley, Otto Hintz, and MIs. Helen Callaway for carrying out much of the laborious computition. 'The paper has benefited greatly from information received from L. Glen Shields, Chief. Department of Buildings and Safety, City of Detroit, and from numerous Canadian sources. and the authors express their appreciation of the courtesy and patience of the individuals who answered their numerous inquiries.

\section{References}

[1] Report of Proceedings of the 1913 and 1911 Conventions of the Canadian Institute of Sanitary Fugineers. (Reynolds Ltd., Logan and Princess, Minnipeg, Canada)

[2] Recommended Minimum Requirencnts for Plumbins. National Burrau of Standards. Elimination of $1 \mathrm{I}^{\mathrm{B}} \mathrm{A}=\mathrm{C}$ Series, Report of Subcommittee on Plum?ing of the Building Code Committee, L* S. Department of Commerce, BH13 (1932).

[3] Willign Beall Gray, Plumbing design and installation (David Willams Co., New Iork. X. I.. 1916).

[i] W. H. McAdam, Heat transmiscion (Mclitaw-Hill Book Co., Ine., Yew York, X. Y.. 1942).

[5] Report of the Research ('mumittee, learinow of the American Society of Sanitary linginesing. Iol. : p. 178 .

[6] Report of Procedings, Anerican society of stuitar!

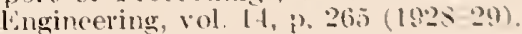

Washingtox, Jamuary 2, 19it. 

[Continued from cover page II]

BMIS32 Structural Properties of Two Brick-Concrete-Block Wall Constructions and a Concrete-

BMS33

BMS34

BMS35

B.MS36

BMS37

BMS38

BMS39

BMS40

BMS41

BMS42

BMS43

BMS 44

BMS45

BMS46

BMS47

BMS48

BMS49

BMS50

BMS51

BMS52

BMS53

BMS54

BMS55

BMS56

BMIS57

BMS58

BMS59

BMS60

BMS61

BMS62

BMS63

BMS64

BMS65

BMS66

BMS67

BMS68

BMS69

BMS70

BMS71

BMS72

BMS73

BMS74

BMS75

BMS76

BMS77

BMS78

BMS79

BMS80

BMS81

- Out of print.

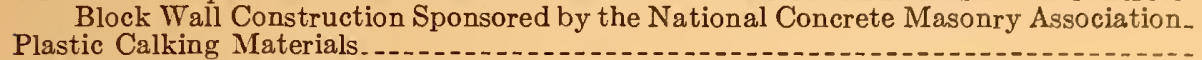

Performance Test of Floor Coverings for Use in Low-Cost Housing: Part 1...... 15

Stability of Sheathing Papers as Determined by Accelerated Aging

Structural Properties of Wood-Frame Wall, Partition, Floor, and Roof Constructions With "Red Stripe" Lath Sponsored by The Weston Paper and Manufacturing Co Floors, Sponsored by Palisade Homes
Structural Properties of Two "Dunstone" Wall Constructions Sponsored by the W. E. Dunn Manufacturing Co

Wisconsin Units Co
Structural Properties of a Wall Construction of "Knap Concrete Wall Units" Sponsored by Knap America, Inc Effect of Heating and Cooling on the Permeability of Masonry Walls
Structural Properties of Wood-Frame Wall and Partition Construction with "Celotex" Insulating Boards Sponsored by The Celotex Corporation Performance Test of Floor Coverings for Use in Low-Cost Housing: Part 2. Surface Treatment of Steel Prior to Painting Air Infiltration Through Windows
Structural Properties of "Scot-Bilt" Prefabricated Sheet-Steel Constructions for Walls, Floors, and Roofs Sponsored by The Globe-Wernicke Co.

Structural Properties of Prefabricated Wood-Frame Constructions for Walls, Partitions, and Floors Sponsored by American Houses, Inc.

Structural Properties of "Precision-Built" Frame Wall and Partition Constructions Sponsored by the Homasote Co
Metallic Roofing for Low-Cost House Construction

Stability of Fiber Building Boards as Determined by Accelerated Aging -
Structural Properties of "Tilecrete Type A" Floor Construction Sponsored by the Tilecrete Co.

Effect of Ceiling Insulation Üpon Summer Comfort

Structural Properties of a Masonry Wall Construction of "Munlock Dry Wall Brich" Sponsored by the Munlock Engineering Co

Effect of Soot on the Rating of an Oil-Fired Heating Boiler

A Survey of Humidities in Residences.

Roofing in the United States - Results of a Questionnaire

Strength of Soft-Soldered Joints in Copper Tubing

Properties of Adhesives for Floor Coverings Bricks Produced in the United States

Structural Properties of Two Nonreinforced Monolithic Concrete Wall Constructions.-

Structural Properties of a Precast Joist Concrete Floor Construction Sponsored by the Portland Cement Association

Moisture Condensation in Building Walls

Solar Heating of Various Surfaces

Methods of Estimating Loads in Plumbing Systems

Plumbing Manual Structural Properties of "Mu-Steel" Prefabricated Sheet-Steel Constructions for Walls,
Partitions, Floors, and Roofs, Sponsored by Herman A. Mugler

Performance Test for Floor Coverings for Use in Low-Cost Housing: Part 3......

Stability of Fiber Sheathing Boards as Determined by Accelerated Aging

Asphalt-Prepared Roll Roofings and Shingles...

Fire Tests of Wood- and Metal-Framed Partitions

Structural Properties of "Precision-Built, Jr." Prefabricated Wood-Frame Wall Construction Sponsored by the Homasote Co

Indentation Characteristics of Floor Coverings

Structural and Heat-Transfer Properties of "U. S. S. Panelbilt" Prefabricated SheetSteel Constructions for Walls, Partitions, and Roofs Sponsored by the Tennessee Coal, Iron \& Railroad Co

Survey of Roofing Materials in the North

Effect of Outdoor Exposure on the North Central States

Properties and Performance of Fiber Tile Boards

Structural, Heat-Transfer, and Water-Permeability Properties of Five Earth-Wall Constructions

Water-Distributing Systems for Buildings

Performance Test of Floor Coverings for Use in Low-Cost Housing: Part 4

Field Inspectors' Check List for Building Constructions (cloth cover, $5 \times 71 / 2$ inches)

35 


\section{BUILDING MATERIALS AND STRUCTURES REPORTS}

\section{[Continued from cover page III]}

BMS82

BMS83

BMS84

BMS85

BMS86

BMS87

BMS88

BMS89

BMS90

BMS91

BMS92

BMS93

BMS94

BMS95

BMS96

BMS97

BMS98

BMS99

BMS100

BMS101

BMS102

BMS103

BMS104

BMS105

BMS106

BMS107

BMS108

BMS109

BMS110

BMS111

BMS112

BMS113

BMS114

BMS115

BMS116

BMS117

BMS118

BMS119

BMS120

BMS121

BMS122

BMS123

BMS124

BMS125

BMS126

BMS127

BMS128

BMS129

BMS130

BMS131

BMS132

BMS133

BMS134

BMS135

BMS136

BMS137

BMS138

BMS139

BMS140

BMS141

BMS142 BMS143

-Out of print.

* In press.
Water Permeability of Walls Built of Masonry Units Strength of Sleeve Joints in Copper Tubing Made With Various Lead-Base Solders Survey of Roofing Materials in the South Central States
Dimensional Changes of Floor Coverings With Changes in Relative Humidity and Temperature

Structural, Heat-Transfer, and Water-Permeability Properties of "Speedbrik" Wall Construction Sponsored by the General Shale Products Corporation--
A Method for Developing Specifications for Building Construction-Report of Subcommittee on Specifications of the Central Housing Committee on Research, Design, and Construction. Recommended Building Code Requirements for New Dwelling Construction With Special Reference to War Housing Structural Properties of "Precision-Built, Jr." (Second Construction) Prefabricated Wood-Frame Wall Construction Sponsored by the Homasote Co -
Structural Properties of "PHC" Prefabricated Wood-Frame Constructions for Walls, Floors, and Roofs Sponsored by the PHC Housing Corporation. A Glossary of Housing Terms.

Fire-Resistance Classifications of Building Constructions. Accumulation of Moisture in Walls of Frame Construction During Winter Exposure.Water Permeability and Weathering Resistance of Stucco-Faced, Gunite-Faced, and "Knap Concrete-Unit" Walls

Tests of Cement-Water Paints and Other Waterproofings for Unit-Masonry Walls Properties of a Porous Concrete of Cement and Uniform-Sized Gravel............ Experimental Dry-Wall Construction With Fiber Insulating Board

Physical Properties of Terrazzo Aggregates.

Structural and Heat-Transfer Properties of "Multiple Box-Girder Plywood Panels" for Walls, Floors, and Roofs Relative Slipperiness of Floor and Deck Surfaces Strength and Resistance to Corrosion of Ties for Cavity Walls . Painting Steel

Measurements of Heat Losses From Slab Floors

Structural Properties of Prefabricated Plywood Lightweight Constructions for Walls, Partitions, Floors, and Roofs Sponsored by the Douglas Fir Plywood Association.

Paint Manual with particular reference to Federal Specifications _._. Laboratory Observations of Condensation in Wall Specimens. Building Code Requirements for New Dwelling Construction . . Temperature Distribution in a Test Bungalow With Various Heating Devices...... 15\& Strength of Houses: Application of Engineering Principles to Structural Design Paints for Exterior Masonry Walls _ _. Performance of a Coal-Fired Boiler Converted to Oil Properties of Some Lightweight-Aggregate Concretes With and Without an AirEntraining Admixture.

Fire Resistance of Structural Clay

Tertions_. Temperature in a Test Bungalow With Some Radiant and Jacketed Space Heaters.-- 25 A Study of a Baseboard Convector Heating System in a Test Bungalow......... $20 \phi$ Preparation and Revision of Building Codes....... 20 Fire Resistance of Walls of Lightweight Aggregate Concrete Masonry Units..... 25 Stack Venting of Plumbing Fixtures_. Wet Venting of Plumbing Fixtures Fire Resistance of Walls of Gravel-Aggregate Concrete Masonry Units.. Investigation of Failures of White-Coat Plasters Physical Properties of Some Samples of Asbestos-Cement SidingFire Tests of Wood-Framed Walls and Partitions With Asbestos-Cement Facings_-.-- 15\& Fire Tests of Steel Columns Protected With Siliceous Aggregate Concrete. Stone Exposure Test Wall_._. The Self-Siphonage of Fixture Traps Effect of Aging on the Soundness of Regularly Hydrated Dolomitic Lime Putties... 15 Atmospheric Exposure Tests of Nailed Sheet Metal Building Materials_........... 20 Fire Endurance of Shutters for Moving-Stairway Openings Methods and Equipment for Testing Printed-Enamel Felt-Base Floor Covering Fire Tests of Gunite Slabs and Partitions Capacities of Plumbing Stacks in Buildings. Live Loads on Floors in Buildings . Fire Resistance of Concrete Floors.- Tests of Steel Columns Encased With Gypsum Lath and Plaster. Properties of Cavity Walls Influence of the Wash From Bronze on the Weathering of Marble. Effect of Edge Insulation Upon Temperature and Condensation on Concrete-Slab Floors_... Studies of Stone-Setting Mortars... Selected Bibliography on Building Construction and Maintenance...... 30 Fire Endurance of Open-Web Steel Joist Floors With Concrete Slabs and Gypsum Ceilings . . Frost Closure of Roof Vents in Plumbing Systems. Fire Tests of Brick Walls 